KELLY CRISTINA SAITO

\title{
Envolvimento de Rac1 na excitotoxicidade induzida por NMDA na retina de ratos
}

Tese apresentada ao Programa de Pós-Graduação em Biologia Celular e Tecidual do Instituto de Ciências Biomédicas da Universidade de São Paulo, para a obtenção do título de Doutor em Ciências. 
KELLY CRISTINA SAITO

\section{Envolvimento de Rac1 na excitotoxicidade \\ induzida por NMDA na retina de ratos}

Tese apresentada ao Programa
de Pós-Graduação em Biologia
Celular e Tecidual do Instituto de
Ciências Biomédicas da
Universidade de São Paulo, para
a obtenção do título de Doutor
em Ciências.

Área de concentração:

Biologia Celular e Tecidual

Orientadora:

Dânia Emi Hamassaki

Versão Original 
DADOS DE CATALOGAÇÃO NA PUBLICAÇÃO (CIP)

Serviço de Biblioteca e Informação Biomédica do

Instituto de Ciências Biomédicas da Universidade de São Paulo

reprodução não autorizada pelo autor

\section{Saito, Kelly Cristina.}

Envolvimento de Rac1 na excitotoxicidade induzida por NMDA na retina de ratos / Kelly Cristina Saito. -- São Paulo, 2011.

Orientador: Dânia Emi Hamassaki.

Tese (Doutorado) - Universidade de São Paulo. Instituto de Ciências Biomédicas. Departamento de Biologia Celular e do Desenvolvimento. Área de concentração: Biologia Celular e Tecidual. Linha de pesquisa: Retina.

Versão do título para o inglês: Involviment of Rac1 in NMDA-induced excitotoxicity in the rat retina

$\begin{array}{lll}\text { Descritores: 1. Retina } & \text { 2. Receptores NMDA } & \text { 3. GTPases Rho } 4 .\end{array}$ Rac1 5. Células gliais de Müller 6. Morte neuronal I. Hamassaki, Dânia Emi II. Universidade de São Paulo. Instituto de Ciências Biomédicas. Programa de Pós-Graduação em Biologia Celular e Tecidual III. Título. 
Candidato(a):

Título da Tese:
Kelly Cristina Saito.

Envolvimento de Rac1 na excitotoxicidade induzida por NMDA na retina de ratos.

Orientador(a): Dânia Emi Hamassaki.

A Comissão Julgadora dos trabalhos de Defesa da Tese de Doutorado, em sessão pública realizada a .................., considerou

\section{( ) Aprovado(a) ( ) Reprovado(a)}

$\begin{array}{ll}\text { Examinador(a): } & \text { Assinatura: } \\ & \text { Nome: ........ } \\ & \text { Instituição: } \\ \text { Examinador(a): } & \text { Assinatura: } \\ & \text { Nome: ....... } \\ & \text { Instituição: } \\ \text { Examinador(a): } & \text { Assinatura: } \\ & \text { Nome: ........ } \\ & \text { Instituição: } \\ \text { Examinador(a): } & \text { Assinatura: } \\ & \text { Nome: ....... } \\ & \text { Instituição: } \\ & \text { Assinatura: } \\ \text { Presidente: } & \text { Nome: .......... } \\ & \text { Instituição: }\end{array}$




\section{Certificado}

Certificamos que o protocolo registrado sob $n^{\circ} 052$ nas fls. 16 do livro 2 para uso de animais em experimentação, sob a responsabilidade da Profa. Dra. Dânia Emi Hamassaki, Coordenadora, da Linha de Pesquisa "Desenvolvimento, degeneraçāo da retina de vertebrados: aspectos celulares e moleculares" do qual participou(aram) o(s) aluno(s): Carolina Beltrame Del Debbio,Eliane Rossi, Fernanda Siwiec, Ize Penhas de Lima, Kelly Cristina Saito, Marcelo Lamers,Márcio Roberto Otávio Gonçalves, Mariane Secco,Marley Januário da Silva, Mônica Aparecida Belmonte, Ricardo Moraes Borges e os pesquisadores Chão Yun Irene Yan, Marinilce Fagundes dos Santos, Alexandre Hiroaki Kihara, Suely da Fátima Parreira, Érica Pereira da Costa, está de acordo com os Principios Éticos de Experimentaçāo Animal adotado pelo Colégio Brasileiro de Experimentação Animal (COBEA) e foi aprovado pela COMISSÃO DE ÉTICA EM EXPERIMENTAÇĀO ANIMAL (CEEA) em 02.06.2005.

São Paulo, 02 de junho de 2005.

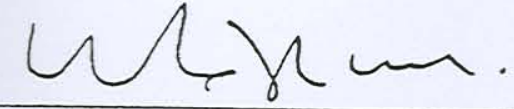

Prof. Dr. Wothan Tavares de Lima Vice-Coordenadora da CEEA

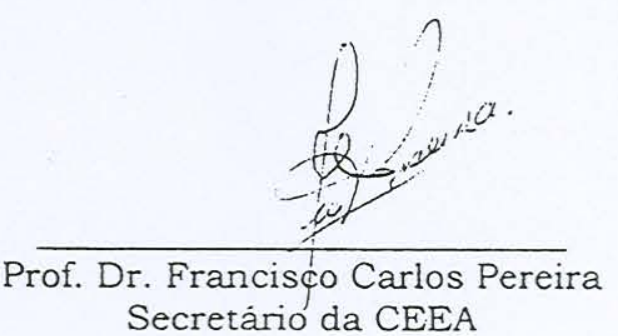


À minha família, com muito amor e gratidão. 
Este trabalho teve apoio financeiro da FAPESP, CNPq, PRONEX/MCT em forma de auxílio à pesquisa. A pós-graduanda recebeu bolsa de Doutorado da FAPESP durante o período. 


\section{AGRADECIMENTOS}

Meus sinceros agradecimentos à todos que contribuíram para o meu amadurecimento profissional no Departamento de Biologia Celular e do Desenvolvimento.

À Profa. Dra. Dânia Emi Hamassaki por todo apoio e oportunidades profissionais oferecidas ao longo desses anos.

À Profa. Dra. Marinilce Fagundes dos Santos pelas discussões que contibuíram para o desenvolvimento deste trabalho.

Aos Profs. Drs. Luiz Roberto Giorgetti de Britto, Norma Yamanouye, Alison Coulquhoun pelas sugestões no meu exame de qualificação.

Ao Prof. Dr. Rui Curi e sua aluna Hosana Gomes Rodrigues pela colaboração com os experimentos de ELISA para TNF- $\alpha$.

Ao Prof. Dr. João Relvas e seus alunos Augusta, Lina, Nuno e Pipa pelo ótimo acolhimento profissional e pessoal durante minha estadia em Portugal.

Aos colegas do Laboratório de Comunicação Celular (Cristiane, Diogo "Mossoró", Leandro, Lilian e Natália); Laboratório de Embriologia Molecular de Vertebrados (Antonio, Felipe, Gláuber, Magá, Ricardo e Tati); Laboratório de Migração Celular (Ana Flávia, Cilene, Gabi, Juliana, Kelly, Maíra, Mariana) pela convivência e pelos empréstimos.

Aos meus colegas de departamento Alex, Ana, Cezar, Lú e Murilo pelos divertidos almoços.

Aos colegas de laboratório Carol, Loreni e Cristiano por todos os momentos bons e ruins decorrentes da convivência diária.

Ao Leandro e Sayami por toda a amizade e pelo o auxílio técnico. 
À minha fiel amiga Marley por ser simplesmente como ela é, e me alegrar todos os dias com o seu alto-astral.

Ao Adilson pelo auxílio técnico.

À minha familia pelo apoio incondicional.

Ao Hiro pelo carinho e paciência.

À todos os funcionários do ICB, muito obrigada! 


\section{RESUMO}

SAITO, K. C. Envolvimento de Rac1 na excitotoxicidade induzida por NMDA na retina de ratos 2011. 102 f. (Doutorado em Biologia Celular e Tecidual) - Instituto de Ciências Biomédicas, Universidade de São Paulo, 2011.

A ativação excessiva dos receptores NMDA tem sido relacionada com a morte neuronal que ocorre em doenças, como o glaucoma e a retinopatia diabética. É possível que a combinação das subunidades (NR2A/D) possa ativar distintas vias de sinalização que resultam na morte ou sobrevivência. Nosso objetivo foi investigar o envolvimento de subunidades NR2 e Rac1, um membro da família GTPases Rho, na morte e/ ou sobrevivência de neurônios da retina de ratos in vitro e in vivo. A excitotoxicidade induzida por glutamato e NMDA foi detectada in vitro pelo ensaio de lactato desidrogenase e in vivo por TUNEL. A morte celular foi parcialmente reduzida in vitro e in vivo pelo bloqueio da subunidade NR2B (Ro 25-6981) e inibição das GTPases Rho (Toxina A) e Rac1 (NSC 23766). Nenhuma diferença foi observada após o uso PPDA (bloqueador de N2C/D). Interessantemente, Rac1 ativo detectado em processos das células de Müller após o tratamento NMDA, não foi evidente após o bloqueio NR2B, sugerindo que esta célula glial pode mediar a morte de células ganglionares. Medições por ELISA mostraram que a produção de TNF- $\alpha$ após o NMDA foi reduzida pelo bloqueio NR2B e Rac1. Em conjunto, nossos resultados sugerem que a ativação de receptores NMDA formados pela subunidade NR2B pode desencadear a excitotoxicidade na retina, e que Rac1 participa da morte de células ganglionares através da liberação de TNF-a por células da glia de Müller.

PALAVRAS-CHAVE: Retina. Receptores NMDA. GTPases Rho. Rac1. Células gliais de Müller. Morte neuronal. 
SAITO, K. C. Involvement of Rac1 in NMDA-induced excitotoxicity in the rat retina. 2011. 102 p. (Ph. D. Tissue and Cell Biology) - Instituto de Ciências Biomédicas da Universidade de São Paulo, 2011.

Overactivation of NMDA receptors has been described to trigger neuronal death that occurs in diseases, such as glaucoma and diabetic retinopathy. It is possible that the combination of subunits (NR2A-D) activate intracellular signaling pathways that result in death or survival. Our aim was to investigate the involvement of NR2 subunits and Rac1, a member of Rho GTPase family, in retinal neuronal death and/or survival of rat retinal neurons in vitro and in vivo. Glutamate and NMDA -induced excitotoxicity were detected in vitro by lactate dehydrogenase and in vivo by TUNEL assays. Cell death was partially reduced in vitro and in vivo by NR2B subunit blockade (Ro 256981) and inhibition of Rho GTPases (Toxin A) and Rac1 (NSC 23766). No difference was observed after using PPDA (NR2C/D antagonist). Interestingly, Active Rac1 was present in Müller cell processes after NMDA treatment, but it was not so evident after NR2B blockade, suggesting that this glial cell could mediate ganglion cell death. Measurements by ELISA showed that TNF- $\alpha$ production induced by NMDA treatment was reduced by blocking NR2B and Rac1. Taken together, our results suggest that NR2B-containing NMDA receptors activation may trigger excitotoxicity in the retina, and that Rac1 mediates ganglion cell death via TNF- $\alpha$ release by Müller glial cells.

KEYWORDS: Retina. NMDA receptor. Rho GTPases. Rac1. Müller glial cells. Neuronal cell death. 
$\underline{\text { ÍNDICE }}$

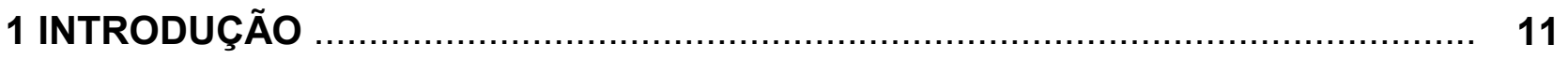

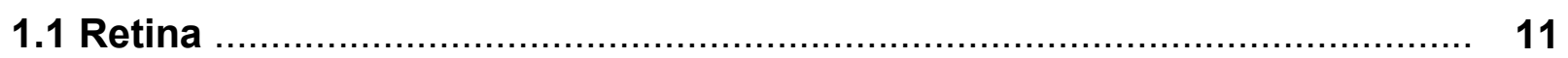

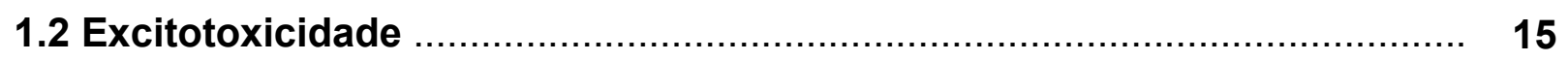

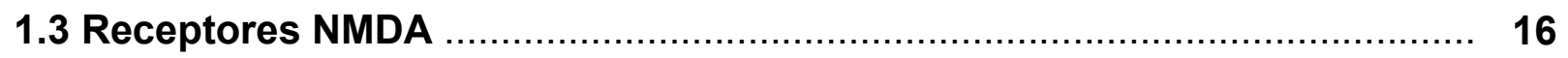

1.4 Vias de sinalização disparadas pelos receptores NMDA ......................... 17

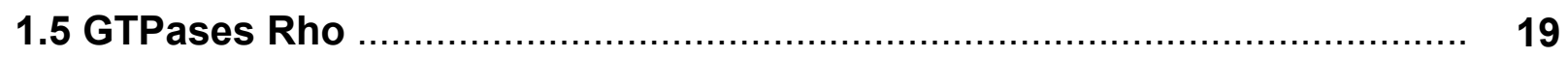

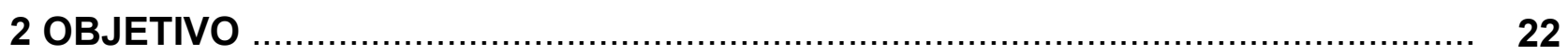

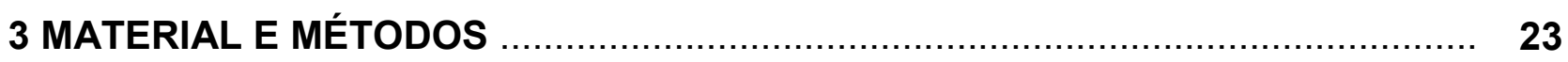

3.1 Cultura Organotípica da retina de rato ................................................ 23

3.2 Cultura purificada/ enriquecida de células gliais de Müller ...................... 24

3.3 Cultura primária de neurônios retinianos ……….................................. 25

3.4 Atividade de lactato desidrogenase (LDH) .......................................... 25

3.5 Detecção da apoptose pelo método TUNEL (TdT-mediated dUTP nick

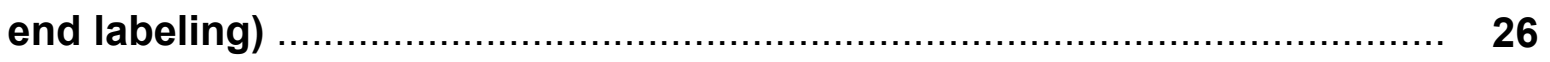

3.6 Injeção intraocular ................................................................... 26

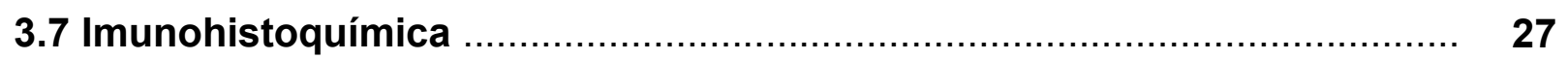

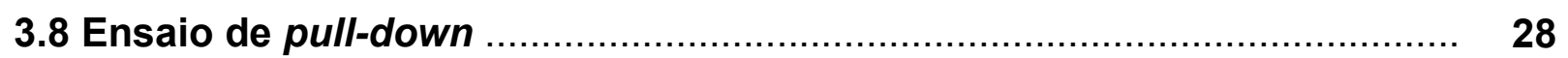

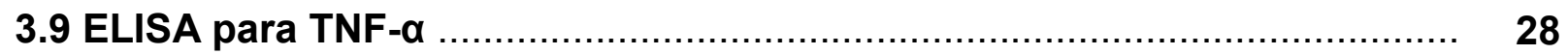

4 RESULTADOS

4.1 O bloqueio dos receptores NMDA formados pelas subunidades NR2B, mas não NR2C/D reduzem a morte celular induzida pela excitotoxicidade.

4.2 A inibição GTPases Rho (Rac1) reduziu a morte celular induzida pela excitotoxicidade

4.3 $O$ bloqueio dos receptores NMDA formados pela subunidade NR2B alterou a ativação de Rac1

4.4 A forma ativa de Rac1 foi detectada nas células gliais de Müller

4.5 Células gliais de Müller como mediadores da morte das células ganglionares

5 DISCUSSÕES

6 CONCLUSÕES 


\section{INTRODUÇÃO}

\subsection{Retina}

A retina exerce um papel imprescindível na percepção visual de vertebrados. Este tecido neural possui organização laminar composta por três camadas de corpos celulares que estabelecem sinapses entre si através de camadas constituídas por seus processos (KOLB, 1994; BOYCOTT e WÄSSLE, 1999). Diversos tipos e subtipos neuronais altamente especializados estão presentes: cones e bastonetes (camada nuclear externa), células horizontais, bipolares, amácrinas e ganglionares deslocadas (camada nuclear interna), e ganglionares e amácrinas deslocadas (camada de células ganglionares) (KOLB, 1994; BOYCOTT e WÄSSLE, 1999; RANDLETT et al., 2011) (Figura 1).

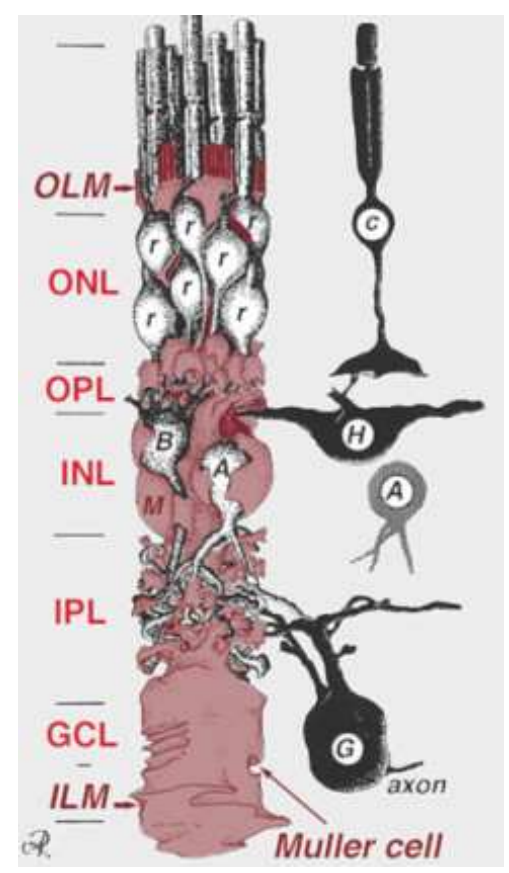

Figura 1. Organização estrutural da retina. $O L M=$ membrana limitante externa; $O N L=$ camada nuclear externa; OPL= camada plexiforme externa; INL= camada nuclear interna; IPL= camada plexiforme interna; $\mathrm{GCL}=$ camada de células ganglionares; $\mathrm{ILM}=$ membrana limitante interna. (KOLB, 2011).

Mais de 50 subtipos neuronais compreendem as populações acima descritas que podem variar, por exemplo, em forma, tamanho e arborização dendrítica (MASLAND, 2001; GOLLISCH e MEISTER, 2009; RANDLETT et al., 2011) (Figura 2). 


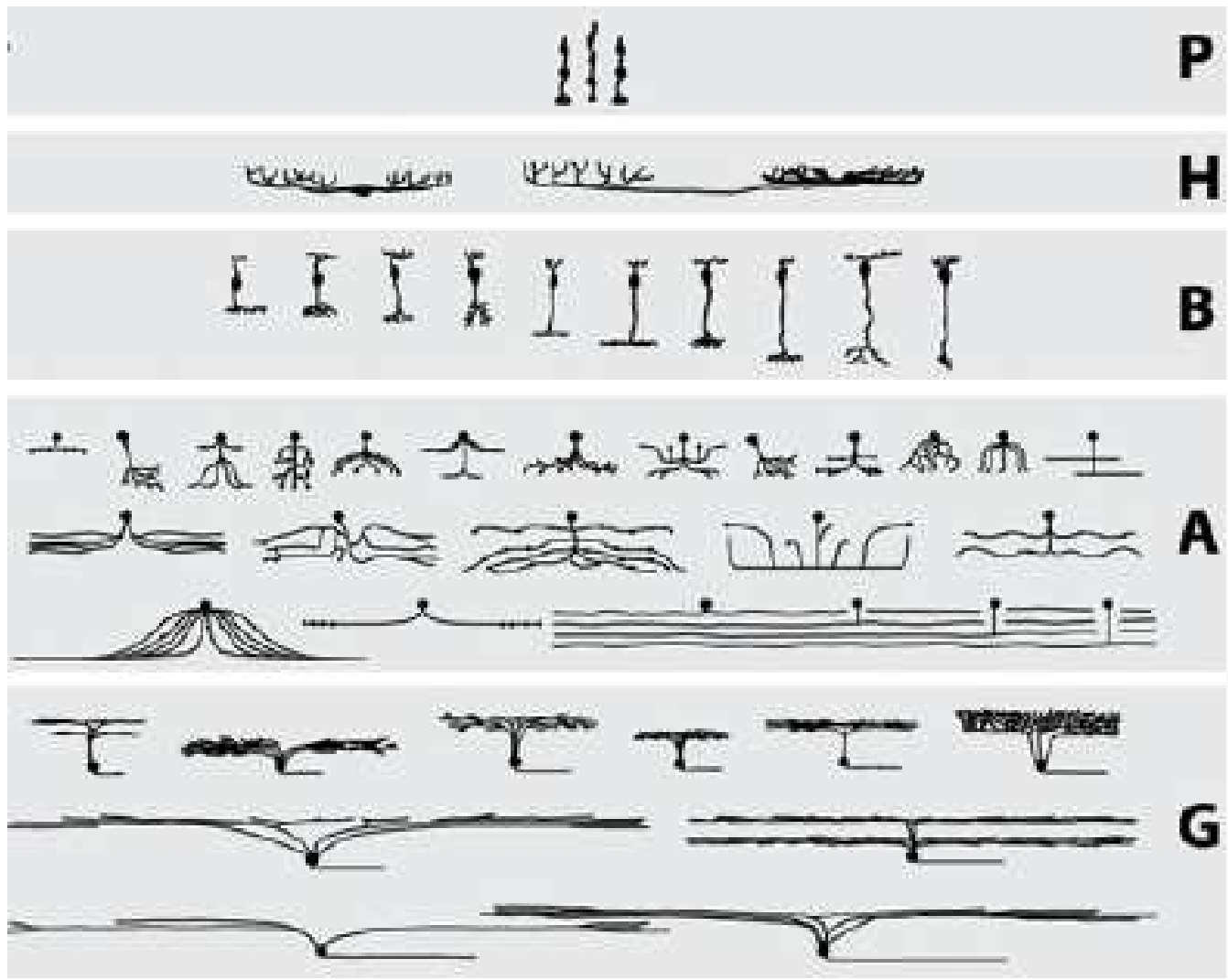

Figura 2. Diferentes subtipos de fotorreceptores $(P)$, células horizontais $(H)$, bipolares $(B)$, amácrinas $(A)$ e ganglionares $(G)$ compõem a diversidade neuronal da retina. (Fonte: MASLAND, 2001).

Além dos neurônios anteriormente descritos, a retina possui ainda na camada nuclear interna, os corpos celulares das células gliais de Müller, cujos processos se estendem radialmente entre a membrana limitante interna e externa (Figura 1). Sua presença é essencial para a atividade normal da retina, devido às suas funções de manutenção estrutural, tamponamento de potássio, seqüestro e inativação de glutamato (NEWMAN, 2004), e mais recentemente descrita, a regeneração (FISCHER e REH, 2003; FISCHER, 2005; FISCHER e BONGINI, 2010).

A fototransdução tem início no segmento externo dos fotorreceptores (cones e bastonetes), e posteriormente este sinal é transmitido para outros neurônios através do terminal sináptico. Nas esférulas dos bastonetes e pedículos dos cones podem ser encontradas as sinapses em fita (ribbon), compostas em geral, por dois dendritos centrais provenientes das células bipolares e dois processos laterais de células horizontais. Diferentemente dos bastonetes, os cones podem estabelecer contato com um número maior de células bipolares (EULER e WÄSLLE, 1995; BOYCOTT e WÄSSLE, 1999; BRANDSTÄTTER, 2002). 
Bastonetes e cones eram conhecidos por convergirem seus sinais para populações distintas de células bipolares: bipolares de bastonetes do tipo $\mathrm{ON}$, e bipolares de cone tipo ON e OFF, respectivamente. Entretanto, na retina de ratos e camundongos as células bipolares OFF de cones também estabelecem contato com os bastonetes (TSUKAMOTO et al., 2001; BRANDSTÄTTER, 2002).

Através das células bipolares e de outros neurônios intermediários, como as células amácrinas e algumas células horizontais, é que as células ganglionares recebem os sinais provenientes dos fotorreceptores. Os axônios, dos diferentes subtipos de células ganglionares (Figura 3 ), formam o nervo óptico pelo qual a informação processada na retina prossegue em direção ao sistema nervoso central. Um pequeno grupo de células ganglionares expressa o fotopigmento denominado de melanopsina que auxilia em algumas funções, tais como: controle do clico circadiano e constrição da pupila (PROVENCIO et al., 1998, 2000; HANKINS et al., 2008; HATORI e PANDA, 2010).

Essa descrição apresenta uma visão bem simplificada da retina, pois sua organização funcional é bastante complexa, incluindo circuitarias sinápticas muito elaboradas e atuação concomitante de diversos neurotransmissores e receptores.

No escuro, o glutamato liberado pelos fotorreceptores na fenda sináptica se liga aos seus receptores específicos expressos na membrana do neurônio póssináptico, que podem ser classificados em metabotrópicos (que se acoplam a proteínas $\mathrm{G}$, ativando segundos mensageiros) e ionotrópicos (que formam canais catiônicos não seletivos) (HOLLMANN e HEINEMANN, 1994; DINGLEDINE et al., 1999; DE BLASI et al., 2001; BRANDSTÄTTER, 2002; VANDENBERGHE e BREDT, 2004; STAWSKI et al., 2010). A ligação do glutamato é um processo dinâmico que envolve a mudança transiente na conformação protéica dos seus receptores (KUBO e ITO, 2004). 


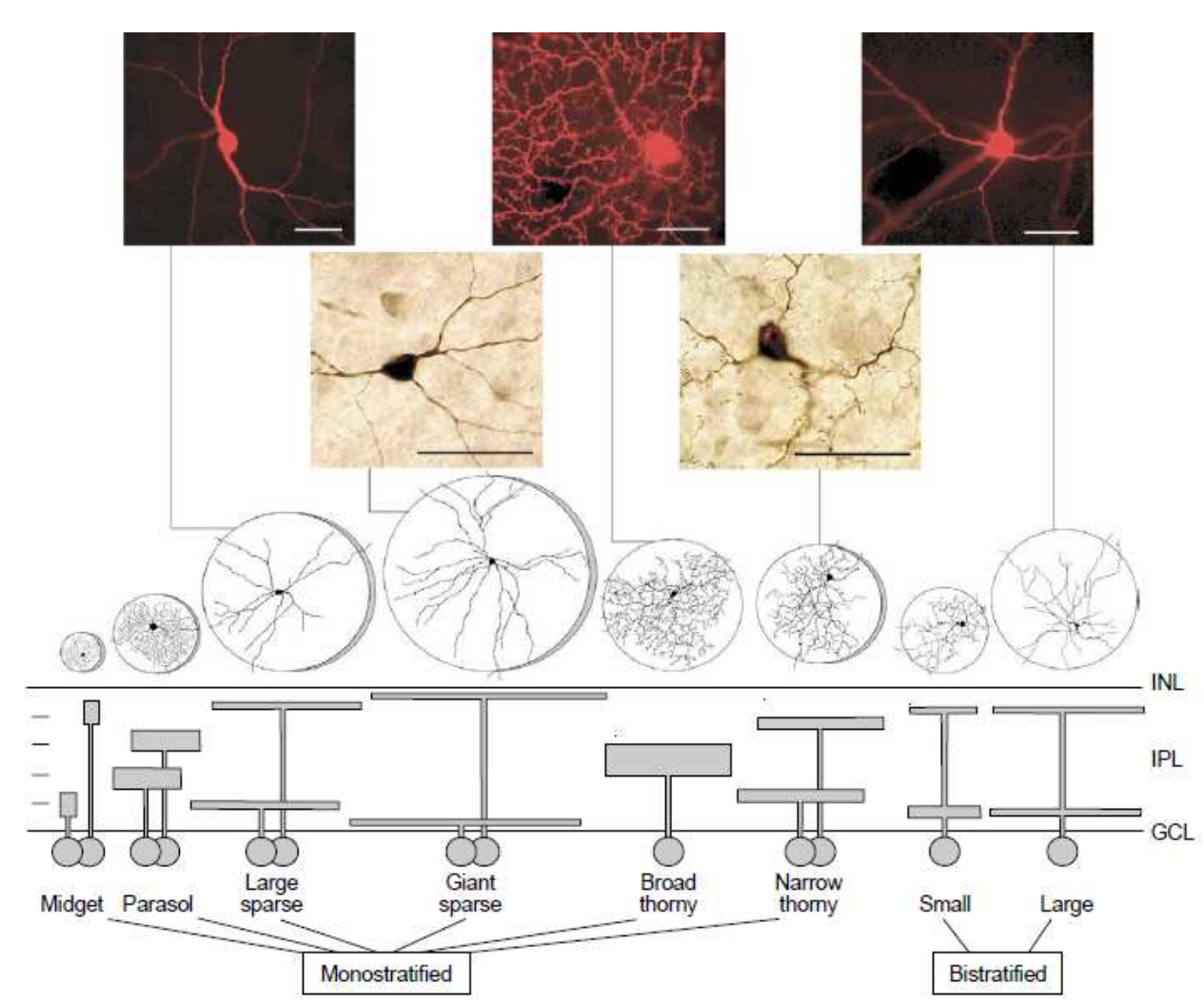

Figura 3. Diferentes subtipos de células ganglionares (Fonte: DACEY e PACKER, 2003).

O excesso desse neurotransmissor na fenda é sequestrado pelas células gliais de Müller que o converte em glutamina, através da enzima glutamina sintetase (RIEPE e NOREMBERG, 1977; POW e ROBINSON, 1994).

Os receptores metabotrópicos diferem dos ionotrópicos, dentre outras razões, por constituírem um receptor funcional com apenas uma proteína. Múltiplos subtipos de receptores metabotrópicos de glutamato (mGluR1-mGluR8) com diferentes isoformas foram clonados (MASU et al., 1991; HOUAMED et al., 1991; DE BLASI et al., 2001, BRANDSTÄTTER et al., 2002; JINGAMI et al., 2003; CASTILLO et al., 2010; DUNCAN e LAWRENCE, 2011) e, similarmente a outros receptores acoplados a proteínas $\mathrm{G}$ heterotriméricas, possuem sete domínios que atravessam a membrana plasmática. Entretanto, os receptores metabotrópicos de glutamato, diferem dos GPCRs (receptores acoplados à proteína G) clássicos por apresentarem um amplo domínio extracelular e nenhuma conservação aparente na seqüência de amino-ácidos do domínio transmembrana (NAKANISHI e MASU, 1994; BOCKAERT e PIN, 1999; JINGAMI et al., 2003).

Os receptores ionotrópicos de glutamato são codificados a partir de 18 genes (MAYER, 2005; TRAYNELIS et al., 2010) e de acordo com as suas características farmacológicas, esses receptores foram subdivididos em três classes principais: 
AMPA (ácido alfa-amino-3-hidróxi-5-metil-isoxazol-4-propiônico; subunidades GluR14), KA (cainato; subunidades GluR5-7, KA1-2), NMDA (N-metil-D-aspartato; subunidades NR1, NR2A-D, NR3A-B) e duas subunidades órfãs $\delta 1$ e 2 (WISDEN e SEEBURG, 1993; HOLLMANN e HEINEMANN, 1994; DINGLEDINE et al., 1999; CULL-CANDY et al., 2001, MADDEN, 2002; CARROL e ZUKIN, 2002; BRANDSTÄTTER, 2002; MAYER, 2005; STWASKI et al., 2010).

Além da via excitatória direta e vertical (fotorreceptores-células bipolarescélulas ganglionares) mediada pelo glutamato (THORENSON e WITKOVSKY, 1999; KALLONIATIS e TOMISICH, 1999; BRANDSTÄTTER, 2002), interações inibitórias laterais são promovidas por células horizontais e amácrinas através da liberação de GABA e glicina (EHINGER, 1983). Uma grande variedade de outros neuromediadores, tais como a acetilcolina, dopamina e neuropeptídios em geral, também é encontrada em células amácrinas, participando dos campos receptivos, controle dos sinais sinápticos (MASLAND, 2001), sensibilidade ao movimento (YOSHIDA et al., 2001), entre outros.

\subsection{Excitotoxicidade}

Apesar de desempenhar um importante papel como neurotransmissor, em altas concentrações o glutamato também pode atuar como uma potente neurotoxina do sistema nervoso central (LUCAS e NEWHOUSE, 1957; CHOI, 1988, 1992; NICHOLLS, 1999; SATTLER e TYMIANSKI, 2001), do qual a retina faz parte. A ativação excessiva dos receptores de glutamato está relacionada, pelo menos em parte, com a morte neuronal (excitotoxicidade) (OLNEY, 1970, 1971) que ocorre em diversas doenças degenerativas, como o glaucoma e retinopatia diabética (DREYER et al., 1996; DINGLEDINE et al., 1999; CARTER-DAWSON, 2002; KOWLURU, 2002).

Embora não seja a única via envolvida, muitos autores relatam que o evento central da morte neuronal induzida por glutamato seja a elevação dos níveis intracelulares de cálcio (FERREIRA et al., 1996; SATTLER e TYMIANSKI, 2003) que ocasiona desarranjos metabólicos, como a ativação de proteases, fosfolipases, fosfatases, endonucleases e formação de radicais livres (SATTLER e TYMIANSKI, 2001). 
A ativação dos receptores AMPA e metabotrópicos de glutamato modulam os níveis de cálcio na célula, entretanto o fluxo gerado não é freqüentemente associado ao processo de excitotoxicidade (LYNCH e GUTTMANN, 2002).

Neste sentido, devido a sua maior permanência no estado sensibilizado, os receptores NMDA são descritos como os maiores mediadores da morte neuronal, por promover o alto fluxo de cálcio intracelular durante a presença prolongada de glutamato (WAXMAN e LYNCH, 2005).

\subsection{Receptores NMDA}

Ao longo dos anos, diferentes nomenclaturas foram utilizadas para identificar uma única subunidade pertencente à classe dos receptores do tipo NMDA: NR1

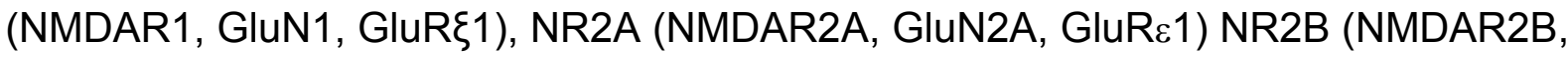

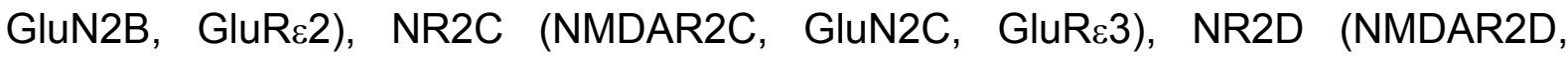
GluN2D, GluRe4), NR3A (Glun3A), NR3B (GluN3B) e as subunidades órfãns $\delta 1$ (GluD1) e 2 (GluD2) (IKEDA et al., 1992; KUTSUWADA et al., 1992; TRAYNELIS et al., 2010; STWASKI et al., 2010).

De modo geral, cada subunidade é composta por um domínio amino-terminal extracelular, quatro segmentos hidrofóbicos (TMI-TMIV), sendo TMII margeando a parte interna do canal, e um domínio carboxi-terminal intracelular (DINGLEDINE et al., 1999; STONE e ADDAE, 2002; MAYER e ARMSTRONG, 2004; CHEN e WYLIE, 2006; STWASKI et al., 2010). Na região amino-terminal, encontram-se os segmentos S1 e S2 de ligação para o agonista (LAUBE et al., 1998; FURUKAWA e GOAUX, 2003; MAYER et al., 2005).

A combinação de quatro subunidades forma a composição tetramérica do receptor (LAUBE et al., 1998; ROSENMUND et al., 1998; CULL-CANDY et al., 2001; BRANDSTÄTTER, 2002; GOUAUX, 2004), sendo em sua maioria dímeros de NR1 com homo-dímeros de NR2A-D (LAUBE et al., 1998; CULL-CANDY et al., 2001; PRYBYLOWSKI e WENTHOLD, 2004).

A subunidade NR1 é essencial para a funcionalidade do receptor e possui o sítio de ligação para glicina (KURYATOV et al., 1994; HIRAI et al., 1996), já as subunidades NR2A-D possuem o sítio de ligação para o glutamato (ANSON et al., 1998; LAUBE et al., 1997). A combinação das subunidades NR1 e NR3 formam um 
receptor excitatório responsivo à glicina mesmo na ausência de glutamato (CHATTERTON et al., 2002).

Além da combinação entre as subunidades, as alterações pós-transcrição e tradução aumentam ainda mais a diversidade estrutural e funcional dos receptores ionotrópicos de glutamato (DINGLEDINE et al., 1999; BREDT e NICOLL, 2003).

Neste sentido, o gene que codifica a subunidade NR1 consiste de 22 éxons, sendo que o 5, 21 e 22 podem sofrer splices alternativos produzindo as 8 isoformas da proteína (SUGIHARA et al., 1992; LAURIE e SEEBURG, 1994). Assim, com relação ao complexo formado entre as subunidades NR1 e NR2, a heterogeneidade farmacológica é determinada pela combinação de NR2A-D com os splicings alternativos de NR1 (MONAGHAM e JANE, 2009). A fosforilação dos sítios específicos de cada subunidade é outro mecanismo regulatório importante da plasticidade sináptica, pois está diretamente relacionado com o aumento da afinidade do receptor ao agonista (DINGLEDINE et al., 1999).

A presença e distribuição dos RNAm e protéica das subunidades de receptores NMDA já foram descritas na retina de vertebrados em geral (HAMASSAKI-BRITTO et al., 1993; ZHANG et al., 1996; BRANDSTÄTTER et al., 1998; THORESON e WITKOWSKI, 1999; SILVEIRA DOS SANTOS BREDARIOL e HAMASSAKI-BRITTO, 2001), desde o desenvolvimento embrionário até a fase adulta (ZHANG et al., 1996; SILVEIRA DOS SANTOS BREDARIOL e HAMASSAKIBRITTO, 2001).

Essa expressão e distribuição dos receptores não constituem um sistema estático e fixo. Os receptores podem se mover na membrana neuronal (CARROL e ZUKIN, 2002; GROC et al., 2006) translocando de regiões sinápticas para não sinápticas, ou sendo exo e endocitados dependendo do estímulo e das proteínas sinalizadoras envolvidas (MALINOW e MALENKA, 2002; WENTHOLD et al., 2003; NONG et al., 2004).

\subsection{Vias de sinalização disparadas pelos receptores NMDA}

Os receptores NMDA foram amplamente descritos com participação direta na perda neuronal com o envolvimento de MAP cinases (p38 e c-JNK) (MANABE e LIPTON, 2003; MUNEMASA et al., 2006), caspase-3 (KWONG e LAM, 2000; CHEN et al., 2001; ALAVEZ et al., 2006) entre outras. Sendo assim, o bloqueio dos 
receptores NMDA poderia, então, ser utilizado do tratamento de diversas doenças. Entretanto, a administração de antagonistas desses receptores também pode resultar no aumento da morte neuronal (IKONOMIDOU e TURSKI, 2002).

Outro aspecto interessante é que apesar das células ganglionares serem as que mais expressam receptores NMDA, a morte não ocorre simultaneamente em todas as células após o estímulo degenerativo (OSBORNE et al., 1999; ULLIAN et al., 2004), ou seja, é possível que outras vias além da morte possam ser disparadas.

Neste sentido, foi demonstrado que a ativação crônica dos receptores NMDA é capaz de proteger as células retinianas diferenciadas contra a exposição ao glutamato (ROCHA et al., 1999). Reforçando essa idéia alguns fatores, tais como o BDNF (MARTINS et al., 2005) e as proteínas PI3-K-Akt (LUO et al., 2003; MANABE e LIPTON, 2003) e ERK1/2-CREB (YING et al., 2002) foram disparados após ativação desses receptores, resultando na sobrevivência neuronal.

Por muitos anos acreditou-se que o influxo de cálcio gerado pela ativação dos receptores NMDA era o único responsável por controlar e disparar a resposta na célula. Assim, níveis moderados de ativação eram considerados benéficos enquanto a sua ativação excessiva, e subseqüente alto influxo de cálcio, degenerativo (HARDINGHAM e BADING, 2011).

Entretanto, atualmente o paradoxo dos receptores NMDA tem sido explicado por alguns autores pela combinação das subunidades que formam o receptor e a sua localização, e neste sentido é descrito que sua presença na região sináptica desencadeia a sobrevivência, enquanto a extra-sináptica a morte (TOVAR e WESTBROOK, 1999; PAPADIA, 2008).

Com relação à combinação das subunidades, o disparo das vias de sinalização de morte e de sobrevivência pode ser reflexo da presença de subunidades especificas (NR1, NR2A-D, NR3A-B) no receptor (CULL-CANDY e LESZKIEWICZ, 2004; PAOLETTI e NEYTON, 2006). Essa possibilidade poderia ser justificada pelo seguinte fato: o domínio C-terminal intracelular das subunidades NR2A-D é a região menos conservada na seqüência de amino ácidos (IKEDA et al., 1992) e é ela a responsável por promover a interação com diversas proteínas intracelulares.

No caso da proteína PSD-95, a inibição da sua associação com NR2 aumenta a excitotoxicidade, sugerindo a sua participação na neuroproteção (GARDONI et al., 
2002). Entretanto, uma análise mais específica revelou que a interação entre PSD95 com NR2B potencializa a morte neuronal (AARTS et al., 2002). Além disso, PTEN, conhecida por desencadear a morte celular pela inibição da via Akt, é capaz de interagir com NR2B, mas não com NR2A (NING et al., 2004). Ou seja, cada subunidade pode disparar mecanismos moleculares distintos dependendo da proteína que está associada a ela.

Assim como as proteínas acima descritas, muitas outras podem se ligar ao domínio C-terminal das subunidades dos receptores NMDA após a sua ativação, gerando diferentes respostas celulares. Por exemplo, os receptores NMDA podem interagir com proteínas que controlam a atividade das GTPases Rho, participando de eventos, como a regulação dendrítica (TOLIAS et al., 2005; NAKAZAWA et al., 2008).

\subsection{GTPases Rho}

Atualmente, mais de 20 membros da família das GTPases Rho (Rashomology) já foram descritos, sendo RhoA (Ras homologous member A), Rac1 (Ras-related C3 botulinum toxin substrate 1) e Cdc42 (Cell division cycle 42) as mais estudadas.

Essas proteínas possuem baixo peso molecular (21-25 kDa) e ciclam entre um estado ativo (ligadas ao GTP) e inativo (ligadas ao GDP) reguladas pelos GEFs (guanine nucleotide exchange factors) e GAPs (GTPase-activating proteins), respectivamente (RIDLEY, 2001; ETIENNE-MANNEVILLE e HALL, 2002; BOS et al., 2007). Os GEFs são mediadores do desligamento de GDP associado às GTPases Rho, facilitando a ligação do GTP; e os GAPs, por sua vez, promovem a atividade catalítica intrínsica, inativando essas proteínas (SCHMIDT e HALL, 2002) (Figura 4).

No entanto, existe outro mecanismo de regulação das GTPases Rho através dos GDIs (GDP dissociation inhibitors). Esses inibidores possuem a capacidade de interagir com as GTPases Rho formando um complexo que impede a dissociação do GDP (UEDA et al., 1990), ou ainda inibem a atividade catalítica intrínseca (OLOFSSON, 1999) dessas proteínas (Figura 4). 
A ligação de GTP ou GDP nas GTPases Rho promove variações na conformação da proteína em dois loops chamados de região I e II, que corresponde no caso de Cdc42 aos aminoácidos 26-45 e de Rac 59-74 (IHARA et al., 1998).

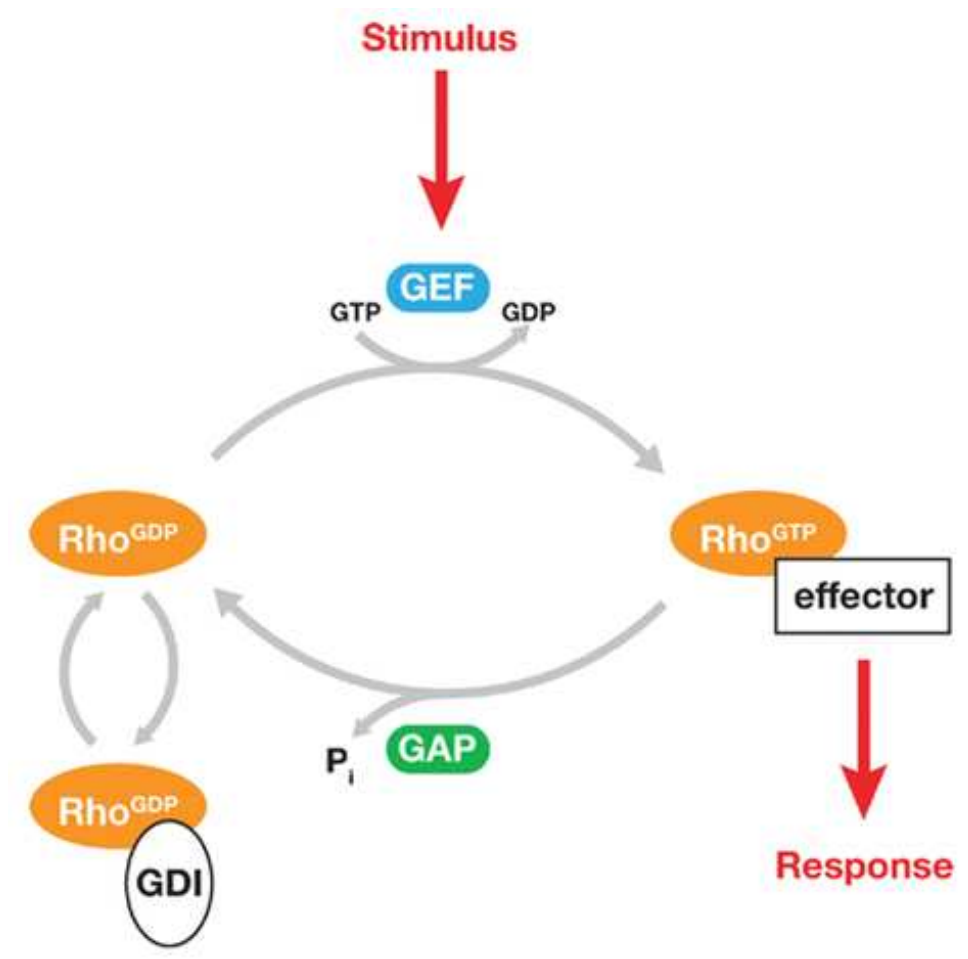

Figura 4. As GTPases Rho ciclam entre o estado ativo e inativo controlado por GEFs e GAPs, respectivamente. Além disso, os GDls atuam como moduladores destas proteínas (Fonte: JAFE e HALL, 2005).

Uma vez ativada, a proteína Rho é translocada do citoplasma para a membrana da célula, onde se associa com seus efetores, prosseguindo a via de sinalização (MOLNÁR et al., 1997; HALL, 2005).

Inicialmente essas proteínas foram descritas como reguladoras da polimerização do citoesqueleto de actina, mas atualmente sabe-se que podem estar envolvidas na regulação de vários outros processos celulares, tais como: ciclo celular, diferenciação, tráfego de vesículas, sobrevivência e apoptose (HALL, 1998; ETIENNE-MANNEVILLE e HALL, 2002; SCHMIDT e HALL, 2010).

Em vista do envolvimento das GTPases Rho em diversos processos celulares, grandes esforços estão sendo realizados para identificar os seus diferentes efetores. Aproximadamente mais de 30 potenciais efetores das GTPases Rho já foram identificados (BISHOP e HALL, 2000). 
Dentre os efetores de Rac, PAK ( $p 21$-activated kinase) é o mais bem caracterizado (WELLS e JONES, 2010). Em mamíferos são conhecidas 6 isoformas PAK1-6 (ARIAS-ROMERO e CHERNOFF, 2008) que estão divididas em duas classes principais, Grupo I (PAK1-3) e Grupo II (PAK4-6) de acordo com a semelhança estrutural (JAFFER e CHERNOFF, 2002; KREIS e BARNIER, 2009).

Rac interage com as PAKs e com p67 (componente de NADPH oxidase) através de uma região próxima ao domínio carboxi-terminal (aminoácido 143-175). A análise estrutural dessa interação revelou ainda que essas proteínas ativas inibem a interação intramolecular autoinibitória, promovendo a exposição do domínio que se liga ao substrato (BAGRODIA e CERIONE, 1999; TU e WIGLER, 1999).

Algumas vias de sinalização conhecidas das GTPases Rho como a produção de espécies reativas de oxigênio (ROS) (CHENG et al., 2004; CACICEDO et al., 2005; VERMA et al., 2002; CHUNG et al., 2003) e JNK (LINSEMAN et al., 2001; LE et al., 2005) foram observadas regulando a morte celular, enquanto PI3-K, PKB e Akt, a sobrevivência (OZAKI et al., 2003; JIANG et al., 2003; KANEKURA et al., 2005).

$\mathrm{Na}$ retina, estudos do nosso laboratório demonstraram que Rac1 esteve presente em núcleos apoptóticos de fotorreceptores nos modelos de degenerações induzida por luz ou hereditária (BELMONTE et al., 2006), e que a expressão gênica dos seus efetores PAK3 e PAK4 foi aumentada, enquanto PAK5 permaneceu inalterada. Posteriormente, Haruta et al. (2010) confirmaram a participação de Rac1 na degeneração dos fotorreceptores através do animal knockout condicional para esta proteína.

De modo geral, até recentemente, a correlação existente entre os receptores de glutamato e as GTPases Rho no sistema nervoso central abordava os processos de sinaptogênese e dendritogênese que ocorrem durante o desenvolvimento (WONG et al., 2000; HENLE et al., 2006). Apesar de ter sido demonstrado que a excitotoxicidade por glutamato pode ocasionar a morte celular com o envolvimento de RhoA em cultura de neurônios corticais (SEMENOVA et al., 2007) e na retina de ratos (REF), ainda não existem evidências do envolvimento da GTPase Rac1 nesse processo. 


\section{OBJETIVO}

Considerando a relevância dos receptores NMDA e das GTPases Rho nos processo de morte e sobrevivência celular, este projeto teve como objetivo principal investigar o efeito da combinação das subunidades de receptores NMDA, assim como o possível envolvimento downstream de Rac1 em vias de morte e/ou sobrevivência dos neurônios retinianos de ratos.

Especificamente, foram avaliados:

- o efeito do bloqueio in vitro dos receptores NMDA formados pelas subunidades NR2B e NR2C/D na morte e/ ou sobrevivência de neurônios retinianos após a excitotoxicidade por glutamato. Para tanto, utilizamos os bloqueadores específicos para as subunidades NR2B (Ro 25-6981) e NR2C/D (PPDA) e o ensaio de lactato desidrogenase (LDH) para a detecção da morte celular.

- a participação das GTPases Rho, mais especificamente Rac1 na via de sinalização disparada pela ativação dos receptores NMDA in vitro. Para isso foram utilizados inibidores (Toxina A e NSC 23766) e o ensaio de LDH para avaliar a morte celular.

- se os resultados obtidos in vitro eram reproduzidos in vivo. Utilizamos a injeção intravítrea de NMDA na ausência e/ ou presença do bloqueador de NR2B (Ro256981) e do inibidor de Rac1 (NSC 23766). A morte celular foi avaliada pelo método de TUNEL. A atividade de Rac1 foi investigada por meio de imunohistoquímica com anticorpos contra a forma ativa e ensaio de pull-down.

- a participação da célula glial de Müller na morte neuronal e a produção de TNF-a após os diferentes tratamentos (NMDA; NMDA+Ro 25-6981; NMDA+NSC 23766). 


\section{MATERIAL E MÉTODOS}

Todos os procedimentos no uso de animais e experimentações seguiram os princípios éticos aprovados pela Comissão de Ética em Experimentação Animal (CEEA) do Instituto de Ciências Biomédicas da Universidade de São Paulo (protocolo $\mathrm{n}^{\circ}$ 07899). Os animais com 1-10 dias pós-natal (P1-10) foram fornecidos pelo Biotério Central do Instituto de Ciências Biomédicas e utilizados imediatamente para experimentação. Os ratos Wistar adultos foram mantidos em biotério com temperatura controlada $\left(23 \pm 1^{\circ} \mathrm{C}\right)$ e em regime de fotoperíodo 12 horas claro: 12 horas escuro (período claro com início às 7:00 horas) com água e ração ad libitum.

Os animais utilizados para a obtenção da cultura primária de neurônios e purificada de células gliais de Müller (neonatos), assim como aqueles empregados nos experimentos de cultura de explante (adultos) foram anestesiados e, posteriormente, decaptados. Os demais animais adultos utilizados para injeção intravítrea foram anestesiados com xilazina (10 $\mathrm{mg} / \mathrm{Kg}$ de peso corpóreo, i.p.) e quetamina (50 mg/kg de peso corpóreo, i.p.), e perfundidos com solução salina $(0,9 \%)$ tamponada (PBS) seguida de solução de paraformaldeído $2 \%$ em tampão fosfato (PB 0,1 M; $\mathrm{pH}=7,4$ ). Os olhos dissecados foram crioprotegidos em uma solução de sacarose $30 \%$ por 24-48 horas e embebidos em O.C.T. (Optimal Cutting Temperature, Sakura Finetek) para a obtenção de cortes $(12 \mu \mathrm{m})$ em criostato Leica (Jung Frigocut 2800N).

\subsection{Cultura Organotípica da retina de rato}

As retinas de ratos adultos foram dissecadas em HBSS (Hank's Buffered Salt Solution) e cortadas radialmente (Figura 5). Posteriormente, o material foi transferido com o auxílio de um pincel para membranas millicell (Millipore) onde foi cultivado com a camada de células ganglionares orientada para baixo em $2 \mathrm{ml}$ de meio de cultura MEM (Minimum Essential Medium Eagle) contendo soro fetal bovino 10\%, glicose 0,8\%, L-glutamina 2 mM, HEPES (4-(2-hidroxietil)-1piperazinaetanosulfonico ácido) $25 \quad \mathrm{mM}$, suplemento $\mathrm{B} 27 \quad 2 \% \quad \mathrm{e}$ penicilina/estreptomicina 100UL (RZECZINSKI et al., 2006; RUSCHER et al., 2007). O tratamento excitotóxico foi realizado com $5 \mathrm{mM}$ de glutamato (Sigma) adicionado 
por 12 ou 24 horas. Após este período, o material foi devidamente processado para a realização da imunohistoquímica.

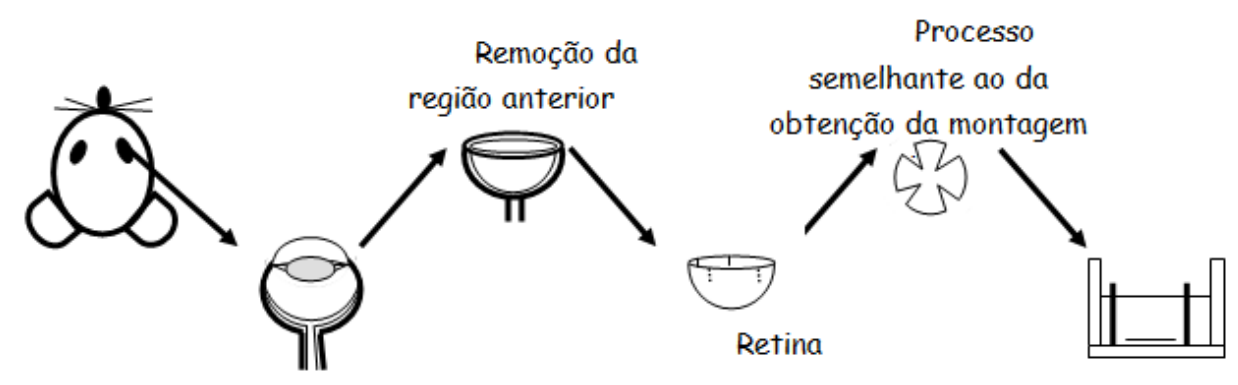

Figura 5. Representação esquemática do protocolo.

Os antagonistas do receptor NMDA (MK-801, (+)-5-metil-10,11-diidro-5Hdibenzo[a,d] ciclohepteno-5,10-imina maleato) (Sigma), das subunidades NR2B (Ro-

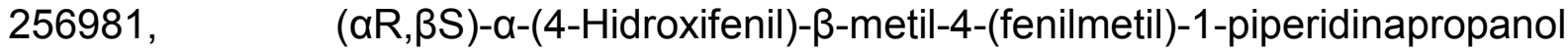
maleato) (Sigma) e NR2C/D (PPDA, $\left(2 S^{*}, 3 R^{*}\right)$-1-(fenantreno-2-carbonil)piperazina2,3-dicarboxilico ácido) (Tocris) foram utilizados na concentração de $10 \mu \mathrm{M}$, sendo adicionados 15 minutos antes e durante os tratamentos excitotóxicos. Para inativação das GTPases Rho utilizamos a Toxina A (Toxina A de Clostridium difficile, $1 \mathrm{ng} / \mathrm{ml}$, List Biological Laboratories, Inc.) e para a inibição de Rac1, a retina foi incubada em NSC 23766 (N6- [2-[ [4-(Dietilamino)-1- metilbutil] amino]-6-metil-4pirimidinil] -2-metil-4,6-quinolinodiamino trihidroclorido, $100 \mu \mathrm{M}$, Calbiochem). A Toxina A e o NSC 23766 foram adicionados 12 horas antes e durante o tratamento excitotóxico.

\subsection{Cultura purificada/ enriquecida de células gliais de Müller}

A cultura purificada de células de Müller foi baseada nos trabalhos de Hick e Courtois (1990). O globo ocular foi incubado em meio DMEM (Dulbecco's modified Eagle's medium) por 24 horas à $4{ }^{\circ} \mathrm{C}$. Posteriormente, foi transferido para meio DMEM contendo tripsina $0,1 \%$ e colagenase $70 \mathrm{U} / \mathrm{ml}$ à $37^{\circ} \mathrm{C}$ por 45 minutos. Os olhos foram, então, lavados em DMEM com $10 \%$ de soro fetal bovino. Durante a dissecção, a região anterior do globo ocular e o epitélio pigmentar foram removidos, restando apenas a retina. A dissociação mecânica da retina em pequenos agregados foi feita em DMEM com soro para posterior cultivo. O sobrenadante com 
debris foi removido em média a cada 3-4 dias. Após 8-10 dias de cultivo as células foram tripsinizadas e mantidas por mais 5 dias para a purificação.

\subsection{Cultura primária de neurônios retinianos}

A cultura primária da retina de ratos foi obtida de acordo com o protocolo de Lipton (1993), seguido de algumas alterações. Retinas obtidas de ratos Wistar com idades entre P1-10 foram incubadas em solução de HBSS (Hank's Buffered Salt Solution) contendo tripsina $0,1 \%$, papaína $32 \mathrm{U} / \mathrm{ml}$ e L-cisteína $0,01 \%$ à $37^{\circ} \mathrm{C}$ por 15 minutos. O material foi centrifugado à 1000 rpm por 5 minutos. O sobrenadante foi substituído por DMEM (Dulbecco's modified Eagle's medium) contendo soro fetal bovino $10 \%$. As retinas foram mecanicamente dissociadas e plaqueadas a uma densidade de $2 \times 10^{6}$ células $/ \mathrm{ml}$. Após 24 horas, o meio foi substituído por NeurobasalA (Gibco), contendo suplemento B27, que permite a produção de culturas com 99\% de neurônios (BREWER et al. 1993), juntamente com a adição de NMDA $(500 \mu \mathrm{M})$ por 24 horas.

\subsection{Atividade de lactato desidrogenase (LDH)}

A avaliação da atividade de LDH foi realizada com um kit colorimétrico de acordo com as instruções do fabricante (Labtest). A desidrogenase láctica catalisa a reação reversível lactato-piruvato na presença de NAD que é reduzido à NADH. O princípio do kit é baseado na medida colorimétrica da quantidade de NADH formada pela ação enzimática. Em suma, o meio de cultura do explante dos diferentes tratamentos foi coletado após 12 ou 24 horas, centrifugado $100 \mathrm{~g}$ por 5 minutos e o sobrenadante retirado para a análise. As amostras foram incubadas com $1 \mathrm{ml}$ de substrato (Reagente 2) à $37^{\circ} \mathrm{C}$ por 2 minutos, seguido do reagente colorimétrico por 5 minutos e estabilizador por mais 5 minutos. Juntamente, foram preparadas amostras controle do kit que consiste do substrato juntamente da amostra e o padrão contendo tampão (Reagente 1) e padrão (Reagente 3). A leitura em 500 nm foi realizada em espectofotômetro Spectra Max Plus (Molecular Device). O valor de desidrogenase láctica foi obtido de acordo com a seguinte fórmula: Desidrogenese láctica $(U / L)=[($ Absorbância do grupo-Absorbância do controle)/ Absorbância do padrão] x 150. O valor liberado de LDH de cada amostra foi expresso em 
porcentagem em relação ao total presente no tecido obtido pelo do congelamento e descongelamento do tecido em nitrogênio líquido.

\subsection{Detecção da apoptose pelo método TUNEL (TdT-mediated dUTP nick end labeling)}

Para este experimento de detecção de células em apoptose foi utilizado o kit Roche (Mannheim, Germany) de acordo com as instruções do fabricante. Resumidamente, os corte da retina foram lavados 3 vezes em salina tamponada $0,05 \mathrm{M} \mathrm{pH}=7,4$ (PBS) por 5 minutos cada, e incubados em solução permeabilizante de PBS, com Triton X-100 0,1\% e citrato de sódio $0,1 \%$ por 2 minutos à $4{ }^{\circ} \mathrm{C}$. Para o alongamento dos fragmentos de DNA, os cortes foram expostos por 1 hora à $37^{\circ} \mathrm{C}$ com a enzima transferase (TdT-transferase) juntamente os nucleotídeos marcados com fluoresceína para incorporação nos terminais das moléculas de DNA fragmentado. A reação foi interrompida com uma solução de Tris-HCl 4 mM e EDTA $5 \mathrm{mM}$ por 5 minutos. Após 3 novas lavagens em PBS 0,05 M por 5 minutos cada, os cortes foram montados com Vectashield (Vector) e analisados no microscópio confocal Nikon PCM2000. No controle negativo, omitiu-se a incubação com a enzima TdT. A quantificação se restringiu ao grupo de 6 horas, início do aparecimento da morte neuronal observada apenas na camada de células ganglionares que são as células relacionadas com a perda visual que ocorre no glaucoma. Para cada retina foi avaliada uma área de aproximadamente $105 \times 10^{3}$ $\mu \mathrm{m}^{2}$ (total de 3-5 retinas por grupo). Os valores foram expressos em porcentagem de células em apoptose (TUNEL-positivas)/ total de células (DAPI-positivas) ou porcentagem de células ganglionares em apoptose (TUNEL e Thy-1-positivas)/ total de células (DAPI-positivas) \pm desvio padrão, utilizando o Teste de Tukey.

\subsection{Injeção intraocular}

Os animais receberam anestesia geral com tiopental $(30 \mathrm{mg} / \mathrm{Kg}$ do peso corpóreo do animal) e local com cloridrato de tetracaína $1 \%$ e cloridrato de fenilifrina $0,1 \%$ (5 $\mu \mathrm{L} /$ olho), juntamente com o dilatador de pupila cloridrato de ciclipentolato $1 \%(5 \mu \mathrm{L} /$ olho). As injeções foram realizadas no vítreo com uma seringa Hamilton 
de $10 \mu$ no quadrante dorsal do olho. No olho esquerdo (controle) foi injetado $5 \mu$ de salina tamponada estéril e no direito (experimental), $5 \mu \mathrm{l}$ de NMDA (100 nmol) (MUNEMASA et al., 2005). O material foi coletado após 3, 6, 12 e 24 horas de sobrevida. O antagonista das subunidades NR2B (10 $\mu \mathrm{M}$ - Ro-256981-Sigma) e o inibidor de Rac1 (100 $\mu \mathrm{M}$, NSC 23766) foram injetados isolados ou juntamente com o NMDA.

\subsection{Imunohistoquímica}

As retinas obtidas foram fixadas em paraformaldeído $2 \%$ em PB 0,1 M por 15 minutos, crioprotegidos em sacarose $30 \%$ em PB $0,1 \mathrm{M}$ por no mínimo 16 horas. Os cortes foram pré-bloqueados com soro normal por 1 hora e incubados por 16 horas em temperatura ambiente com anticorpos primários contra Rac1 (Santa Cruz), Rac 1 ativo (Neweast), RhoA ativo (Neweast), TNF- $\alpha$ (Santa Cruz), Thy 1 (Chemicon) e glutamina sintetase (Chemicon). Em alguns casos o bloqueio foi omitido. Após três lavagens em tampão fosfato 0,1 M (PB) por 10 minutos, o material foi incubado com anticorpos secundários conjugados com FITC (isoticiocianato de fluoresceína) e/ ou TRITC (tetrametil isoticiocianato de rodamina, 1:200 Jackson Labs.) por duas horas. Todos os anticorpos empregados foram diluídos em solução contendo $0,3 \%$ de Triton-X100 em PB 0,1 M. Os núcleos foram evidenciados com DAPI (1:1000). Posteriormente, as lâminas montadas com VectaShield foram analisadas em microscópio confocal Nikon PCM2000.

Quadro 1. Anticorpos utilizados.

\begin{tabular}{|l|l|l|}
\hline \multicolumn{1}{|c|}{ Anticorpo } & \multicolumn{1}{c|}{ Empresa } & \multicolumn{1}{c|}{ Concentração de Uso } \\
\hline Rabbit anti-Rac1 & SC270, Santa Cruz & $\begin{array}{l}\text { Imunohistoquímica: } 10 \mu \mathrm{g} / \mathrm{ml} \\
\text { Western blotting: } 1,0 \mu \mathrm{g} / \mathrm{ml}\end{array}$ \\
\hline Mouse anti-Rac1 ativo & 26903, Neweast & $10 \mu \mathrm{g} / \mathrm{ml}$ \\
\hline Mouse anti-RhoA ativo & 26904, Neweast & $10 \mu \mathrm{g} / \mathrm{ml}$ \\
\hline Goat anti-TNF- $\alpha$ & SC1350, Santa Cruz & $2 \mu \mathrm{g} / \mathrm{ml}$ \\
\hline Mouse anti-Thy-1 & CBL1500, Chemicon & $2 \mu \mathrm{g} / \mathrm{ml}$ \\
\hline Rabbit Anti-Glutamina sintetase & G2781, Chemicon & $12,6 \mu \mathrm{g} / \mathrm{ml}$ \\
\hline
\end{tabular}




\subsection{Ensaio de pull-down}

O ensaio de pull-down para medir a ativação de Rac1 foi realizado de acordo com o protocolo descrito por Ren e Schwartz (2000) (Figura 6). As bactérias BL21 foram transformadas com o plasmídeo pGEX-2T contendo o inserto para PBD (PAKbinding domain) fusionado ao GST. A expressão da proteína PBD-GST foi induzida por IPTG (Isopropyl $\beta$-D-1-thiogalactopyranoside) por 4 horas. Em seguida, o material foi lisado, centrifugado e coletado pelas micro-esferas. As retinas foram dissociadas em tampão de lise (CLB, Tris 50 mM, pH7, 2, Triton X-100 1\%; NaCl 50 $\mathrm{mM} ; \mathrm{MgCl}_{2} 5 \mathrm{mM}$; DTT $1 \mathrm{mM}$, PMSF $1 \mathrm{mM}$, coquetel de inibidores) e centrifugado. Em cada ensaio de pull-down, $1 \mathrm{mg}$ de retina lisada foi incubada com PBD-GST acoplado às micro-esferas de glutationa-Sefarose (Amersham Biosciences) por 1 hora a $4{ }^{\circ} \mathrm{C}$. Posteriormente, as micro-esferas foram lavadas com CLB, a proteína eluída em tampão de amostra Laemmli e separada por SDS-PAGE. A presença de Rac1 ativa foi visualizada por western blotting usando anticorpo contra Rac1 (Santa Cruz).

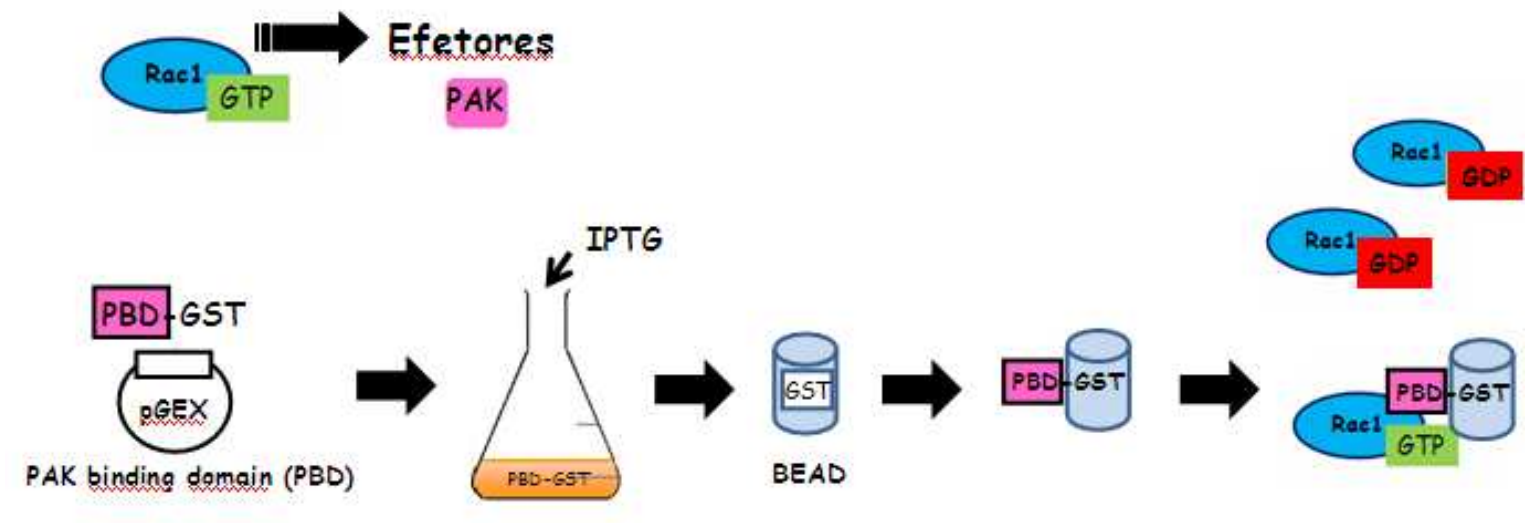

Figura 6. A expressão de PBD-GST foi induzida por IPTG. Posteriormente, a seqüência foi fusionada na esfera de sefarose para futura incubação com o material.

\subsection{ELISA para TNF- $\alpha$}

Este procedimento foi realizado de acordo com as informações do fabricante (DuoSet $\circledast$ ELISA Development System kit for rat TNF- $\alpha$, RandD System). Em suma, $50 \mu \mathrm{l}$ de salina tamponada estéril (PBS) contendo soro de albumina 0,1\%, e anticorpo contra TNF- $\alpha 44 \mu \mathrm{g} / \mathrm{mL}$ foram incubados por poço em placas para ensaio 
de ELISA durante o período de16 horas à temperatura ambiente. Posteriormente, a solução foi aspirada e cada poço lavado por 3 vezes com Tween 0,05\% em PBS, e incubado novamente com PBS e soro de albumina 1\% por 1 hora em temperatura ambiente. Os poços foram lavados com Tween 0,05 \% em PBS. As retinas previamente lisadas em tampão RIPA (Tris $\mathrm{HCl}$ pH 8,0 50 mM, NaCl 150 mM, NP-40 $1 \%$, deoxicolato de sódio $0,5 \%$, SDS $0,1 \%$, coquetel de proteases) foram centrifugadas à $10.000 \mathrm{~g}$ por 10 minutos, e $50 \mu \mathrm{L}$ do sobrenadante incubado na placa sensibilizada juntamente com o branco, controle negativo e a curva de concentração por 2 horas em temperatura ambiente. As lavagens foram repetidas e $225 \mathrm{ng} / \mathrm{mL}$ de anti-TNF-a biotinilado foram incubados por poço por mais 2 horas em temperatura ambiente. Repetidas lavagens foram realizadas e $50 \mu \mathrm{L}$ de anticorpo conjugado com estreptoavidina-HRP (concentração não informada no kit) adicionado

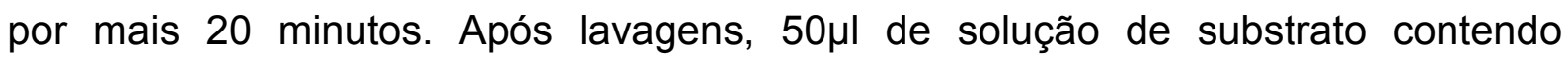
reagente de cor $A(\mathrm{H} 2 \mathrm{O} 2)$ e reagente de cor $B$ (Tetrametilbenzidina) foram utilizados por 20 minutos, seguido do reagente de parada da reação. A leitura em $540 \mathrm{~nm}$ foi realizada em espectofotômetro Spectra Max Plus (Molecular Device, Sunnyvale, California, United States). 


\section{RESULTADOS}

\subsection{O bloqueio dos receptores NMDA formados pelas subunidades NR2B, mas não NR2C/D reduzem a morte celular induzida pela excitotoxicidade}

Visando estudar os receptores do tipo NMDA, os experimentos iniciais em cultura foram realizados com o tratamento de NMDA em diferentes concentrações excitotóxicas (100 $\mu \mathrm{M}-1 \mathrm{mM})$ e tempos (12 e 24 horas). Entretanto, apesar dos diferentes meios de cultura testados com omissão de íons $\mathrm{Mg}^{2+}$ (íon que inibe os receptores NMDA), aumento dos níveis extra-celulares de $\mathrm{Ca}^{2+}$ e adição de glicina (co-agonista), as concentrações de NMDA utilizadas não foram suficientes para induzir a morte, avaliada pelo ensaio de lactato desidrogenase (LDH) (Figura 7).

\section{EXPLANTE 24 HS}

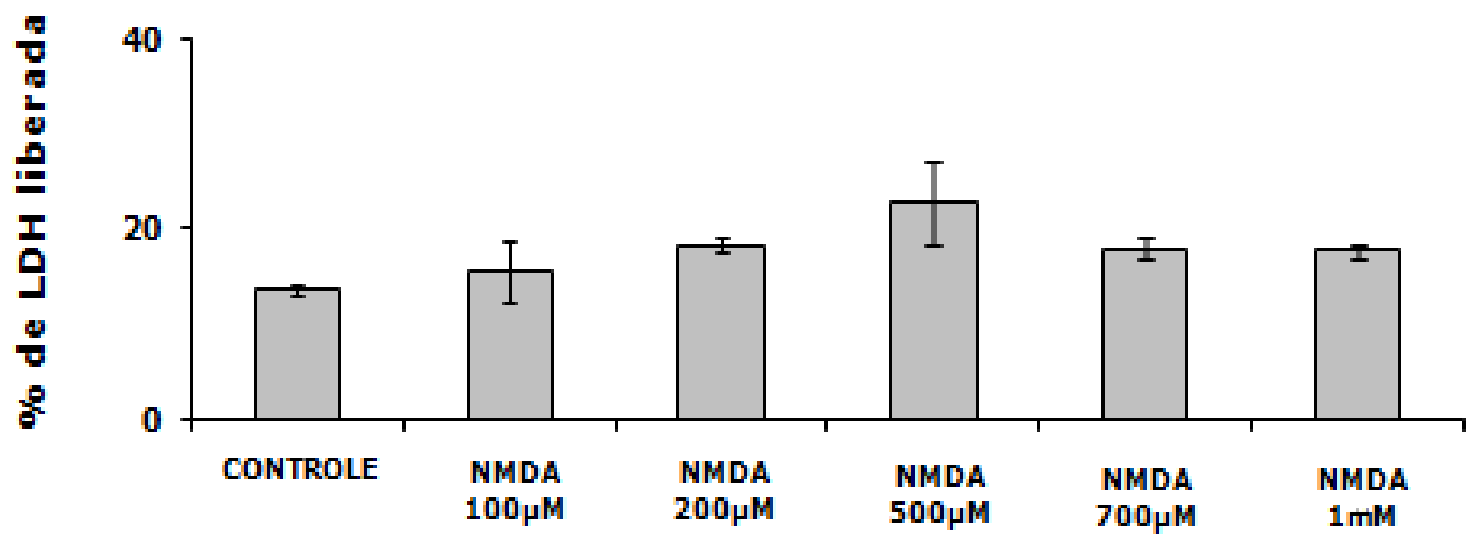

Figura 7. Avaliação da morte celular pelo ensaio de LDH após 24 horas do tratamento com NMDA. As diferentes concentrações de NMDA utilizadas não são capazes de induzir a morte celular em explante da retina de ratos adultos. Valores expressos em porcentagem de LDH liberada em relação ao total de enzima presente no tecido \pm desvio padrão. Teste de Tukey, $n=3-5$ retinas.

Sendo assim, utilizamos o glutamato para induzir a excitotoxicidade e analisamos a participação dos receptores NMDA na morte celular por meio de seu bloqueio com o MK-801 (10 $\mu \mathrm{M})$. O explante de retina de ratos adultos foi exposto ao glutamato em diferentes doses excitotóxicas $(1-5 \mathrm{mM})$ e tempos (30 min - $24 \mathrm{~h}$ ), sendo os resultados mais eficientes obtidos com $5 \mathrm{mM}$ durante o período de 12 e 24 h. 
No grupo de $12 \mathrm{~h}$, o glutamato ( $5 \mathrm{mM}$ ) promoveu a morte celular indicada pelo aumento significativo da porcentagem de LDH liberada para $62 \pm 2 \%(P<0,001)$ em relação ao controle (11 $\pm 6 \%$ ) (Figura 8). Após $24 \mathrm{~h}$, esse valor aumentou para $74 \pm 4 \%$ (controle $=17 \pm 1 \%, P<0,001$ ) (Figura 8).

O tratamento com MK-801 reduziu parcialmente o efeito do glutamato tanto após 12 horas $(62 \pm 2 \%$ para $46 \pm 7 \%, P<0,01)$ como após 24 horas $(74 \pm 4 \%$ para $48 \pm 7 \%, P<0,001$ ) (Figura 8).

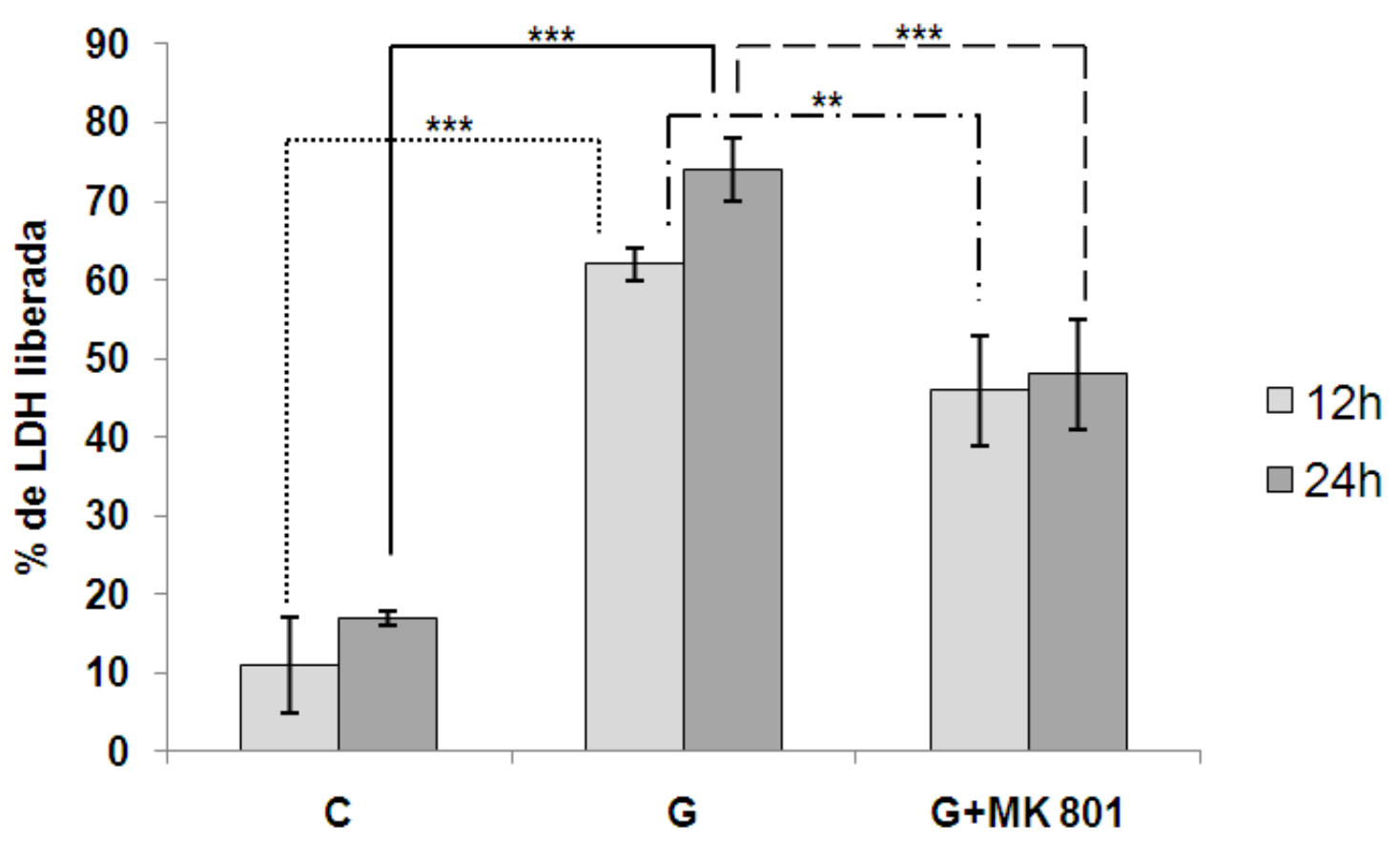

Figura 8. Avaliação da morte celular pelo ensaio de LDH após 12 e 24 horas de tratamento com glutamato e MK-801. Nos grupos de 12 e 24 horas, o aumento da \% de LDH liberada após o tratamento do explante da retina de rato com glutamato $(5 \mathrm{mM})$ foi parcialmente reduzido pelo bloqueio dos NMDARs por seu antagonista MK-801. Valores expressos em porcentagem de LDH liberada em relação ao total presente no tecido \pm desvio padrão. Teste de Tukey. ${ }^{* *} P<0,01 ;{ }^{* * *} P<0,001$. ( $n=3-7$ retinas).

Dados da literatura sugerem que a presença das subunidades NR2A-D no receptor NMDA pode ser crucial para determinar a sua funcionalidade (TOVAR e WESTBROOK, 1999; PAPADIA, 2008). Bloqueadores específicos disponíveis comercialmente existem apenas para as subunidades NR2B, C e D. Sendo assim, em nosso modelo de excitotoxicidade por glutamato avaliamos a participação das subunidades NR2B e NR2C-D, por meio dos bloqueadores Ro 25-6981 e PPDA, respectivamente. 
No explante da retina de ratos observamos que a adição do bloqueador da subunidade NR2B (10 $\mu \mathrm{M}$ - Ro 25-6981) juntamente com glutamato $(5 \mathrm{mM})$ reduziu significativamente a \% de liberação de LDH no grupo de $24 \mathrm{~h}(74 \pm 4 \%$ para $49 \pm 2 \%$, $\mathrm{P}<0,001)$. Por outro lado, a inibição de NR2C/D por seu antagonista específico PPDA não foi capaz de alterar a morte celular em $12(62 \% \pm 2$ vs. $65 \pm 5)$ e 24 horas ( $74 \pm 4 \%$ vs. $62 \pm 4 \%$ ) (Figura 9 ).

Alguns dos resultados mais relevantes obtidos in vitro foram reproduzidos no modelo in vivo com a injeção intraocular de dose excitotóxica de NMDA (100 nmol). A efetividade do tratamento foi avaliada pelo método de TUNEL.

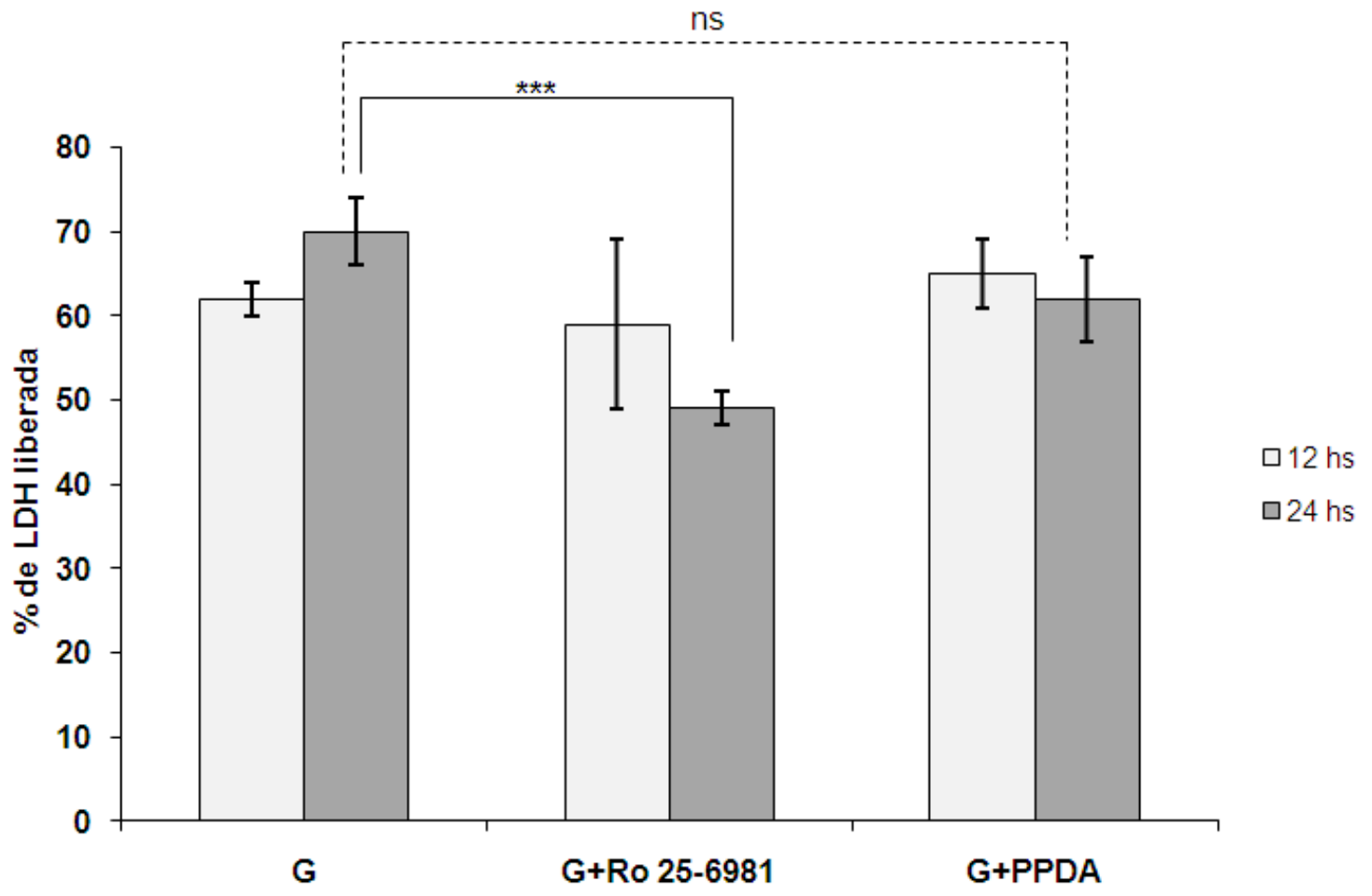

Figura 9. Avaliação da morte celular pelo ensaio de LDH após 24 horas de tratamento com glutamato e antagonistas das subunidades NR2B e NR2C-D. O bloqueio da subunidade NR2B por Ro 25-6981 diminue significativamente a morte celular no explante da retina de rato, avaliada pela redução da \% de LDH liberada em relação ao tratamento com glutamato. O mesmo não é observado após bloqueio das subunidades NR2C/D por PPDA. Valores expressos em porcentagem de LDH liberada em relação ao total presente no tecido \pm desvio padrão. Teste de Tukey. ${ }^{*}$ $P<0,01$; ${ }^{* * *} P<0,001$. ( $n=3-5$ retinas).

No grupo controle com injeção de salina tamponada estéril (PBS) não foi observada nenhuma célula em apoptose (TUNEL-positiva) nos diferentes tempos analisados (3, 6, 12 e 24 horas). Entretanto, no grupo tratado com NMDA (100 nmol) 
as células TUNEL-positivas foram evidentes a partir de 6 horas na camada de células ganglionares, sendo visíveis após 24 horas também na camada nuclear interna (Figura 10).

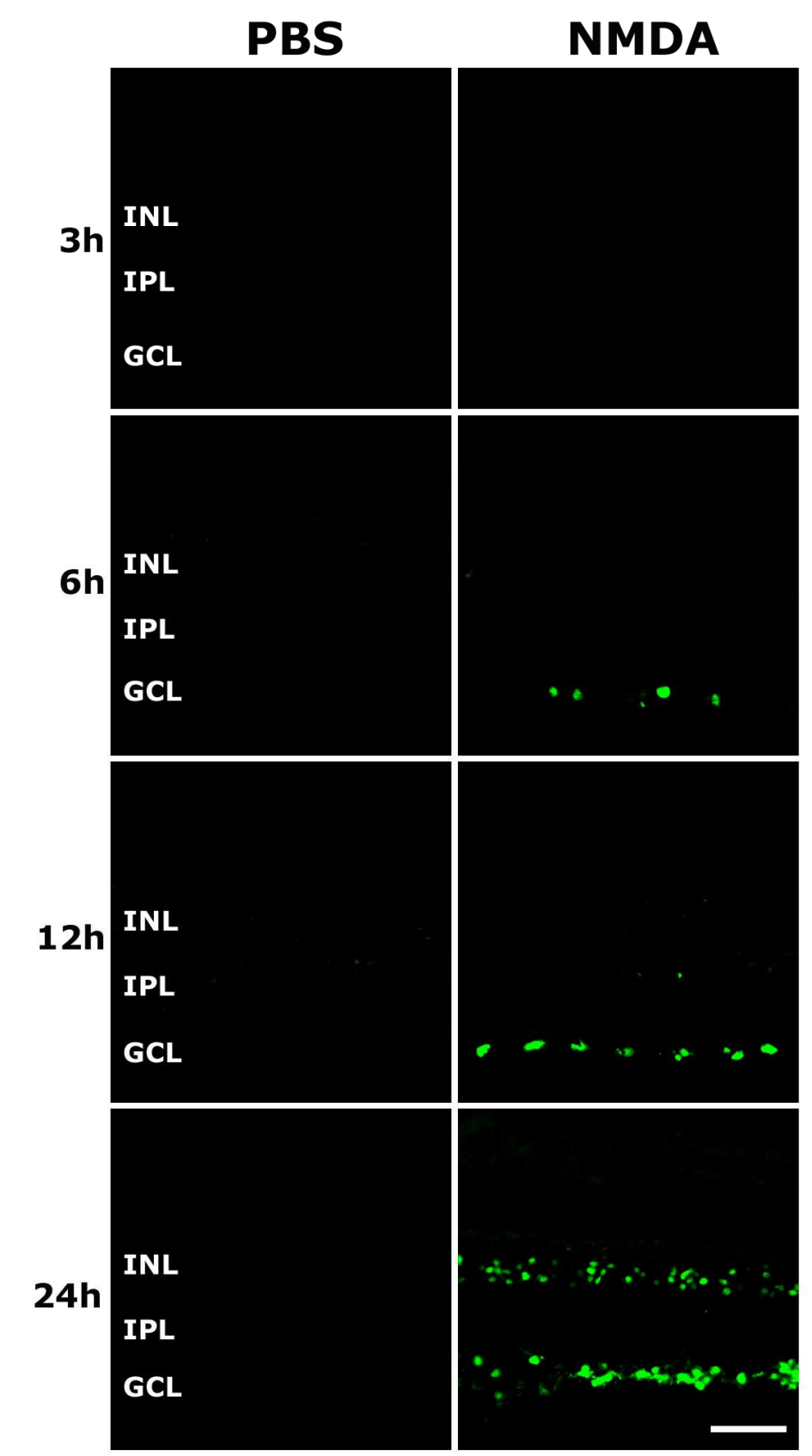

Figura 10. Detecção das células em apoptose por meio do método de TUNEL em cortes transversais da retina. Nenhuma célula TUNEL-positiva foi observada no grupo controle (PBS), entretanto, no grupo tratado com NMDA (100 nmol) as células em apoptose aparecem a partir de 6 horas na camada de células ganglionares. INL= camada nuclear interna; IPL= camada plexiforme interna; GCL= camada de células ganglionares. Escala $=50 \mu \mathrm{m}$. 
A partir desses resultados, a análise quantitativa se restringiu ao grupo de 6 horas, início do aparecimento da morte neuronal observada apenas na camada de células ganglionares que são as células relacionadas com a perda visual que ocorre no glaucoma e que nos interessa neste estudo.

A quantificação da morte induzida pela injeção de NMDA foi inicialmente expressa em porcentagem obtida da contagem do número de células em apoptose (TUNEL-positivas) em relação ao número total de células presentes (DAPI) na camada de células ganglionares.

Após 6 horas de tratamento com NMDA (100 nmol) foi observado $42 \pm 6 \%$ $(\mathrm{P}<0,001)$ de células em apoptose na camada de células ganglionares (TUNELpositivas), enquanto o controle (PBS) não apresentou nenhuma célula marcada (Figura 11).

\section{\% MORTE/ TOTAL DE CÉLS.}

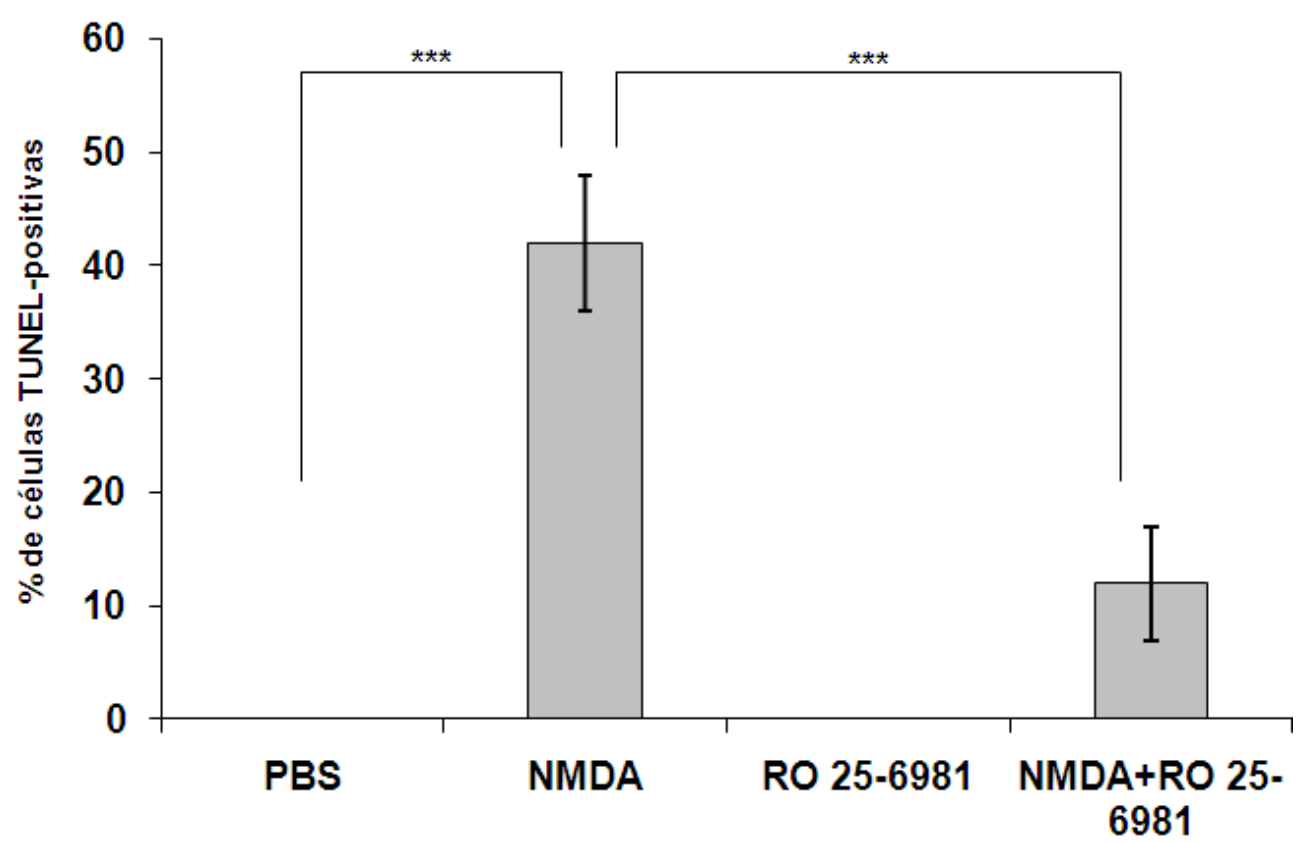

Figura 11. Quantificação da morte neuronal na camada de células ganglionares após 6 horas da injeção de NMDA e bloqueador de NR2B (Ro 25-6981). O bloqueio dos receptores NMDA formados pela subunidade NR2B reduz a morte induzida por NMDA. Valores expressos em \% do número de células em apoptose (TUNELpositivas) em relação ao total de células presentes na camada de células ganglionares (DAPI) \pm desvio padrão. Teste Tukey. $P<0,001^{* * *}$. $(n=3-5)$.

$\mathrm{Na}$ cultura de explante da retina, apenas o bloqueio dos receptores NMDA formados pela subunidade NR2B foi capaz de reduzir a morte induzida por glutamato. Com o intuito de verificar a participação dessa subunidade NR2B na 
indução de morte in vivo, foram realizadas administrações conjuntas de NMDA e Ro 25-6981 (bloqueador de NR2B). Esse tratamento foi capaz de reduzir a porcentagem de células apoptóticas promovida pelo tratamento com NMDA de $42 \% \pm 6$ para $12 \% \pm 5(P<0,001)$. A injeção de Ro $25-6981$ sozinho não induziu o surgimento de nenhuma célula em apoptose (Figura 11).

Entretanto, apesar da quantificação geral de morte celular, sabe-se que cerca de $60 \%$ das células na camada de células ganglionares correspondem de fato às células ganglionares, sendo o restante referente às células amácrinas deslocadas. Sendo assim, foi realizada a quantificação de morte após tratamento com NMDA (100 nmol) apenas das células ganglionares, identificadas por imunohistoquímica com anticorpo contra Thy-1.

Essa análise revelou que $48 \pm 8 \%(P<0,001)$ das células ganglionares estavam em apoptose após o tratamento com NMDA. O bloqueio da subunidade NR2B dos NMDARs reduziu a morte dessas células para $10 \pm 4 \%(P<0,001)$ (Figuras 12 e 13).

\section{CÉLS. GANGLIONARES (THY 1+) EM APOPTOSE}

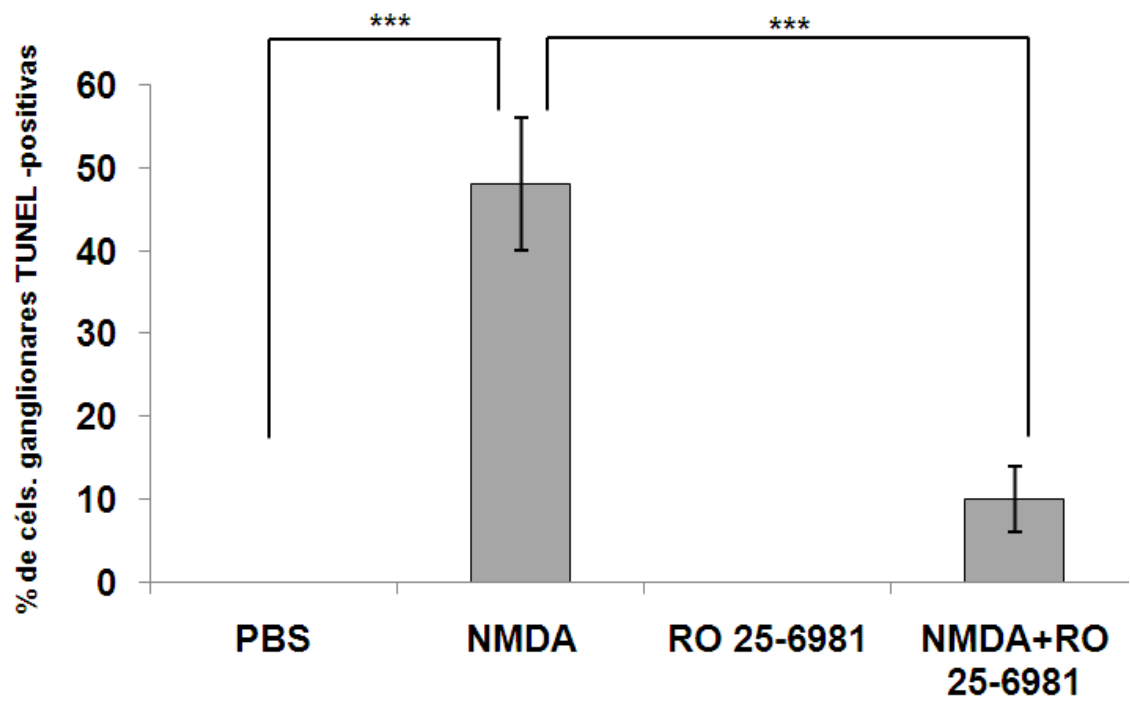

Figura 12. Quantificação de células ganglionares em apoptose após 6 horas tratamento com NMDA e bloqueador de NR2B (Ro 25-6981). O bloqueio dos receptores NMDA formados pela subunidade NR2B reduz a \% de morte das células ganglionares resultante do tratamento com NMDA. Valores expressos em $\%$ do número de células em apoptose (TUNEL-positivas) em relação ao total de células ganglionares (Thy-1 positivas) \pm desvio padrão. Teste Tukey. $P<0,001^{* * *}$. $(n=3-$ 5). 


\section{Thy-1/TUNEL}
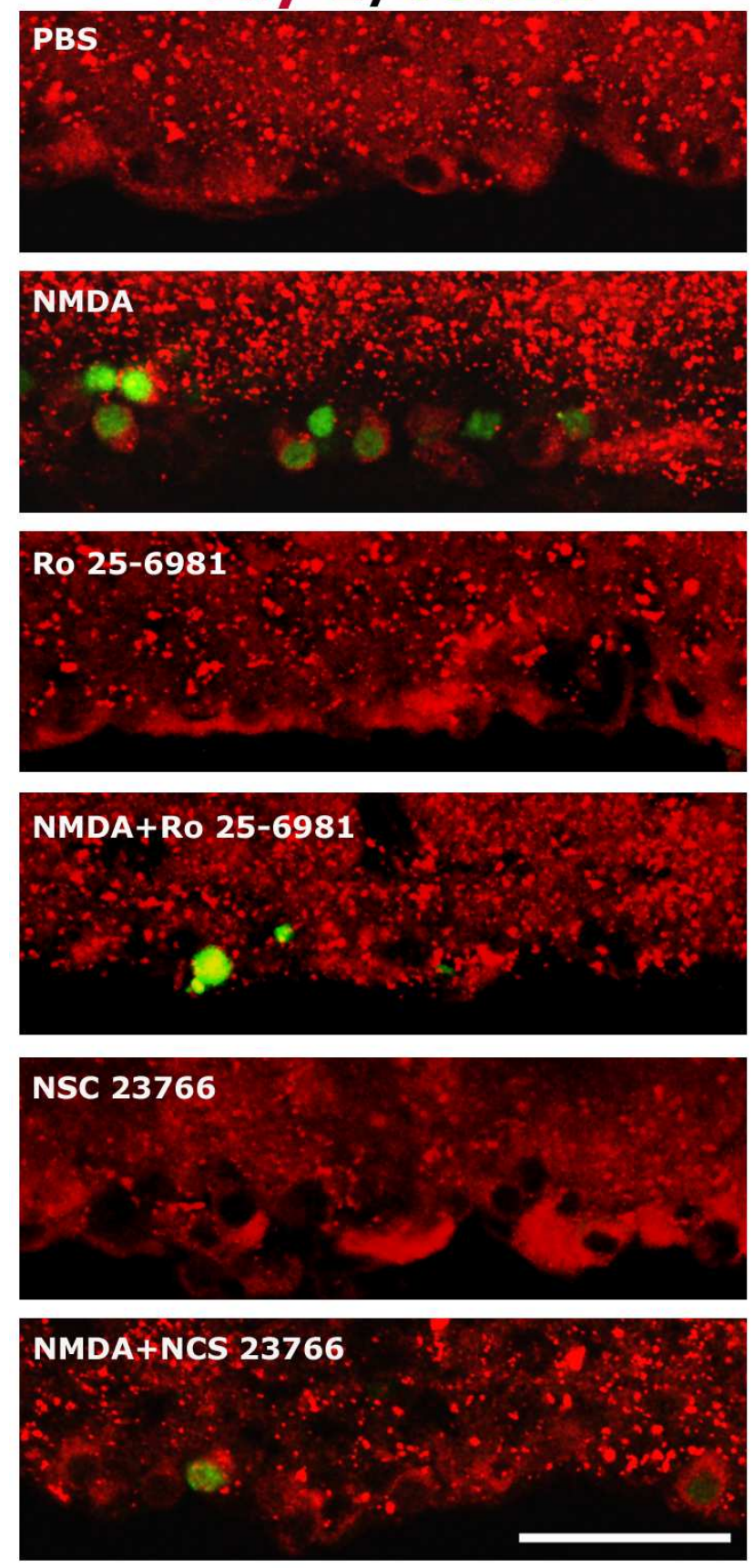

Figura 13. Detecção de células ganglionares (Thy1-vermelho) em apoptose (TUNEL-verde) após diferentes tratamentos. Cortes transversais da retina mostram que a indução de morte por NMDA $(100 \mathrm{nmol})$ é reduzida com o bloqueio da subunidade NR2B (Ro 25-6981) dos receptores NMDA e do bloqueio de Rac1 (NSC 23766). Escala $=50 \mu \mathrm{m}$. 


\subsection{A inibição GTPases Rho (Rac1) reduziu a morte celular induzida pela excitotoxicidade}

Dados anteriores do nosso laboratório sugeriam a participação de Rac1 na degeneração hereditária e induzida por luz dos fotorreceptores (BELMONTE et al., 2006). Por essa razão foi utilizado um inibidor mais geral (Toxina A) que atua sobre as GTPases Rho e um mais específico para Rac1 (NSC 23766).

A utilização da Toxina A $(1 \mathrm{ng} / \mathrm{ml})$ em conjunto com o glutamato $(5 \mathrm{mM})$ reduziu a \% de liberação de LDH em relação ao tratamento apenas com o glutamato $(62 \% \pm 2$ para $12 \% \pm 7$ em 12 h e $74 \% \pm 4$ para $46 \% \pm 1$ em 24 h, $P<0,001$ ) (Figura 14). Além disso, a inibição específica de Rac1 por NSC 23766 no nosso modelo também foi eficiente na redução da morte celular, como pode ser visto pela diminuição da \% de $\mathrm{LDH}$ liberada em relação ao tratado apenas com glutamato após $12 \mathrm{~h}(62 \pm 2 \%$ vs $15 \pm 3 \%, P<0,001)$ e $24(74 \% \pm 4$ vc $51 \pm 6 \%, P<0,001)$ (Figura 15).

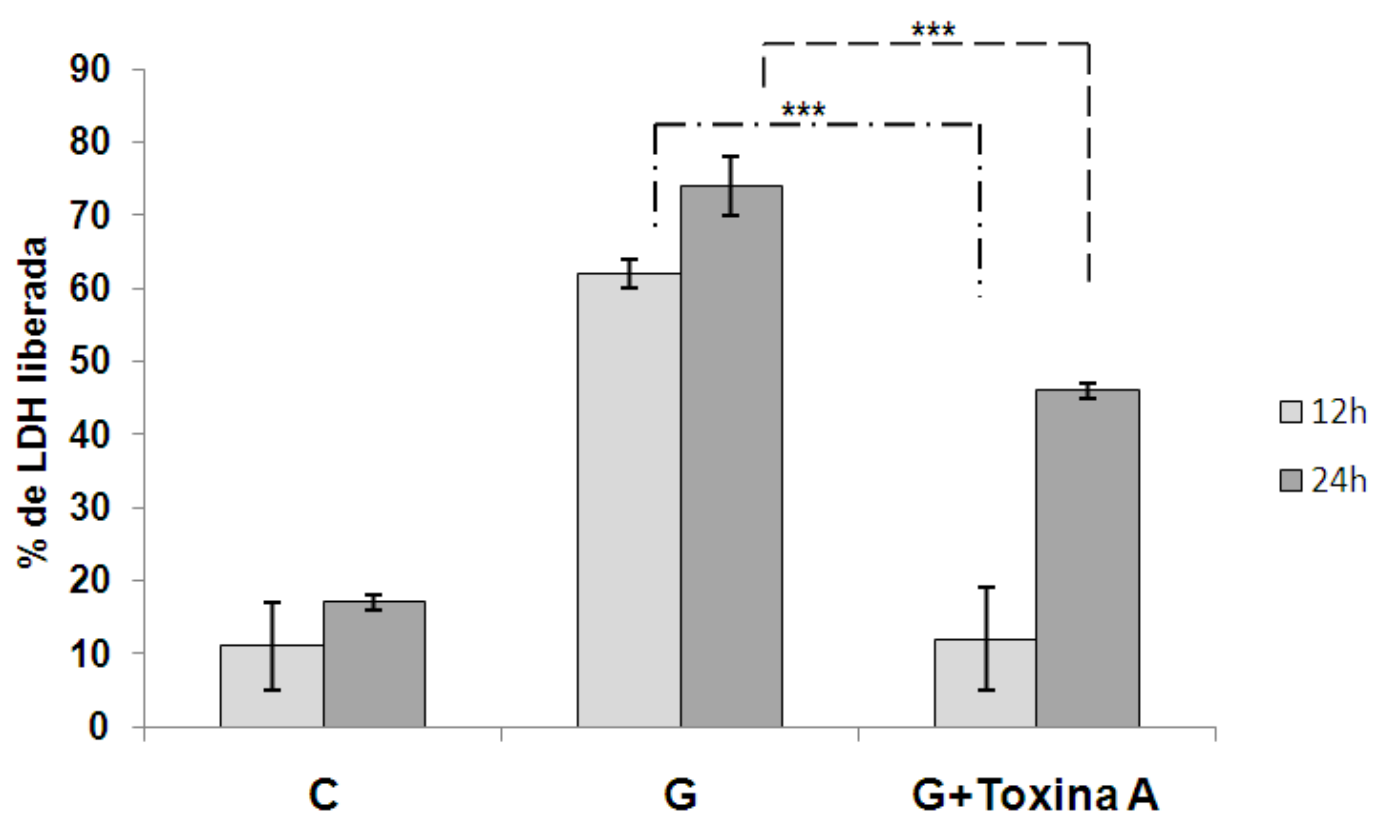

Figura 14. Avaliação da morte pelo ensaio de LDH pós 24 horas de tratamento com glutamato e inibidor das GTPases Rho. A porcentagem de LDH liberada pelo explante da retina de rato tratado com glutamato $(5 \mathrm{mM})$ é reduzido pela inibição das GTPases Rho pela Toxina A (1ng/ml) após 12 e 24 horas. Valores expressos em porcentagem de LDH liberada em relação ao total presente no tecido \pm desvio padrão. Teste de Tukey. ${ }^{* *} \mathrm{P}<0,01 ;{ }^{* * *} \mathrm{P}<0,001$. ( $n=3-5$ retinas). 


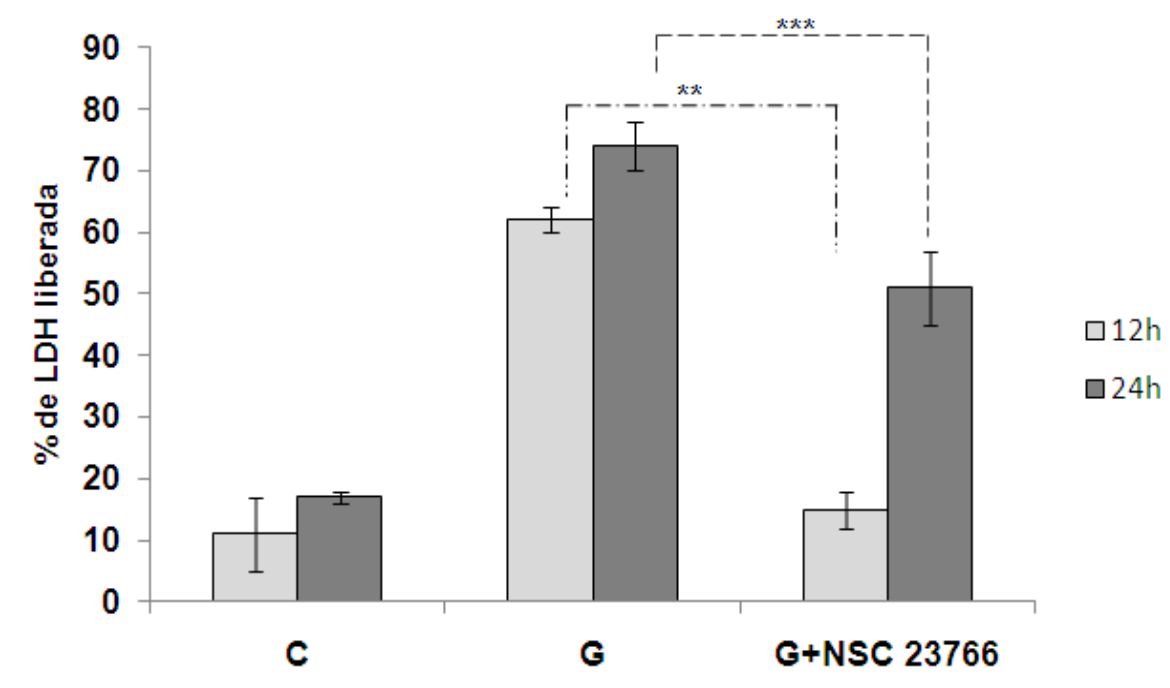

Figura 15. Avaliação da morte pelo ensaio de LDH após 24 horas de tratamento com glutamato e inibidor de Rac1. A porcentagem de LDH liberada pelo explante da retina de rato tratado com glutamato $(5 \mathrm{mM})$ após 12 e $24 \mathrm{~h}$ é reduzido com a inibição de Rac1 por NSC 23766. Valores expressos em porcentagem de LDH liberada em relação ao total presente no tecido \pm desvio padrão. Teste de Tukey. ${ }^{* *} \mathrm{P}<0,01 ;{ }^{* * *} \mathrm{P}<0,001$. ( $\mathrm{n}=3-5$ retinas $)$.

A injeção intravítrea do NSC 23766 sozinho não causou nenhuma alteração na porcentagem de morte celular na camada de células ganglionares nas retinas analisadas em relação ao controle (PBS). Entretanto, o inibidor de Rac1 foi capaz de reduzir a $\%$ de morte celular induzida por NMDA após 6 horas $(42 \pm 6 \%$ para $6 \pm 4 \%$, $P<0,001$ ) (Figura 16).

\% MORTE/ TOTAL DE CÉLS.

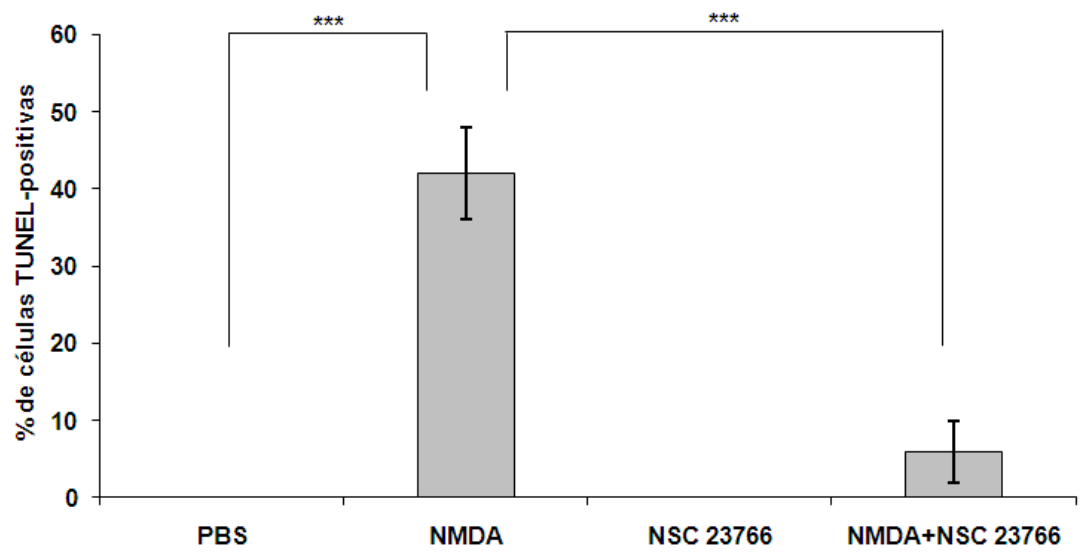

Figura 16. Quantificação da morte neuronal após 6 horas de injeção de NMDA e inibidor de Rac1. A inibição de Rac1 reduz a \% de morte induzida por NMDA. Valores expressos em \% do número de células em apoptose (TUNEL-positivas) em relação ao total de células presentes na camada de células ganglionares (DAPI) \pm desvio padrão. Teste Tukey. $P<0,001^{* * *}$. $(n=3-5)$. 
Quando somente as células ganglionares (Thy1-positivas) foram analisadas, o resultado foi semelhante, ou seja, a inibição de Rac1 reduziu a morte de células ganglionares resultante do tratamento com NMDA $(48 \% \pm 8$ para $11 \% \pm 2, P<0,001)$ (Figura 13 e 18).

\section{CÉLS. GANGLIONARES (THY-1+) EM APOPTOSE}

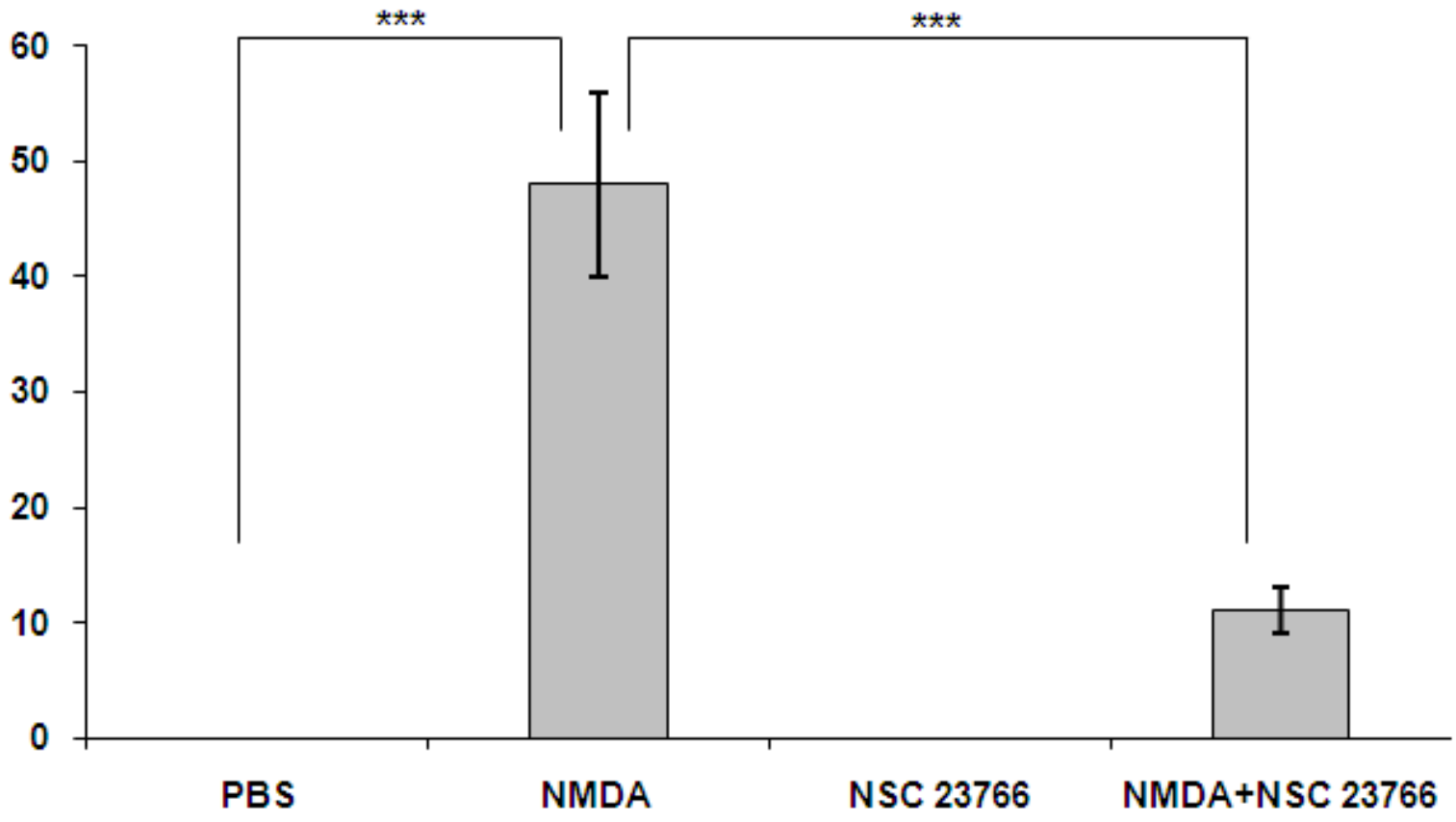

Figura 17. Quantificação de células ganglionares em apoptose após 6 horas de injeção de NMDA e inibidor de Rac1. A inibição de Rac1 reduz a morte de células ganglionares decorrente do tratamento excitotóxico com NMDA. Valores expressos em \% do número de células em apoptose (TUNEL-positivas) em relação ao total de células ganglionares (Thy-1 positivas) \pm desvio padrão. Teste Tukey. $P<0,001^{* * *}$. $(n=3-5)$.

\subsection{O bloqueio dos receptores NMDA formados pela subunidade NR2B alterou a ativação de Rac1}

Considerando que as GTPases Rho ciclam entre um estado inativo (ligadas ao GDP) e ativo (ligadas ao GTP), e que apenas a forma ativa se associa a seus efetores para disparar a cascata de sinalização, a próxima etapa foi analisar o que ocorre com a ativação de Rac1 6 horas após os diferentes tratamentos in vivo.

Para isso, a atividade de Rac1 foi avaliada por meio do ensaio de pull-down e pela imunohistoquímica com o anticorpo contra a forma ativa da proteína. 
A técnica de pull-down utiliza a seqüência PBD (p21-binding domain), correspondente ao domínio de ligação do efetor PAK à Rac1 quando esta proteína está ativa. Essa seqüência foi expressa em bactérias competentes contendo o plasmídeo pGEX-2T com inserto para PBD fusionado ao GST (PBD-GST). A efetividade da expressão foi confirmada em gel de agarose (Figura 18).

\section{BSA}

$1 \mathrm{mg} 5 \mathrm{mg} 10 \mathrm{mg}$

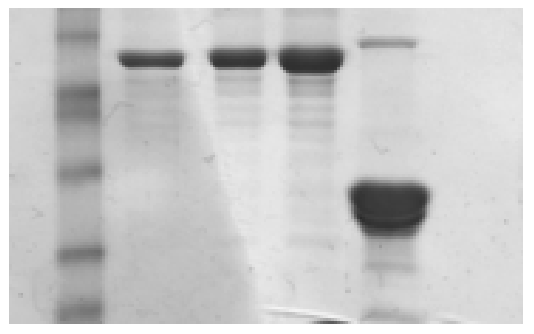

PBD-GST

Figura 18. Expressão de PBD-GST. Controle de BSA (albumina de soro bovina) em diferentes concentrações (1, 5 e $10 \mathrm{mg})$.

Para o ensaio de pull-down foram realizados os seguintes controles: seqüência PBD-GST fusionada às micro-esferas sem incubação com a amostra, e a seqüência PBD-GST fusionada às micro-esferas incubadas com as amostras tratadas somente com o inibidor de Rac1 (NSC 23766). No primeiro controle relatado acima não foi observada nenhuma banda para Rac1 ativo. Entretanto, apesar de ser visualizada uma pequena banda de Rac1 ativo no tratamento com seu inibidor (NSC 23766), ela foi menor que a banda detectada no PBS, sugerindo a eficiência do inibidor de Rac1 e do ensaio de pull-down (Figura 19).

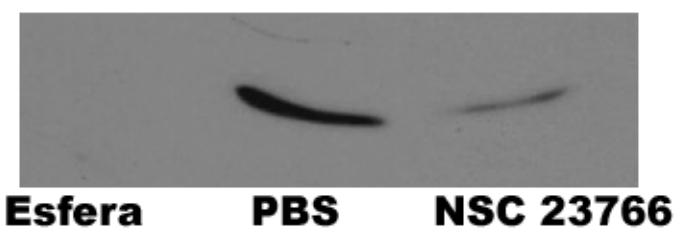

Figura 19. Para o controle do ensaio de pull-down utilizamos as micro-esferas e o tratamento com o inibidor de Rac1 (NSC 23-766). Banda $20 \mathrm{kDa}$. 

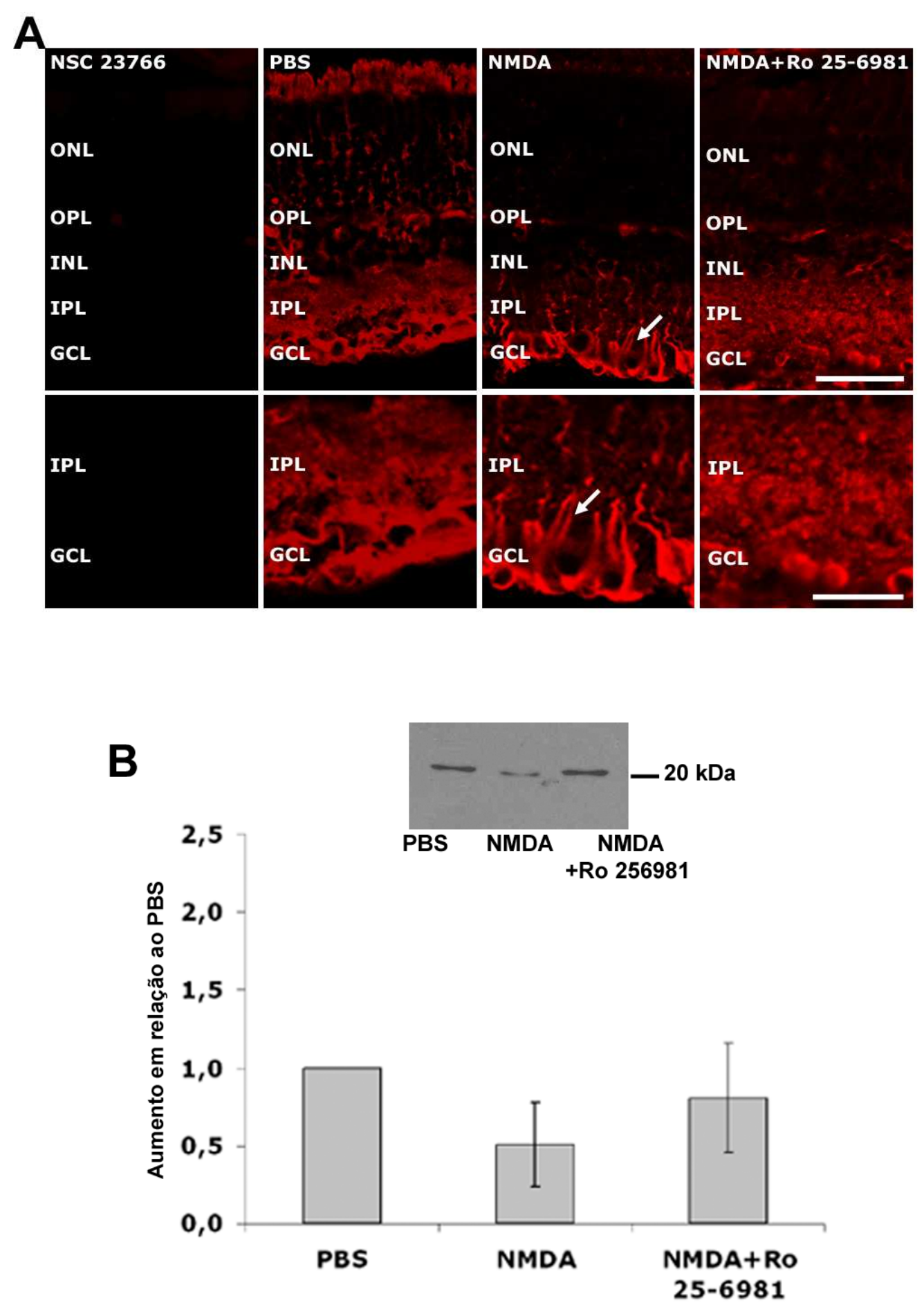

Figura 20. Análise da ativação de Rac1 após 6 horas de injeção de NMDA e do bloqueador de NR2B. A) Rac1 ativo pode ser visto por imunofluorescência em processos (setas) que se originam de regiões abaixo da camada de células ganglionares e se dirigem para as camadas mais externas da retina após o tratamento com NMDA, mas de modo mais difuso nos outros tratamentos (PBS e NMDA + Ro 256981). As imagens na linha inferior mostram detalhes da camada de células ganglionares. B) Essa alteração não foi detectada pelo ensaio de pull-down. $\mathrm{ONL}=$ camada nuclear externa; $\mathrm{OPL}=$ camada plexiforme externa; INL= camada nuclear interna; IPL= camada plexiforme interna; $G C L=$ camada de células ganglionares. Escala $=50 \mu \mathrm{m}$. 
Apesar da injeção de NMDA ocasionar morte neuronal e a inibição de Rac1 reduzir este processo, após 6 horas do tratamento com NMDA (100 nmol) foi detectada uma tendência a diminuição da atividade de Rac1 em relação ao controle PBS pelo ensaio de pull-down (Figura 20).

Em conjunto com o ensaio de pull-down realizamos a imunohistoquímica com o anticorpo contra a forma ativa de Rac1. Como controle do anticorpo utilizamos o inibidor de Rac1 (100 $\mu \mathrm{M}$, NSC 23766). Nas retinas submetidas a esse tratamento, Rac1 ativo não foi detectado (Figura 20).

No grupo controle (PBS), Rac1 ativo esteve distribuído de modo escasso por todas as camadas da retina e no citoplasma de algumas células (Figura 20). Após 6 horas de injeção com NMDA (100 nmol) foi observada uma redução de Rac1 ativo nas camadas mais externas da retina, e uma intensa marcação de processos partindo de regiões próximas ao vítreo, abaixo da camada de células ganglionares, em direção às camadas mais externas da retina (Figura 20). As alterações detectadas em Rac1 ativo resultantes da injeção com NMDA (100 mol após 6 horas) foram inibidas quando a subunidade NR2B foi bloqueada por Ro 25-6981.

\subsection{A forma ativa de Rac1 foi detectada nas células gliais de Müller}

Nas camadas mais externas da retina foi detectado a diminuição de Rac1 ativo pela imunohistoquímica após 6 horas da injeção de NMDA. Entretanto, uma marcação intensa e definida de processos se estendendo da região mais interna, próxima ao vítreo, para a camada nuclear interna foi observada. Esse padrão de marcação se assemelha aos processos das células gliais de Müller. Com o intuito de verificar se Rac1 ativo estava presente nessa célula da glia, utilizamos o anticorpo contra glutamina sintetase.

A co-localização de Rac1 ativo e glutamina sintetase (Figura 21) indicou que a forma ativa de Rac1 está presente majoritariamente em processos de células de Müller e não em células ganglionares. 


\section{Rac1 ativo}

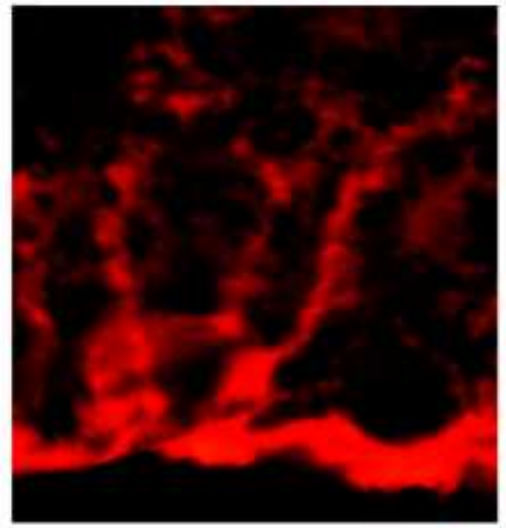

\section{Glutamina Sintetase}

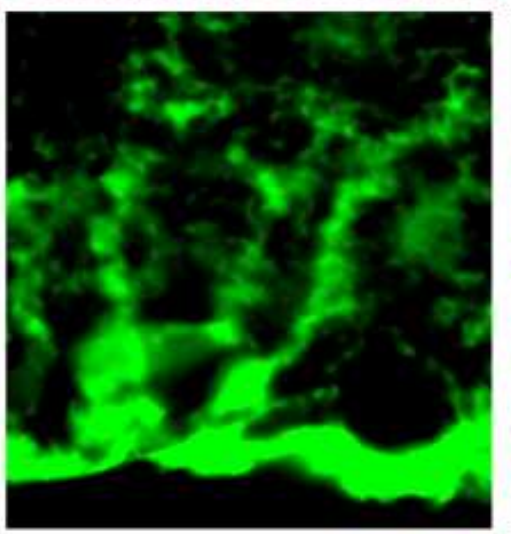

Figura 21. Presença de Rac1 ativo nas células gliais de Müller após 6 horas de injeção de NMDA. Co-localização de Rac1 ativo (Vermelho) juntamente com o anticorpo contra glutamina sintetase (Verde) que reconhece as células gliais de Müller no grupo tratado com NMDA. Escala $=15 \mu \mathrm{m}$.

É interessante observar que embora Rac1 ativo tenha sido visto em células de Müller, o bloqueio de Rac1 por NSC 23766 foi capaz de reduzir a morte de células ganglionares. Isso sugere que de alguma maneira as células gliais de Müller estariam participando do processo degenerativo das células ganglionares.

\subsection{Células gliais de Müller como mediadores da morte das células ganglionares}

Para determinar a influência da célula glial de Müller na morte neuronal foram realizadas culturas primárias de neurônios retinianos cultivados isoladamente ou em co-cultura com as células purificadas de Müller. Preferencialmente foram utilizadas retinas de animais P1-10, tendo em vista a maior adesão dos neurônios obtidos nas fases mais precoces. Esta cultura apresenta 99\% de neurônios, segundo Brewer et al. (2003).

Na cultura primária, $8,8 \pm 4,9 \%$ de células em apoptose (TUNEL-positivas) foram detectadas no grupo controle, permanecendo esta porcentagem sem alterações significativas após o tratamento com o NMDA (4,2士1,3\%) (Figuras 22 e 23).

Tendo em vista a invulnerabilidade neuronal da cultura primária diante da exposição ao NMDA, testamos se na presença das células gliais de Müller, ocorreria 
alguma modificação. Nenhuma alteração na porcentagem de morte da cultura primária em co-cultura com as células gliais de Müller foi observada entre os grupos controle $(12,5 \pm 0,8 \%)$ e tratado $(12,7 \pm 3,2 \%)$ (Figuras 22 e 23). Embora não tenha ocorrido alteração significativa, é interessante notar que a cultura primária isolada apresentou maior resistência em relação à cultura primária em co-cultura com as células da glia.

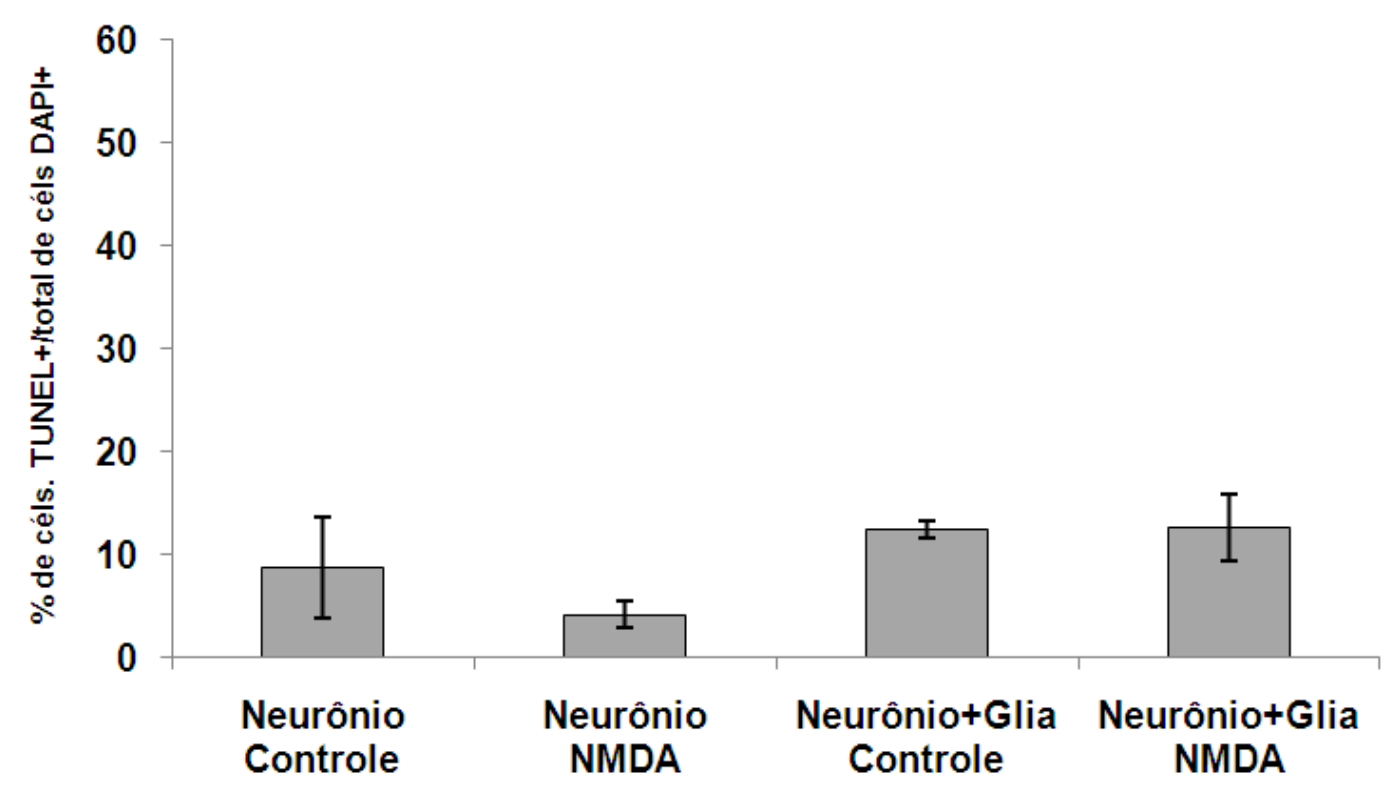

Figura 22. Quantificação da morte neuronal de culturas primárias de neurônios cultivadas isoladas ou em co-cultura com as células gliais de Müller após tratamento com NMDA. Nenhuma alteração é observado na porcentagem de morte celular (células TUNEL-positivas/ total de células DAPI-positivas) foi detectada em neurônios retinianos cultivados isolados ou em co-cultura com as glias de Müller após 24 horas de tratamento com NMDA em relação ao controle. Valores expressos em \% do número de células em apoptose (TUNEL-positivas) em relação ao total de células (DAPI- positivas) \pm desvio padrão. Teste Tukey. $(n=3-$ $5)$. 
CONTROLE

DAPI
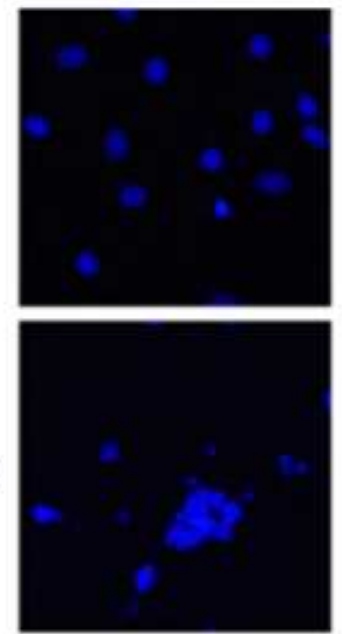

Neurônio

Neurônio

+ Glia
TUNEL
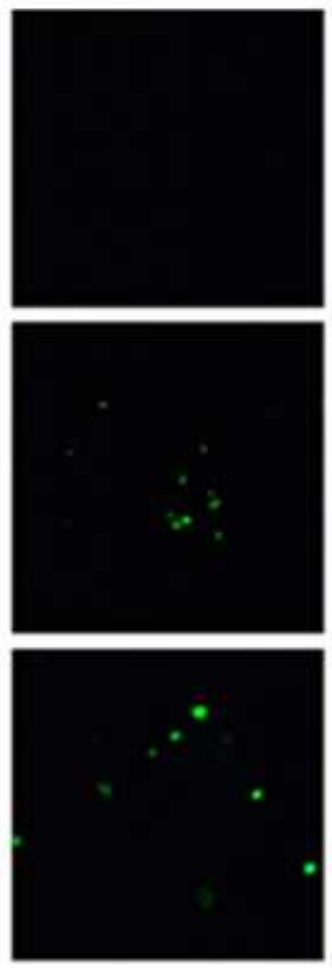

NMDA
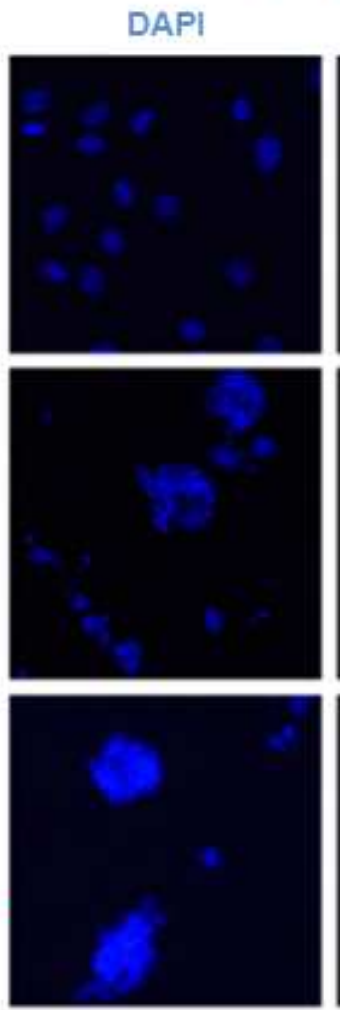

TUNEL
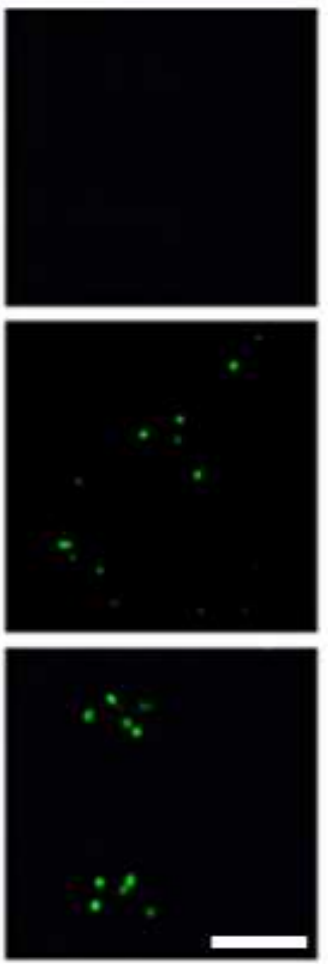

Figura 23. Detecção de apoptose em culturas primárias cultivadas isoladas ou em cocultura com as glias após tratamento com NMDA. Nenhuma alteração na morte (TUNEL-verde) em relação ao total de células (DAPI-azul) é observado em neurônios retinianos cultivados isolados ou em co-cultura com as glias de Müller após 24 horas de tratamento com NMDA. Não são observadas células gliais de Müller em apoptose. Escala $=50 \mu \mathrm{m}$.

Examinamos ainda se o tratamento com NMDA promovia um aumento de Rac1 ativo na cultura purificada de células gliais de Müller, como visto nos resultados de injeção intravítrea de NMDA.

Nas células do grupo controle, a distribuição de Rac1 ativo foi detectada de modo disperso por toda a célula, e em alguns casos, foi possível verificar uma marcação mais intensa e linear acompanhando os longos processos (Figura 24). Após 6 horas de tratamento com NMDA, um leve aumento na marcação de Rac1 ativo foi observado nos processos das células remanescentes nas regiões da placa onde ocorreu o descolamento de células. Nas demais regiões, a distribuição de Rac1 se manteve semelhante ao controle (Figura 24). 
Controle

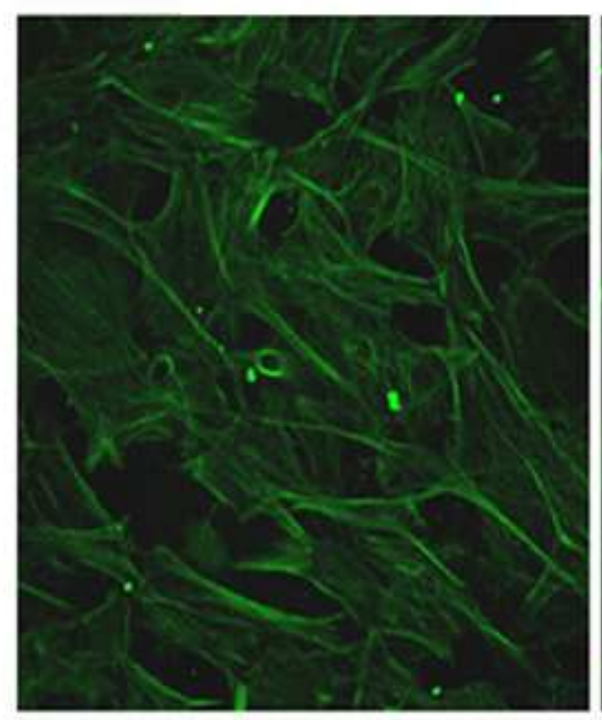

NMDA

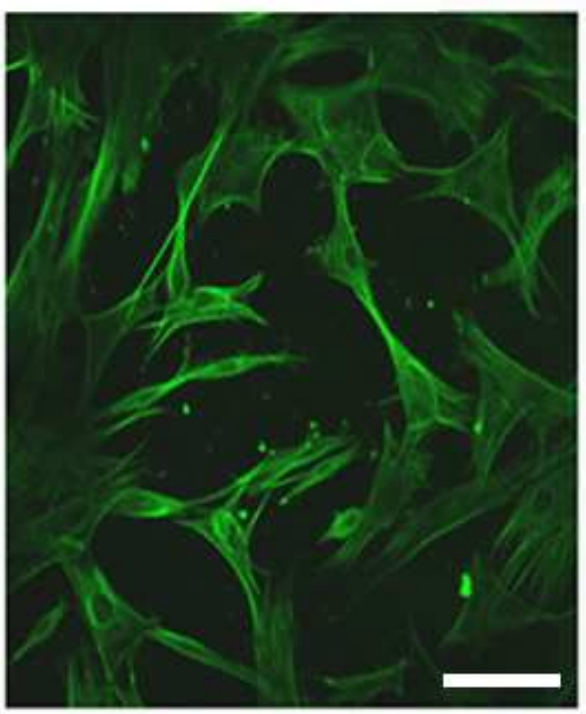

Figura 24. Detecção de Rac1 ativo por imunocitoquímica na cultura purificada de células de Müller. Tratamento com NMDA promove o descolamento de células gliais de Müller em algumas regiões da placa, sendo um leve aumento na marcação de Rac1 ativo observado nos processos das células remanescentes. Escala $=50 \mu \mathrm{m}$.

Considerando que a morte de células ganglionares após o tratamento com NMDA poderia ter sido desencadeada por TNF- $\alpha$ produzido por células gliais de Müller (LEBRUN-JULIEN et al., 2009) verificamos a produção desta citocina na cultura purificada da glia. No entanto, o método utilizado não foi sensível suficiente para detectar alterações in vitro (dados não apresentados), e por isso, nosso próximo passo foi avaliar no modelo in vivo.

A injeção de NMDA promoveu o aumento da produção de TNF-a $(15,63 \pm$ 4,35 pg/ $500 \mu \mathrm{m}$ de extrato total) em relação ao controle PBS. O bloqueio de NR2B reduziu a quantidade de TNF- $\alpha$ em níveis não detectados pelo kit, sugerindo a participação deste receptor na sua produção.

Em seguida, fomos avaliar o possível papel de Rac1 como regulador da expressão de TNF-a. A inibição de Rac1 também reduziu a produção de TNF- $\alpha$ (Figura 25). 


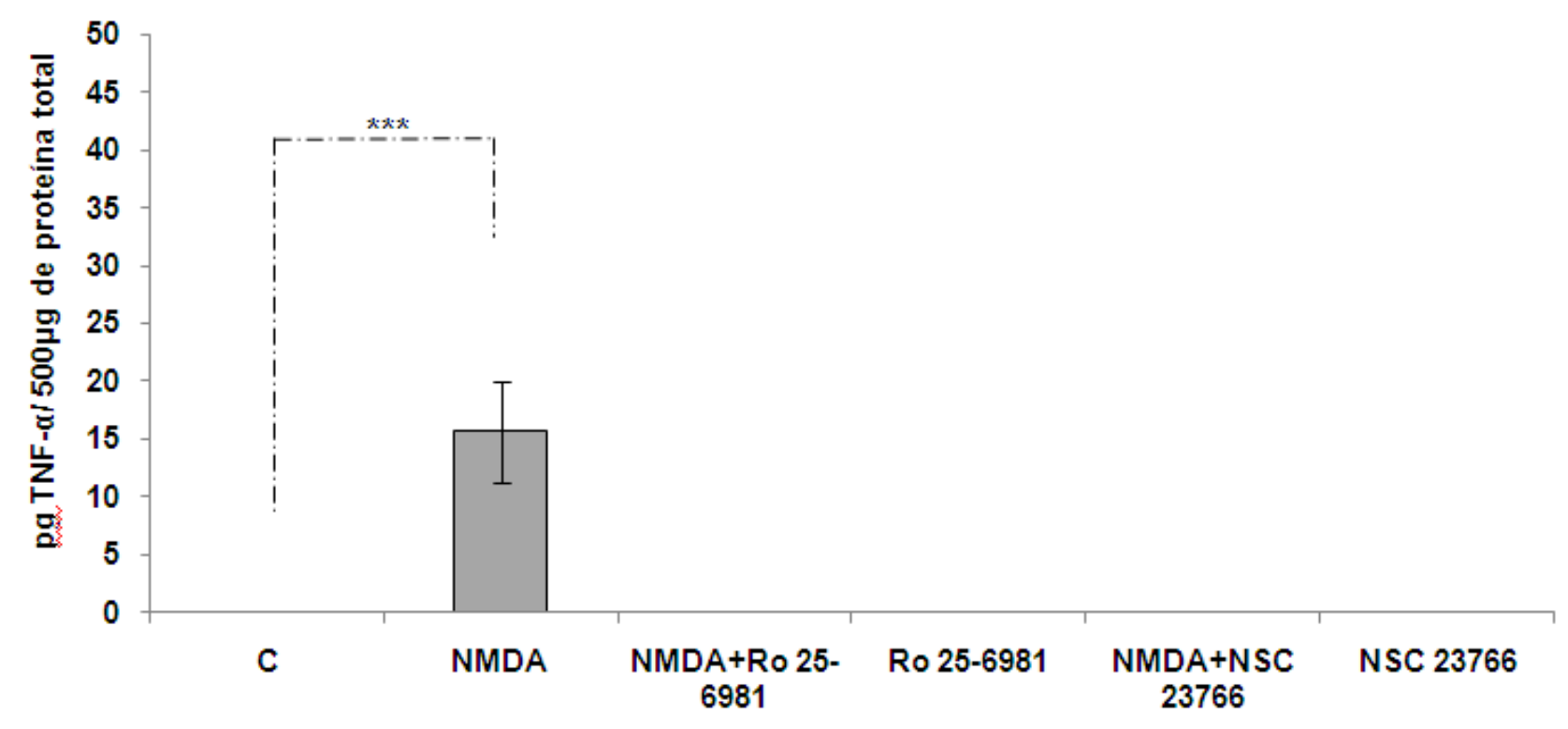

Figura 25. Produção de TNF- $\alpha$ detectado por ELISA. A produção de TNF- $\alpha$ detectado após o tratamento por NMDA foi reduzida com a inibição de Rac1 e bloqueio de NR2B. Média \pm desvio padrão. Tukey Test. ${ }^{* * *} \mathrm{P}<0.001$. $(n=6-9)$.

A imunohistoquímica realizada com anticorpo contra TNF- $\alpha$ revelou uma marcação difusa e fraca no grupo controle (PBS), mas que aumentou após tratamento com NMDA. A co-localização de TNF-a com a glutamina sintetase, marcador de célula de Müller, é um indicativo de sua presença nessas células gliais (Figura 26). Nos tratamentos com NMDA juntamente com o bloqueador de NR2B e inibidor de Rac1 verificou-se uma redução na distribuição da citocina nas células gliais de Müller. A presença da TNF-a foi também observada no citoplasma de algumas células ganglionares. 

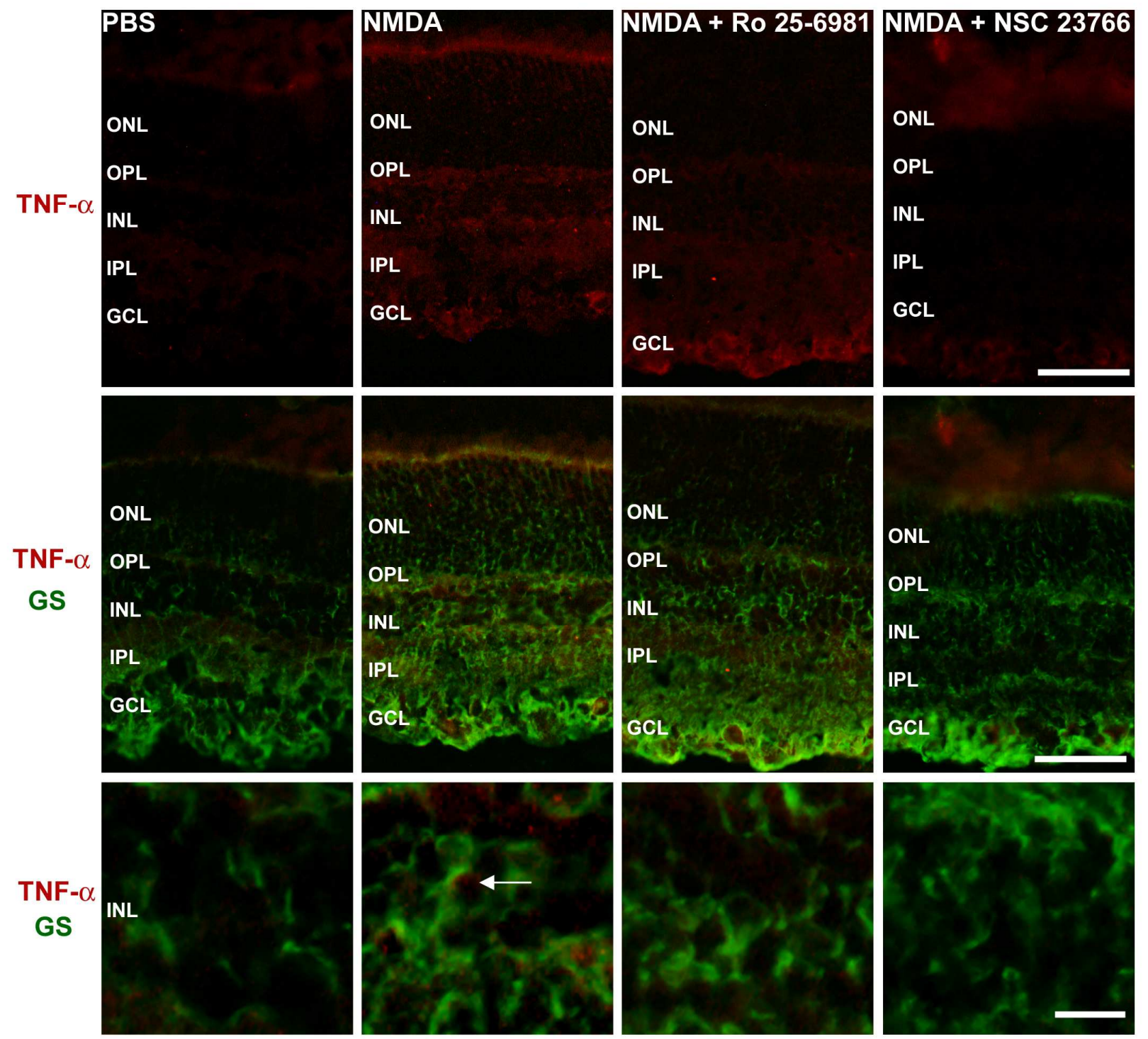

Figura 26. Presença de TNF- $\alpha$ nas células gliais de Müller após 6 horas de injeção de NMDA. Co-localização de TNF-a (Vermelho) juntamente com o anticorpo contra glutamina sintetase (Verde) que reconhece as células gliais de Müller no grupo tratado com NMDA. Escala $=50 \mu \mathrm{m}$, detalhe $30 \mu \mathrm{m}$.

Tendo em vista que Rac1 pode estar participando com outras GTPases Rho neste processo de morte celular induzida por NMDA verificamos também a presença de RhoA ativo na retina após 6 horas de tratamento com NMDA. No grupo controle (PBS), uma leve marcação foi observada na camada de células ganglionares, aparentemente no citoplasma de algumas células dessa camada. Após lesão excitotóxica, o aumento de RhoA ativo foi visualizado basicamente no epitélio pigmentado. Nenhuma alteração na camada de células ganglionares foi observada nos grupos tratados com o bloqueador de NR2B e inibidor de Rac1 (Figura 27). 


\section{Rho A ativo}
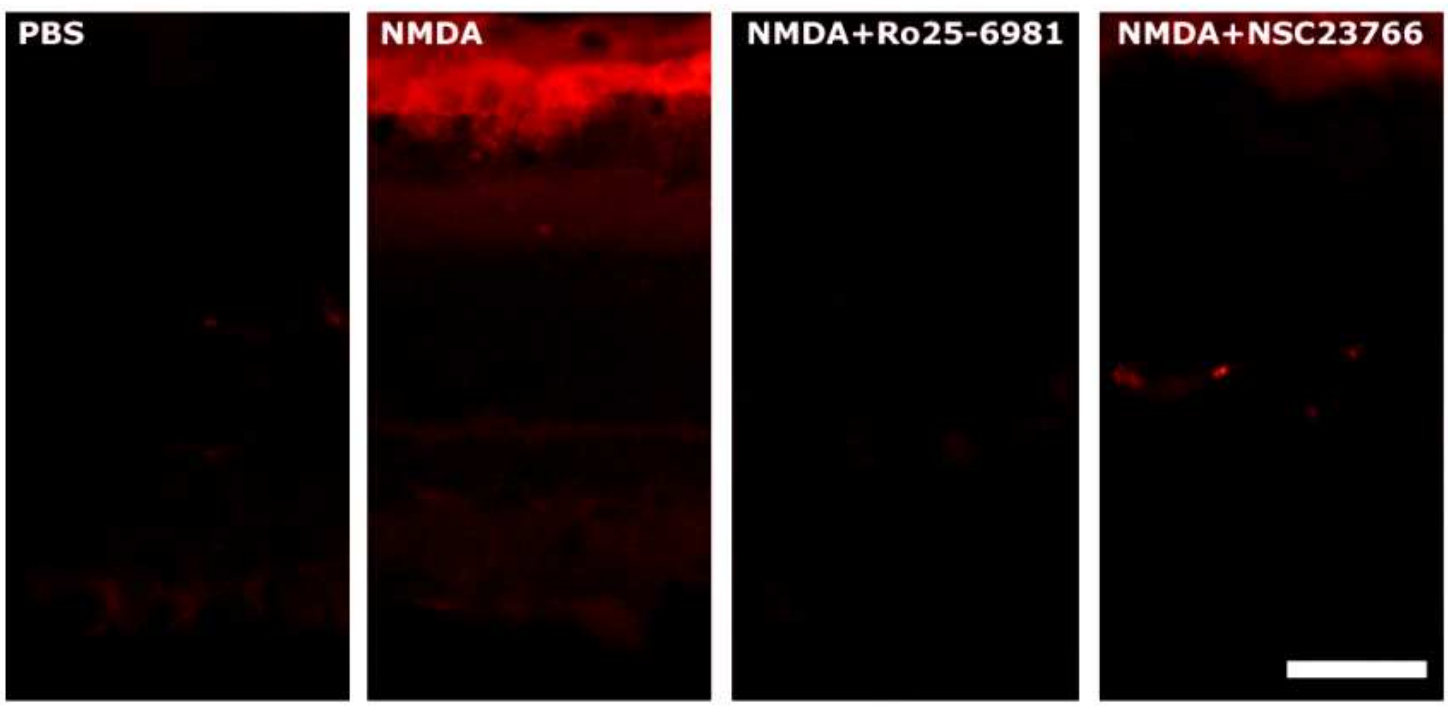

Figura 27. Detecção de RhoA ativo após 6 horas de injeção de NMDA e bloquedores de NR2B e Rac1. A injeção intraocular de NMDA promove aumento na distribuição de RhoA ativo no epitélio pigmentado. Escala $=30 \mu \mathrm{m}$. 


\section{DISCUSSÕES}

A melhor compreensão dos mecanismos pró e anti-apoptótico desencadeados pelos receptores NMDA pode resultar em consideráveis benefícios clínicos (HARDINGHAM, 2006). Sendo assim, avaliamos como a composição desse receptor pode influenciar na morte ou sobrevivência dos neurônios da retina.

Para tanto, os experimentos iniciais foram realizados com a cultura de explante da retina por preservar as conexões originais entre os neurônios, mantendo as propriedades eletrofisiológicas (HOFMANN et al., 2005).

Diante do nosso objetivo de verificar a participação dos receptores NMDA compostos por diferentes subunidades, o tratamento foi realizado com doses excitotóxicas de NMDA. No entanto, esse agonista (100 $\mu \mathrm{M}-1 \mathrm{mM})$ não foi capaz de induzir a morte neuronal avaliada pela liberação de LDH em cultura. Hahn et al. (1988) relataram que a completa omissão do íon $\mathrm{Mg}^{2+}$ não é suficiente para o NMDA ocasionar um efeito letal, sendo necessária a elevação dos níveis de cálcio extracelular de 1,8 para $10 \mathrm{mM}$. Da mesma maneira, apesar das modificações nesses parâmetros, não observamos a morte celular por esse ensaio. A possibilidade do kit de ensaio de LDH utilizado não ter sido suficientemente sensível para detectar pequenas alterações da enzima não foi descartada. Por essa razão, o tratamento in vitro foi realizado com glutamato e a avaliação dos receptores NMDA realizada pela utilização de seus inibidores.

O outro modelo de estudo utilizado foi a injeção intravítrea de NMDA. Muitos laboratórios têm demonstrado que esse tratamento ocasiona uma lesão extensa na retina de mamíferos, principalmente na camada de células ganglionares, sendo menores os danos na camada nuclear interna e principalmente na camada nuclear externa (SILIPRANDI et al., 1992; SABEL et al., 1995).

Munemasa et al. (2005) descrevem que após 6 horas de injeção de NMDA (100 nmol) é possível verificar a morte neuronal por TUNEL, não somente na camada de células ganglionares como também da camada nuclear interna. Apesar de ser utlizada a mesma concentração e tempo, nossos resultados revelaram uma pequena densidade de células em apoptose na camada nuclear interna, sendo possível que esta diferença esteja relacionada com a região da retina analisada, uma vez que, a morte é mais evidente próximo ao local da injeção. 
As células ganglionares foram investigadas mais detalhadamente neste trabalho, pois sua morte via apoptose é descrita em modelos de glaucoma (GARCIA-VALENZUELA et al, 1995; QUIGLEY et al., 1995; NICKELLS et al., 1996) e retinopatia diabética (BARBER et al., 1998; KOWLURU e KOPPOLU, 2002; KERN e BARBER, 2008). Sabe-se que uma grande quantidade das células presentes na camada de células ganglionares são na realidade células amácrinas deslocadas, que constituem aproximadamente $50 \%$ das células em ratos (PERRY et al., 1983). Dessa maneira, utilizamos o anticorpo contra Thy-1, que na retina é amplamente utilizado no reconhecimento de células ganglionares (HUANG et al., 2006; VAN GERGEN et al., 2009), por serem as únicas células da retina que expressam esta proteína (BARNSTABLE et al., 1984).

Devido a importância da participação dos receptores NMDA na indução da morte neuronal, muitos autores têm procurado validar a ação neuroprotetora de diversos compostos que bloqueiam esses receptores (WONG et al., 1986; KINNEY et al., 1998; KEMP e MCKERNAM, 2002; CHEN e LIPTON, 2006; GILLING et al., 2007). Um dos primeiros antagonistas farmacológicos descrito na literatura é o composto MK-801 ((+)-5-metil-10,11-dihidro-5-metil-5H-dibenzo(a,d)ciclohepteno-510-imina malato) (WONG et al., 1986; HUETTNER e BEAN, 1988; OLNEY et al., 1987; FADEN et al., 1989; CHAUDHARY et al., 1998).

Em nosso modelo, o MK-801 inibiu a morte induzida por glutamato, mas não em níveis próximos ao controle. Este dado sugere que os outros receptores de glutamato como AMPA, KA e metabotrópicos também possam estar envolvidos. É importante salientar ainda que o MK-801 pode ter bloqueado não só os receptores NMDA envolvidos em processos de morte, mas também na sobrevivência (PAPADIA e HARDINGHAM, 2007). Dessa forma, a resposta observada no ensaio de LDH pode ter sido resultado da somatória desses efeitos (morte + sobrevivência). Esse dado é curioso, porém o efeito tóxico da administração de MK-801 já foi relatado em trabalhos anteriores com neurônios do sistema nervoso central (IKONOMIDOU et al., 1999, 2000; TAKADERA et al., 1999) e retina (MARTINS et al., 2005; HERNÁNDEZ et al., 2007).

Em razão do MK-801 inibir todos os receptores NMDA, seu papel como neuroprotetor não é tão eficiente, sendo possivelmente um dos motivos pelo qual o MK-801 não obteve sucesso em testes clínicos (IKONOMIDOU e TURSKI, 2002). Isso tem levado diversos grupos a investigar o efeito do bloqueio de subunidades 
específicas (NR2A-D) e suas vias de sinalização. Alguns destes antagonistas são capazes de inibir parcialmente ou totalmente os danos resultantes da excitotoxicidade por NMDA, dependendo do modelo de estudo (WILLIAN et al., 2002; LIU et al., 2007; MARTEL et al., 2009).

Embora na literatura o antagonista para a subunidade NR2A (NVP-AAM077) tem sido utilizado em alguns trabalhos (ZHOU e BAUDRY, 2006; LIU et al., 2007), este composto ainda não está disponível comercialmente.

Sendo assim, utilizamos primeiramente o Ro 25-6981, antagonista nãocompetitivo e independente de voltagem da subunidade NR2B (FISCHER et al., 1997; MUTEL et al., 1998; LYNCH et al., 2001). Essencialmente não há ligação com NR2A (LYNCH e GUTTMANN, 2001, 2002). Este componente tem afinidade com a região alostérica da subunidade NR2B, conhecida como domínio LIVBP (leucina/isoleucina/valina-binding protein) (CHENARD e MENNITI, 1999; KEW e KEMP, 1998; MALHERBE et al., 2003; HATTON e PALEOTTI, 2005).

No explante da retina de ratos, observamos que a adição de Ro 25-6981 juntamente com glutamato reduziu significativamente a \% de liberação de LDH. Por outro lado, o bloqueio de NR2C/D por seu antagonista específico PPDA não foi capaz de alterar consideravelmente a morte.

A diferença na ação entre esses dois bloqueadores pode refletir a possível ativação de distintas vias de sinalização, como também a quantidade de subunidades expressa. Na retina de ratos, sabe-se que todas as subunidades NR2 são expressas desde os estágios iniciais de desenvolvimento, mas não existem evidências sobre a porcentagem de cada uma das subunidades nos neurônios (GRÜNDER et al., 2000). Nas células ganglionares de humanos o RNAm para NR1 (93\%), NR2A (9\%), NR2B (8\%), NR2C (86\%) e NR2D (84\%) é observado em diferentes porcentagens (LAGRĖZE et al., 2000). No cerebelo, NR2A ou NR2C são mais expressas que NR2B e D (CULL-CANDY et al., 2001; TAKAHASHI et al., 1996). Ou seja, dependendo do modelo e espécie, pode ser que o bloqueio das subunidades mais expressas em cada um possa ocasionar um efeito mais evidente.

Além disso, as diferenças podem ser decorrentes da subunidade presente no receptor NMDA. Por exemplo, apesar da lesão na camada de células ganglionares da retina ser conhecida, duas vias distintas são descritas nesse mesmo tipo celular: a de morte, por exemplo, com envolvimento de p38, e a de sobrevivência com PI3KAkt (MANABE e LIPTON, 2003). Neste contexto, foi descrito que a ativação basal 
dos receptores NMDA promove a sobrevivência celular (IKONOMIDOU e TURSK, 2002; PAPADIA e HARDINGHAM, 2007), uma vez que, o seu bloqueio aumenta a apoptose durante o desenvolvimento da retina (MARTINS et al., 2005; HERNÁNDEZ et al., 2007) e outras áreas do sistema nervoso (ADANS et al., 2004).

$\mathrm{Na}$ retina, estudos abordando a subunidade NR2 com morte e/ou sobrevivência ainda são praticamente inexistentes. Nossos resultados in vitro e in vivo sugerem que na retina os NMDARs formados por NR2B possam participar da via de morte celular, ao contrário dos NR2C/D e que o bloqueio da subunidade NR2B reduziu a morte das células presentes na camada de células ganglionares (células ganglionares e células amácrinas deslocadas) induzidos por glutamato e NMDA.

Outra subunidade dos receptores NMDA, a NR3B, tem sido descrita na retina desempenhando um papel neuroprotetor durante a excitotoxicidade por NMDA. Em camundongos knockouts para esta subunidade a morte de células ganglionares aumenta quando comparado ao animal selvagem (NAKANISHI et al., 2009).

Em algumas doenças, como por exemplo, Parkinson e Huntington, o bloqueio da subunidade NR2B é capaz de inibir a degeneração neuronal, indicando que os antagonistas seletivos dessa subunidade possam ser potenciais alvos terapêuticos (GOGAS, 2006). No caso de isquemia, a presença de NR2A ou NR2B promovem a sobrevivência e a morte, respectivamente (LIU et al., 2007; VON ENGELHARDT et al., 2007). No hipocampo, a susceptibilidade ao tratamento excitotóxico é diferencial em neurônios imaturos e adultos e essa diferença resulta da subunidade expressa. Ao contrário do que ocorre em animais adultos, os NMDARs compostos por NR2A são mais abundantes que os NR2B em animais mais jovens, e por isso apresentam mais resistência que os adultos (ZHOU e BAUDRY, 2006).

Esses dados juntamente com os nossos resultados na retina sugerem que o bloqueio farmacológico de NR2B minimiza a extensão dos danos causados pela excitotoxicidade (DI et al., 1997; MENNITI et al., 1997; SORIANO et al., 2008).

Sugere-se que as subunidades NR2A-D possam disparar diferentes cascatas de sinalização como reflexo de proteínas específicas acopladas aos seus domínios C-terminais intracelulares (KOHR et al., 2003). A deleção desse domínio C-terminal altera a localização, atividade e plasticidade sináptica dos NMDARs (CHUNG et al., 2004). 
Algumas vias de sinalização ativadas pelos receptores NMDA/NR2B já foram descritas. Na isquemia cerebral, a interação da proteína cinase 1 associada à morte (DAPK1) com NR2B promove a morte de neuronal em ratos adultos (TU et al., 2010). PTEN, que induz a morte de neurônios do hipocampo, pode interagir com a subunidade NR2B, mas não com NR2A (NING et al., 2004). Além disso, a exposição de NMDA em slices do hipocampo promove a rápida ativação de protease dependente de cálcio, como a calpaína, em neo-natos e não em adultos como resultado da ativação de NR2B e não NR2A (ZHOU e BAUDRY, 2006).

Entretanto, apesar de muitos trabalhos descreverem os receptores NMDA/NR2B em processos de morte, ele também foi descrito em processo de sobrevivência. Neste sentido, Poddar et al. (2010) sugeriram que esse duplo papel dos receptores NMDA compostos por NR2B poderiam resultar da sua estimulação transiente ou sustentada. Na primeira situação, NR2B estimula a STEP, que inibe a ativação da p38 MAPK, aumentando a sobrevida neuronal. No entanto, após a estimulação sustentada, os efeitos protetores da ativação de STEP são perdidos com a sua degradação, permitindo a ativação de p38 MAPK que resulta na morte.

No nosso estudo, o bloqueio de NR2C/D não alterou os níveis de morte induzidos pela excitotoxicidade. Entretanto, Wenzel et al. (1997) descrevem que a subunidade NR2D está concentrada em células bipolares de bastonetes na retina de rato que são relativamente resistentes ao tratamento com NMDA (GOEBEL e POOSCH, 2001), tendo em vista a presença dessa subunidade. Durante os estágios iniciais de desenvolvimento, quando os níveis extra-celulares de glutamato são considerado tóxicos em relação à retina adulta (HABERECH et al., 1997), NR2D é abundantemente expresso. Por outro lado, nos estágios mais tardios de desenvolvimento, quando os níveis de glutamato são reduzidos e a susceptibilidade dos neurônios à excitotoxicidade é maior (HABERECH et al., 1997), a expressão de NR2D cai drasticamente enquanto de NR2A-B aumentam (WENZEL et al., 1996). Portanto, NR2A-B estariam relacionados com a morte, enquanto NR2C/D com a sobrevivência.

A combinação das subunidades também determina o posicionamento do receptor na membrana. Sabe-se que a distribuição dos receptores não é estática podendo variar durante o desenvolvimento. No caso dos neurônios do hipocampo, aproximadamente $3 / 4$ dos receptores NMDA estão localizados na região extrasináptica durante o desenvolvimento, entretanto a quantidade pode aumentar na 
região sináptica no animal adulto (TOVAR e WESTBROOK, 1999). Em neurônios corticais de ratos, a ativação dos receptores NMDA presentes na região sináptica promove o disparo da cascata antioxidante que aumenta a sobrevivência neuronal (PAPADIA et al., 2008).

Esta localização do receptor também é controlada pelo domínio C-terminal das subunidades NR2 através do motivo T/SXV que interage diretamente com o domínio PDZ presente em proteínas intracelulares, como a PSD-95, SAP102, PSD93. Por exemplo, a fosforilação de NR2B inibe sua interação com PSD-95 e SAP 102, diminuindo a presença desse receptor na membrana de regiões sinápticas (CHUNG et al., 2004; GROC et al., 2006).

Além da sinalização e localização dos receptores NMDA, a combinação de diferentes subunidades podem proporcionar divergências nas popriedades cinéticas, sensibilidade à ligantes e permeabilidade iônica (CULL-CANDY et al., 2001).

Levando em consideração a via de sinalização que pode ser disparada pelos receptores NMDA, avaliamos a possível participação de Rac1 nesta cascata. Essas GTPases ciclam entre um estado ativo (ligadas ao GTP) e inativo (ligadas ao GDP) reguladas pelos GEFs e GAPs, respectivamente

Sabe-se que os receptores NMDA podem ativar as GTPases Rho mediado por GEFs específicos, como o Tiam e o Lfc. O influxo de cálcio gerado pela ativação dos receptores NMDA promove a interação com Lfc, ativando as GTPase Rho que resulta na redução da arborização dendrítica (PONIMASKIN et al., 2003). Em contraste, a interação dos receptores NMDA com outro GEF, Tiam, aumenta a atividade de Rac e Akt que promovem alterações morfológicas, como a formação da árvore dendrítica.

De modo geral, os trabalhos que sugerem uma relação entre receptores NMDA e GTPases Rho em processos de degeneração, apresentam como foco principal a proteína RhoA. A expressão e a distribuição de RhoA na retina de ratos após lesão no nervo óptico (WANG et al., 2007) já foi avaliada e a sua inibição parece promover a regeneração dos axônios das células ganglionares (nervo óptico) (BERTRAND et al., 2005). Na retina, Kitaoka et al. (2004) demonstraram que o tratamento com NMDA aumenta a expressão de RhoA total, e que a inibição de seu efetor, ROCK, reduz a morte neuronal, atribuindo a essa proteína a responsabilidade de ativar a degeneração. Em ratos adultos, a aplicação de C3 (inibidor das GTPases Rho) no nervo óptico lesado promove a regeneração do axônio (LEHMANN et al., 
1999), e mesmo quando a toxina C3-C7 (versão modificada de C3-ADPribosiltransferase de Clostridium botulinum) é aplicada no corpo celular, esta droga previne a morte das células ganglionares e estimula a regeneração do nervo óptico (BERTRAND et al., 2005).

Apesar das evidências da participação de RhoA na morte neuronal, nosso trabalho evidencia que o outro membro das GTPases Rho, Rac1, pode estar envolvido na degeneração da retina.

Como já descrito anteriormente, as GTPases Rho podem gerar uma resposta celular apenas quando estas proteínas se encontram no estado ativo ligado ao GTP, o que pode ser analisado pelo ensaio de pull-down. Na cultura primária de neurônios cerebelares, o ensaio de pull-down revelou que RhoA é ativada rapidamente a partir de 3 minutos de tratamento com glutamato, e por outro lado, Rac1 tem sua atividade drasticamente reduzida, assim como a proteína total (SEMENOVA et al., 2007).

No presente estudo, verificamos pelo ensaio de pull-down uma tendência à dimuição da atividade de Rac1 após 30 minutos, 3 e 6 horas do tratamento com NMDA. Entretanto, é possível que a sua ativação possa ter ocorrido em tempos inferiores ao testados. Desse modo, a participação de Rac1 na morte neuronal não foi descartada, uma vez que a sua inibição com NSC 23766 reduziu a degeneração neuronal.

Além disso, o ensaio de pull-down pode não ter evidenciado o aumento total na atividade porque na análise imunohistoquímica foi observada uma redução na distribuição de Rac1 ativo nas camadas mais externas da retina. Essa redução foi acompanhada pelo aparecimento mais evidente da proteína ativa nos processos da glia de Müller, verificado através do anticorpo contra glutamina sintetase, que na retina é amplamente conhecido como um marcador dessa glia (RIEPE e NORENBURG, 1997; NAKAZAWA et al., 2008; BUl et al., 2009).

O princípio do ensaio de pull-down é baseado na detecção de atividade de através da ligação com a seqüência referente ao domínio de PAK, que pode ser utilizado como efetor tanto de Rac quanto de membro das GTPases Rho, a proteína Cdc42 (BAGRODIA et al., 1995; MORREALE et al., 2000). A existência de um sítio comum denominado de CRIB (Cdc42/ Rac-interative binding) entre os efetores dessas duas proteínas corresponde ao fato de Cdc42 e Rac possuírem aproximadamente $70 \%$ de conservação na seqüência (HAKOSHIMA et al., 2003). Portanto, este pode ter sido outra dificuldade para verificar a ativação de Rac. 
Apesar disso, esta ainda é a metodologia mais empregada para a detecção de atividade de Rac.

É interessante ressaltar que esta maior intensidade de marcação de Rac1 ativo nos processos da célula de Müller foi revertida pelo bloqueio da subunidade NR2B, sugerindo que de alguma maneira a ativação de receptores NMDA/NR2B, altera a ativação de Rac1.

Quanto ao outro membro da família de GTPases Rho analisado, RhoA, verificamos que a distribuição de RhoA ativo não estava aumentada na camada de células ganglionares no grupo tratado com NMDA por 6h. Mesmo assim, não podemos descartar a possibilidade de que Rac1 e RhoA participem da mesma via de morte, porém sendo ativadas em tempos diferentes.

Independente da distribuição de NR2B, os nossos resultados sugerem que a célula glial de Müller participa da indução de morte de células ganglionares via Rac1, um vez que a sua inibição reduz a morte neuronal.

Apesar da participação da célula da glia de Müller na morte e/ ou neuronal durante o processo excitotóxico por glutamato e agonistas ser pouco conhecido, Nakazawa et al. (2008) relatam que após a administração de NMDA em concentrações excitotóxicas ocorre um aumento na expressão de ERK1/2 nas células de Müller. Além disso, esses autores descrevem que em camundongos knockouts para essa proteína foi observado um aumento significativo de neurônios retinianos em apoptose quando comparado ao animal selvagem, sugerindo que essas células gliais possam desempenhar um papel neuroprotetor. As células gliais de Müller são importantes fontes de BDNF (fator neurotrófico derivado do cérebro) (DI POLO et al., 1998; TAYLOR et al, 2003; HARADA et al., 2011) que desempenham um importante na sobrevivência de células ganglionares e outros neurônios da retina (DI POLO et al., 1998; ROCHA et al., 1999). Outros autores relatam a capacidade da glia em desdiferenciar e diferenciar em novos neurônios após tratamento excitotóxico na retina de aves e camundongos (FISCHER e REH, 2003; OOTO et al., 2004; TAKEDA et al., 2008; HARADA et al., 2011).

Em contrapartida, as mesmas células de Müller podem participar da morte neuronal. Existem evidências de que o bloqueio da gliose reativa da glia após a excitotoxicidade pode reduzir a morte de células ganglionares da retina (GANESH e CHINTALA, 2011). Esses dados contraditórios do comportamento da glia podem ser justificados pelo fato de alguns autores acreditarem na possibilidade da existência 
de sub-populações de células de Müller que desempenhariam papéis diferentes na retina. Essa idéia é reforçada pela existência de trabalhos que demonstram a ativação de somente algumas células de Müller (marcador GFAP) frente a distintos tratamentos degenerativos, ou seja, as células gliais não respondem de maneira homogênea por toda a retina (VERARDO et al., 2008).

A gliose reativa representa um esforço da glia em manter a homeostase extracelular e a função normal do neurônio após situação de estresse. Entretanto, a persistência da gliose reativa pode estar relacionada com a perda neuronal associado a diversos processos degenerativos, tais como descolamento de retina, retinopatia diabética e glaucoma (NEUFELD e LIU, 2003; PETRUKHIN, 2007). No caso de degeneração, a gliose reativa está relacionada com diversos fatores, como ROS e citocinas (GOUREAU et al., 1994; DONG et al., 2001; TEZEL e WAX, 2000; TEZEL, 2001; TEZEL et al., 2004; NAKAZAWA et al., 2006; SHI et al., 2008) que podem desempenhar um papel central na morte celular.

O TNF- $\alpha$ (fator de necrose tumoral) é uma citocina, clonada em 1984 (PENNICA et al., 1984), sendo seu nome relacionado ao fato de promover a regressão tumoral e induzir a morte celular. Esta citocina solúvel pode ser produzida e liberada por diferentes tipos celulares, tais como: macrófagos, células $\mathrm{T}$, mastócitos, granulócitos, natural killers, fibroblastos, queratinócitos e células musculares lisas (TRACEY et al., 2008). No caso dos macrófagos, vários fatores podem induzir a sua produção, como a presença de vírus, bactérias, citocinas, irradiação, células tumorais, isquemia e trauma. Muitos deles induzem a expressão de gênica de TNF em até 30 minutos, ou podem regular alterações pós-traducionais.

Este fator pode se ligar a dois receptores, os receptores de TNF 1 e 2 (TNFR1 e 2), também utilizados por outros ligantes similares, membros da superfamília TNF e TNFR, como p.ex. TRAIL, NGFR, CD40L (HEHLGANS e PFEFFER, 2005; MATHEW et al., 2009).

O efeito pró-apoptótico envolve a formação de dois complexos distintos formados após a trimerização do TNFR1 em resposta ao TNF- $\alpha$ (MICHEAU et al., 2003). O complexo I consiste de TNFR1, TRADD (TNFR- associated death domain), RIP1 (receptor 1 interacting protein) e TRAF2 (TNF receptor associated factor-2) que rapidamente ativam o fator de transcrição NFאB. Em seguida, TRADD e RIP1 podem se associar com FADD e caspase 8, formando o complexo II que induz a apoptose (MICHEAU e TSCHOPP, 2003; MATHEW et al.,2009). 
Na retina, o TNF-a produzido pela célula glial de Müller (KOZAKI et al., 1994; COTINETI et al., 1997; TEZEL et al., 2000) pode ser um dos fatores que resulta na morte celular (FONTAINE et al., 2002; TEZEL et al., 2004), pela ativação do seu receptor TNF-R1, expresso em principalmente nas células ganglionares durante a isquemia (TEZEL et al., 2000) e o glaucoma (TEZEL et al., 2001). A injeção intravítrea de NMDA também promove o aumento da expressão de TNFR1 na camada de células ganglionares (LAABICH e COOPER, 2002).

Neste sentido, durante a excitotoxicidade por NMDA, o TNF-a produzido por Müller ativa os receptores TNFR1 dos neurônios induzindo apoptose via caspase 8 (BOLDINE et al., 1996; LEBRUN-JULIEN et al., 2009). Além disso, a célula glial poderia potencializar a ação tóxica do glutamato diminuindo a quantidade de transportadores de glumato na sua membrana (GLT-1) ou aumentando a liberação de glutamina e ATP (MATUTE et al., 2002).

Com o intuito de verificar a participação da célula de Müller na morte neuronal via liberação de TNF- $\alpha$, inicialmente seria realizado o tratamento com NMDA na cultura de células ganglionares cultivadas isoladas ou em co-cultura com a glia. No entanto, após algumas tentativas, a cultura purificada de células ganglionares não foi utilizada devido ao baixo rendimento da técnica.

Alternativamente, poderia ser utilizada a linhagem de células ganglionares RGC-5, obtida da transformação de células retinianas de ratos com 1 dia pós-natal, pois é descrita com sensibilidade ao tratamento excitotóxico de glutamato após a sua diferenciação com concavalina A (KRISHNAMOORTHY et al., 2001). Estas células foram amplamente empregadas em estudos de glaucoma, inclusive com evidências de que apenas $35 \%$ da linhagem RGC-5 sobreviviam $24 \mathrm{~h}$ após tratamento com glutamato (AOUN et al., 2003). No entanto, publicações mais recentes relataram que a sensibilidade dessas células ao tratamento excitotóxico é menor, sendo a porcentagem de sobrevivência de 75\%, (FAN et al., 2005), 85\% (MAHER e HANNEKEN, 2005) e até 95\% (VAN BERGER et al., 2009). Diante desses dados, alguns autores sugeriram possíveis alterações na linhagem RGC-5 (VAN BERGER et al., 2009), indicando perda de suas características originais, o que nos levou a utilizarmos a cultura primária da retina cultivada isolada ou em co-cultura com a glia.

Nas culturas de células de Müller, não foram detectadas células em processo de apoptose no grupo controle ou no tratado com NMDA. Esse dado corrobora 
trabalhos anteriores que relatam a resistência da glia em diferentes estímulos degenerativos, tais como a isquemia, hipoglicemia e excitotoxicidade (rev. BRINGMANN et al., 2009). Isso pode ser atribuído à presença de uma reserva intracelular de glicogênio (GOHDO et al., 2001), antioxidantes (PAASCHE et al., 1998) e pela regulação negativa dos receptores de glutamato, respectivamente (TAYLOR et al., 2003).

Reforçando dados da literatura, não observamos a degeneração de neurônios retinianos em cultura primária induzida pela excitotoxicidade por NMDA. No trabalho de Ullian et al. (2004), o autor descreve que apesar de possuírem receptores NMDA funcionais, as células ganglionares em cultura são resistente a altas doses de NMDA. Nem mesmo quando as conexões sinápticas são mantidas com a cultura de explante ou com a co-cultura com astrócitos, o agonista foi capaz de induzir a morte neuronal.

A distribuição de Rac1 ativo e a produção de TNF-a na cultura purificada de células da glia tratadas com NMDA foram similares ao controle. Entretanto, não descartamos a sua participação na morte neuronal, pois em razão da obtenção da cultura purificada de glia ser superior a 3 semanas e o cultivo realizado na ausência de níveis basais de glutamato, a expressão dos receptores pode ter sofrido alterações, reduzindo a resposta glial ao agonista conforme Taylor et al. (2003).

Como pode ser depreendido pelos comentários acima, a ausência de um modelo experimental in vitro eficiente nos levou a utilizar o modelo in vivo. Após o tratamento com NMDA verificamos que TNF-a estava distribuida nas células gliais de Müller. Como a inibição de Rac1 reduziu a produção de TNF-a, que coincide com a inibição da morte neuronal, sugerimos que esta citocina possa ser liberada pela glia.

É possível que Rac1 ativo detectado na célula de Müller participe do controle da produção TNF-a por essas células gliais, como ocorre em outros tipos celulares, tais como: células epiteliais de intestino (JIN et al., 2008) e cardiomiócitos (ZHANG et al., 2011).

Entretanto, esta pode não ser a única via envolvida na morte neuronal. Rac1 também poderia atuar como uma proteína intracelular envolvida na apoptose das células ganglionares desencadeada pela ativação dos receptores NMDA expressos no próprio neurônio, pois os altos níveis de cálcio, assim como o próprio TNF-a, ativam 
Durante o processo de morte, outras proteínas estão envolvidas na via downstream de Rac1 já foram relatados, como por exemplo, o JNK (LINSEMAN et al., 2001; LEE et al., 2005) e ROS (CHUNG et al., 2003; CACICEDO et al., 2005).

A inibição de ROCK, efetor também reduziu a morte neuronal na retina de rodedores, a gliose reativa da glia (TURA et al., 2009), e a produção de citocinas como TNFa, IL6 e interferon gamma.

Nossos resultados revelaram ainda que no modelo in vivo, o bloqueio de NMDA/NR2B reduz a distribuição de Rac1 ativo na glia e a produção de TNF-a, diminuindo a morte neuronal.

Os experimentos realizados neste trabalho, utilizando anticorpo contra NR2B não foram conclusivos para determinar a localização da subunidade em neurônio ou na glia. Na retina, os trabalhos que abordaram a distribuição da subunidade NR2B relatam a presença de RNAm e proteína pricipalmente nas camadas mais internas da retina de ratos, não sendo enfatizada a glia (FLETCHER et al., 2000; GRÜNDER et al., 2000; POURCHO et al., 2001). Entretanto, a expressão da subunidade NR2B é descrita na cultura purificada células gliais de Müller de aves (LAMAS et al., 2005).

Em co-culturas de neurônios corticais e astrócitos, o bloqueio de NR2B é capaz de inibir o aumento de GFAP na glia resultante do tratamento com glutamato. Entretanto o mesmo efeito com o bloqueio de NR2B não foi observado na cultura purificada de astrócitos, sugerindo que este receptor seja expresso pelo neurônio e não na glia (KATO et al., 2006).

Esses dados indicam que a comunição entre célula da glia e neurônio pode ser bidirecional (NEWMAN, 2004). Na retina, a degeneração de fotorreceptores induzida por luz promove a migração da microglia nesta camada e altera a expressão de fatores neurotróficos como o NGF (fator de crescimento dos neurônios), CNTF (fator neurotrófico ciliar) e GDNF (fator neurotrófico derivado da glia) que modulam secundariamente a expressão de outros fatores pelas células gliais de Müller, resultando na proteção ou aumento de apoptose dos fotorreceptores (HARADA et al., 2002).

Em suma, nosso trabalho mostrou que a ativação de NMDA/NR2B promove de modo indireto ou direto o aparecimento de Rac1 ativo na glia que pode influenciar a produção de TNF- $\alpha$, possível indutor da morte neuronal (Figura 28).

Com isso, esperamos contribuir para a melhor compreensão da participação dos receptores NMDA em processos degenerativos da retina e sistema nervoso 
central como um todo. A inibição de proteínas envolvidas nas vias de sinalização de morte, neste caso Rac1, pode se tornar um potencial alvo terapêutico, uma vez que o bloqueio do receptor de NMDA diretamente poderia gerar efeitos adversos devido a sua participação em distintas vias (morte e sobrevivência).
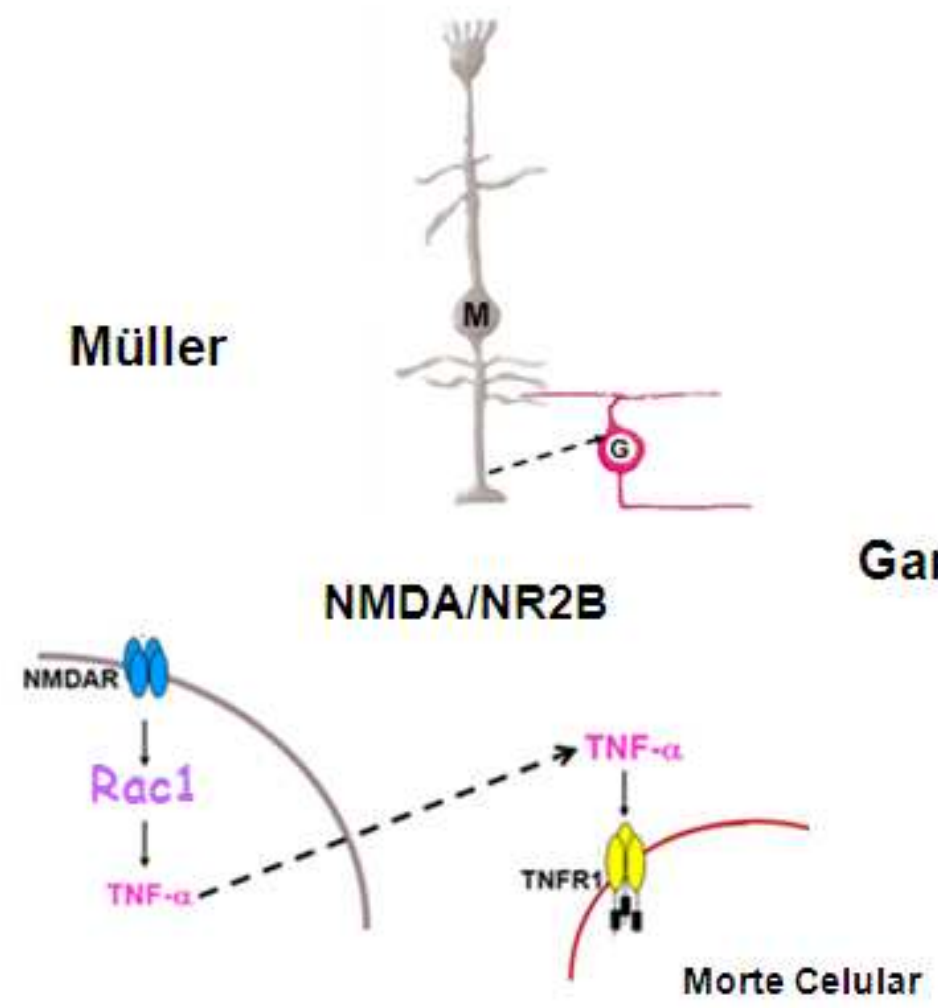

Figura 28. A ativação de NMDA/NR2B (neurônio ou glia) promove de modo indireto ou direto o aparecimento da distribuição de Rac1 ativo na glia que pode influenciar a produção de TNF-a, possível indutor da morte neuronal. 


\section{CONCLUSÕES}

- Os receptores NMDA formados pelas subunidades NR2B, mas não pelas subunidades NR2C/D participam da morte neuronal induzida por glutamato e NMDA. O antagonista de NR2B (Ro 25-6981), mas não de NR2C/D (PPDA) reduziu a liberação de LDH e o aparecimento de células TUNEL.

- Rac1 parece desempenhar o papel de proteína sinalizadora da via de morte neuronal. O NSC 23766 reduziu a liberação de LDH e o aparecimento de células TUNEL-positivas induzida por excitotoxicidade.

- As células gliais de Müller participam da morte neuronal induzida pela excitotoxicidade, possivelmente via liberação de TNF- $\alpha$ produzida pela ativação de Rac1. A imunohistoquímica revelou que a distribuição de Rac1 ativo nos processos da glia e a sua inibição reduz a produção de TNF- $\alpha$ e a morte neuronal após o tratamento com NMDA.

- A ativação dos receptores NMDA formados pelas subunidades NR2B controlam a ativação de Rac1 e a produção de TNF- $\alpha$ pelas células de Müller, o que resulta na morte neuronal. 


\section{REFERÊNCIAS}

AARTS, M.; LIU, Y.; LIU, L.; BESSHOH, S.; ARUNDINE, M.; GURD, J. W.; WANG, Y. T.; SALTER, M. W.; TYMIANSKI, M. Treatment of ischemic brain damage by perturbing NMDA receptor-PSD-95 protein interactions. Science, v. 298, n. 5594, p. 846-50, 2002.

AARTS, M. M.; TYMIANSKI, M. Novel treatment of excitotoxicity: targeted disruption of intracellular signalling from glutamate receptors. Biochem. Pharmacol., v. 15, n. 66, p. 877-86, 2003.

ADAMS, S. M.; DE RIVERO VACCARI, J. C.; CORRIVEAU, R. A. Pronounced cell death in the absence of NMDA receptors in the developing somatosensory thalamus. J. Neurosci., v. 24, n. 42, p. 9441-50, 2004.

ALAVEZ, S.; BLANCAS, S.; MORÁN, J. Effect of N-methyl-D-aspartate receptor blockade on caspase activation and neuronal death in the developing rat cerebellum. Neurosci. Lett., v. 404, n.1-2, p. 176-81, 2006.

ANSON, L. C.; CHEN, P. E.; WYLLIE, D. J.; COLQUHOUN, D.; SCHOEPFER, R. Identification of amino acid residues of the NR2A subunit that control glutamate potency in recombinant NR1/NR2A NMDA receptors. J. Neurosci., 18(2):581-9 p.

AOUN, P.; SIMPKINS, J. W.; AGARWAL, N. Role of PPAR-gamma ligands in neuroprotection against glutamate-induced cytotoxicity in retinal ganglion cells. Invest. Ophthalmol. Vis. Sci., v. 44, n. 7, p. 2999-3004, 2003.

ARIAS-ROMERO, L. E.; CHERNOFF, J. A tale of two Paks. Biol. Cell., v. 100, n. 2, p. $97-108,2008$.

BAGRODIA, S.; CERIONE, R. A. Pak to the future. Trends Cell Biol., v. 9, n. 9, p. 350-5, 1999.

BAGRODIA, S.; DÉRIJARD, B.; DAVIS, R. J.; CERIONE, R. A. Cdc42 and PAKmediated signaling leads to Jun kinase and p38 mitogen-activated protein kinase activation. J. Biol. Chem., v. 270, n. 47, p. 27995-8, 1995.

BARBER, A. J.; LIETH, E.; KHIN, S. A.; ANTONETTI, D. A.; BUCHANAN, A. G.; GARDNER, T. W. Neural apoptosis in the retina during experimental and human diabetes. Early onset and effect of insulin. J. Clin. Invest. v. 102, n. 4, p. 783-91, 1998.

BARNSTABLE, C. J.; DRÄGER, U. C. Thy-1 antigen: a ganglion cell specific marker in rodent retina. Neuroscience, v. 11, n. 4, p. 847-55, 1984.

BEALE, R.; OSBORNE, N. N. Localization of the Thy-1 antigen to the surfaces of rat retinal ganglion cells. Neurochem. Int., v. 4, n. 6, p. 587-95, 1982. 
BELMONTE, M. A.; SANTOS, M. F.; KIHARA, A. H.; YAN, C. Y.; HAMASSAKI, D. E. Light-Induced photoreceptor degeneration in the mouse involves activation of the small GTPase Rac1. Invest. Ophthalmol. Vis. Sci., v. 47, n. 3, p. 1193-200, 2006.

BERTRAND, J.; WINTON, M. J.; RODRIGUEZ-HERNÁNDEZ, N.; CAMPENOT, R. B.; MCKERRACHER, L. Application of Rho antagonist to neuronal cell bodies promotes neurite growth in compartmented cultures and regeneration of retinal ganglion cell axons in the optic nerve of adult rats. J. Neurosci., v. 25, n. 5, p. 111321, 2005.

BISHOP, A. L.; HALL, A. Rho GTPases and their effector proteins. Biochem. J., v. 348, n. 2, p. 241-55, 2000.

BOCKAERT, J.; PIN, J. P. Molecular tinkering of G protein-coupled receptors: an evolutionary success. EMBO J., v. 18, n. 7, p. 1723-9, 1999.

BOLDIN, M. P.; GONCHAROV, T. M.; GOLTSEV, Y. V.; WALLACH, D. Involvement of $\mathrm{MACH}$, a novel MORT1/FADD-interacting protease, in Fas/APO-1- and TNF receptor-induced cell death. Cell, v. 85, n. 6, p. 803-15, 1996.

BOS, J. L.; REHMANN, H.; WITTINGHOFER, A. GEFs and GAPs: Critical Elements in the Control of Small G Proteins. Cell, v. 129, n. 5, p. 865-877, 2007.

BOYCOTT, B.; WÄSSLE, H. Parallel processing in the mammalian retina: the Proctor Lecture. Invest. Ophthalmol. Vis. Sci., v. 40, n. 7, p. 1313-1327, 1999.

BRANDSTÄTTER, J. H. Glutamate receptors in the retina: the molecular substrate for visual signal processing. Curr. Eye Res., v. 25, n. 6, p. 327-31, 2002.

BRANDSTÄTTER, J. H.; KOULEN, P.; WÄSSLE, H. Diversity of glutamate receptors in the mammalian retina. Vision Res., v. 38, n. 10, p. 1385-97, 1998.

BREDT, D. S.; NICOLL, R. A. AMPA receptor trafficking at excitatory synapses. Neuron, v. 40, n. 2, p. 361-379, 2003.

BREWER, G. J.; TORRICELLI, J. R.; EVEGE, E. K.; PRIVE, P. J. Optimized survival of hippocampal neurons in B27-supplemented Neurobasal, a new serum-free medium combination. J. Neurosci. Res., v. 35, n. 5, p. 567-576, 1993.

BRINGMANN, A.; IANDIEV, I.; PANNICKE, T.; WURM, A.; HOLLBORN, M.; WIEDEMANN, P.; OSBORNE, N. N.; REICHENBACH, A. Cellular signaling and factors involved in Müller cell gliosis: neuroprotective and detrimental effects. Prog. Retina Eye. Res., v. 28, n. 6, p. 423-451, 2009.

BUI, B. V.; HU, R. G.; ACOSTA, M. L.; DONALDSON, P.; VINGRYS, A. J.; KALLONIATIS, M. Glutamate metabolic pathways and retinal function. J. Neurochem., v. 111, n. 2, p. 589-99, 2009.

BURNASHEV, N.; KHODOROVA, A.; JONAS, P.; HELM, P. J.; WISDEN, W.; MONYER, H.; SEEBURG, P. H.; SAKMANN, B. Calcium-permeable AMPA-kainate 
receptors in fusiform cerebellar glial cells. Science, v. 256, n. 5063, p. 1566-70, 1992.

CACICEDO, J. M.; BENJACHAREOWONG, S.; CHOU, E.; RUDERMAN, N. B.; IDO, $Y$. Palmitate-induced apoptosis in cultured bovine retinal pericytes: roles of NAD(P)H oxidase, oxidant stress, and ceramide. Diabetes, v. 54, n. 6, p. 1838-1845, 2005.

CARROLL, R. C.; ZUKIN, R. S. NMDA-receptor trafficking and targeting: implications for synaptic transmission and plasticity. Trends Neurosci. v. 25, n. 11, p. 571-7, 2002.

CARTER-DAWSON, L.; CRAWFORD, M. L.; HARWERTH, R. S.; SMITH, E. L.; FELDMAN, R.; SHEN, F. F.; MITCHELL, C. K.; WHITETREE, A. Vitreal glutamate concentration in monkeys with experimental glaucoma. Invest. Ophthalmol. Vis. Sci., v. 43, n. 8, p. 2633-7, 2002.

CASTILLO, C. A.; LEÓN, D. A.; BALLESTEROS-YÁÑEZ, I.; IGLESIAS, I.; MARTÍN, M.; ALBASANZ, J. L. Glutamate differently modulates metabotropic glutamate receptors in neuronal and glial cells. Neurochem. Res., v. 35, n. 7, p. 1050-63, 2010.

CHATTERTON, J. E.; AWOBULUYI, M.; PREMKUMAR, L. S.; TAKAHASHI, H.; TALANTOVA, M.; SHIN, Y.; CUI, J.; TU, S.; SEVARINO, K. A.; NAKANISHI, N.; TONG, G.; LIPTON, S. A.; ZHANG, D. Excitatory glycine receptors containing the NR3 family of NMDA receptor subunits. Nature, v. 415, n. 6873, p. 793-798, 2002.

CHAUDHARY, P.; AHMED, F.; SHARMA, S. C. MK801-a neuroprotectant in rat hypertensive eyes. Brain Res., v. 792, n. 1, p. 154-8, 1998.

CHEN, H. S.; LIPTON, S. A. Pharmacological implications of two distinct mechanisms of interaction of memantine with $\mathrm{N}$-methyl-D-aspartate-gated channels. J. Pharmacol. Exp. Ther., v. 314, n. 3, p. 961-71, 2005.

CHEN, H. S.; LIPTON, S. A. The chemical biology of clinically tolerated NMDA receptor antagonists. J. Neurochem., v. 97, n. 6, p. 1611-26, 2006.

CHEN, M.; LU, T. J.; CHEN, X. J.; ZHOU, Y.; CHEN, Q.; FENG, X. Y.; XU, L.; DUAN, W. H.; XIONG, Z. Q. Differential roles of NMDA receptor subtypes in ischemic neuronal cell death and ischemic tolerance. Stroke, v. 39, n. 11, p. 3042-3048, 2008.

CHEN, P. E.; WYLLIE, D. J. Pharmacological insights obtained from structurefunction studies of ionotropic glutamate receptors. Br. J. Pharmacol., v. 147, n. 8, p. 839-53, 2006.

CHEN, T. A.; YANG, F.; COLE, G. M.; CHAN, S. O. Inhibition of caspase-3-like activity reduces glutamate induced cell death in adult rat retina. Brain Res., v. 904, n. 1, p. 177-88, 2001.

CHENARD, B. L.; MENNITI, F. S. Antagonists selective for NMDA receptors containing the NR2B subunit. Curr. Pharm. Des., v. 5, n. 5, p. 381-404, 1999. 
CHENG, T. L.; SYMONS, M.; JOU, T. S. Regulation of anoikis by Cdc42 and Rac1. Exp. Cell Res., v. 295, n. 2, p. 497-511, 2004.

CHOI, D. W. Calcium-mediated neurotoxicity: relationship to specific channel types and role in ischemic damage. Trends Neurosci., v. 11, n. 10, p. 465-469, 1998.

CHOI, D. W. Excitotoxic cell death. J. Neurobiol., v. 23, n. 9, p. 1261-76. 1992.

CHUNG, H. J.; HUANG, Y. H.; LAU, L. F.; HUGANIR, R. L. Regulation of the NMDA receptor complex and trafficking by activity-dependent phosphorylation of the NR2B subunit PDZ ligand. J. Neurosci., v. 24, n. 45, p. 10248-59, 2004.

CHUNG, Y. M.; BAE, Y. S.; LEE, S. Y. Molecular ordering of ROS production, mitochondrial changes, and caspase activation during sodium salicylate-induced apoptosis. Free Radic. Biol. Med., v. 34, n. 4, p. 434-42, 2003.

COTINET, A.; GOUREAU, O.; HICKS, D.; THILLAYE-GOLDENBERG, B.; DE KOZAK, Y. Tumor necrosis factor and nitric oxide production by retinal Müller glial cells from rats exhibiting inherited retinal dystrophy. Glia, v. 20, n. 1, p. 59-69. 1997.

CULL-CANDY, S.; BRICKLEY, S.; FARRANT, M. NMDA receptor subunits: diversity, development and disease. Curr. Opin. Neurobiol., v. 11, n. 3, p. 327-35, 2001.

CULL-CANDY, S. G.; LESZKIEWICZ, D. N. Role of distinct NMDA receptor subtypes at central synapses. Sci. STKE., v. 2004, n. 255, p. 1-9, 2004.

DE BLASI, A.; CONN, P. J.; PIN, J.; NICOLETTI, F. Molecular determinants of metabotropic glutamate receptor signaling. Trends. Pharmacol. Sci., p. 22, n. 3, p. 114-20, 2001.

DE KOZAK, Y.; NAUD, M. C.; BELLOT, J.; FAURE, J. P.; HICKS, D. Differential tumor necrosis factor expression by resident retinal cells from experimental uveitissusceptible and -resistant rat strains. J. Neuroimmunol., v. 55, n. 1, p. 1-9, 1994.

DI POLO, A.; AIGNER, L. J.; DUNN, R. J.; BRAY, G. M.; AGUAYO, A. J. Prolonged delivery of brain-derived neurotrophic factor by adenovirus-infected Müller cells temporarily rescues injured retinal ganglion cells. Proc. Natl. Acad. Sci. U.S.A., v. 95, n. 7, p. 3978-83, 1998.

DI, X.; BULLOCK, R.; WATSON, J.; FATOUROS, P.; CHENARD, B.; WHITE, F.; CORWIN, F. Effect of CP101,606, a novel NR2B subunit antagonist of the NmethylD-aspartate receptor, on the volume of ischemic brain damage of cytotoxic brain edema after middle cerebral artery occlusion in the feline brain. Stroke, v. 28, n. 11, p. 2244-2251, 1997.

DINGLEDINE, R.; BORGES, K.; BOWIE, D.; TRAYNELIS, S. F. The glutamate receptor ion channels. Pharmacol. Rev., v. 51, n. 1, p. 7-61, 1999.

DONG, Y.; BENVENISTE, E. N. Immune function of astrocytes. Glia, v. 36, n. 2, p. 180-90. 2001. 
DREYER, E. B.; ZURAKOWSKI, D.; SCHUMER, R. A.; PODOS, S. M.; LIPTON, S. A. Elevated glutamate levels in the vitreous body of humans and monkeys with glaucoma. Arch. Ophthalmol., v. 114, n. 3, p. 299-305, 1996.

DUNCAN, J. R.; LAWRENCE, A. J. The role of metabotropic glutamate receptors in addiction: Evidence from preclinical models. Pharmacol. Biochem. Behav., 2011.

EHINGER, B. Connexions between retinal neurons with identified neurotransmitters. Vision Res., v. 23, n. 11, p. 1281-91, 1983.

ETIENNE-MANNEVILLE, S.; HALL, A. Rho GTPases in cell biology. Nature, v. 420, n. 6916, p. 629-35, 2002.

EULER, T.; WÄSSLE, H. Immunocytochemical identification of cone bipolar cells in the rat retina. J. Comp. Neurol., v. 361, n. 3, p. 461-78, 1995.

FADEN, A. I.; DEMEDIUK, P.; PANTER, S. S.; VINK, R. The role of excitatory amino acids and NMDA receptors in traumatic brain injury. Science, v. 244, n. 4906, p. 798800, 1989.

FADEN, A. I.; LEMKE, M.; SIMON, R. P.; NOBLE, L. J. N-methyl-D-aspartate antagonist MK801 improves outcome following traumatic spinal cord injury in rats: behavioral, anatomic, and neurochemical studies. J. Neurotrauma., v. 5, n. 1, p. 3345, 1988.

FAN, W.; AGARWAL, N.; KUMAR, M. D.; COOPER, N. G. Retinal ganglion cell death and neuroprotection: Involvement of the CaMKIlalpha gene. Brain Res. Mol. Brain Res., v. 139, n. 2, p. 306-316, 2005.

FERREIRA, I. L.; DUARTE, C. B.; CARVALHO, A. P. Ca2+ influx through glutamate receptor-associated channels in retina cells correlates with neuronal cell death. Eur. J. Pharmacol., v. 302, n. 1-3, p. 153-62, 1996.

FISCHER, A. J. Neural regeneration in the chick retina. Prog. Retin. Eye Res., v. 24, n. 2, p. 161-182, 2005.

FISCHER, A. J.; BONGINI, R. Turning Müller glia into neural progenitors in the retina. Mol. Neurobiol., v. 42, n. 3, p. 199-209, 2010.

FISCHER, A. J.; REH, T. A. Potential of Müller glia to become neurogenic retinal progenitor cells. Glia, v. 43, n. 1, p. 70-76, 2003.

FISCHER, G.; MUTEL, V.; TRUBE, G.; MALHERBE, P.; KEW, J. N.; MOHACSI, E.; HEITZ, M. P.; KEMP, J. A. Ro 25-6981, a highly potent and selective blocker of Nmethyl-D-aspartate receptors containing the NR2B subunit. Characterization in vitro. J. Pharmacol. Exp. Ther., v. 283, n. 3, p. 1285-92, 1997.

FLETCHER, E. L.; HACK, I.; BRANDSTÄTTER, J. H.; WÄSSLE, H. Synaptic localization of NMDA receptor subunits in the rat retina. J. Comp. Neurol., v. 420, n. 1, p. 98-112, 2000. 
FONTAINE, V.; MOHAND-SAID, S.; HANOTEAU, N.; FUCHS, C.; PFIZENMAIER, K.; EISEL, U. Neurodegenerative and neuroprotective effects of tumor Necrosis factor (TNF) in retinal ischemia: opposite roles of TNF receptor 1 and TNF receptor 2. J. Neurosci., v. 22, n. 7, p. 216, 2002.

FRANDSEN, A.; SCHOUSBOE, A. AMPA receptor-mediated neurotoxicity: role of $\mathrm{Ca} 2+$ and desensitization. Neurochem. Res., v. 28, n. 10, p. 1495-1499, 2003.

FURUKAWA, H.; GOUAUX, E. Mechanisms of activation, inhibition and specificity: crystal structures of the NMDA receptor NR1 ligand-binding core. EMBO J., v. 22, n. 12, p. 2873-85, 2003.

GANESH, B. S.; CHINTALA, S. K. Inhibition of reactive gliosis attenuates excitotoxicity-mediated death of retinal ganglion cells. PLoS One., v. 6, n. 3, p. 18305, 2011.

GARCIA-VALENZUELA, E.; SHAREEF, S.; WALSH, J.; SHARMA, S. C. Programmed cell death of retinal ganglion cells during experimental glaucoma. Exp. Eye Res., v. 61, n. 1, p. 33-44, 1995.

GARDONI, F.; BELLONE, C.; VIVIANI, B.; MARINOVICH, M.; MELI, E.; PELLEGRINI-GIAMPIETRO, D. E.; CATTABENI, F.; DI LUCA, M. Lack of PSD-95 drives hippocampal neuronal cell death through activation of an alpha CaMKII transduction pathway. Eur. J. Neurosci., v. 16, n. 5, p. 777-86, 2002.

GILLING, K.; JATZKE, C.; WOLLENBURG, C.; VANEJEVS, M.; KAUSS, V.; JIRGENSONS, A.; PARSONS, C. G. A novel class of amino-alkylcyclohexanes as uncompetitive, fast, voltage-dependent, N-methyl-D-aspartate (NMDA) receptor antagonists in vitro characterization. J. Neural. Transm., v. 114, n. 12, p. 1529-1537, 2007.

GOEBEL, D. J.; POOSCH, M. S. Transient down-regulation of NMDA receptor subunit gene expression in the rat retina following NMDA-induced neurotoxicity is attenuated in the presence of the non-competitive NMDA receptor antagonist MK801. Exp. Eye Res., v. 72, n. 5, p. 547-58, 2001.

GOGAS, K. R. Glutamate-based therapeutic approaches: NR2B receptor antagonists. Curr. Opin. Pharmacol., v. 6, n. 1, p. 68-74, 2006.

GOHDO. T.; UEDA, H.; OHNO, S.; IIJIMA, H.; TSUKAHARA, S. Heat shock protein 70 expression increased in rabbit Müller cells in the ischemia-reperfusion model. Ophthalmic. Res., v. 33, n. 5, p. 298-302, 2001.

GOLLISCH, T.; MEISTER, M. Modeling convergent ON and OFF pathways in the early visual system. Biol. Cybern., v. 99, n. 4-5, p. 263-78, 2008.

GOUAUX, E. Structure and function of AMPA receptors. J. Physiol., v. 15, n. 554, p. 249-53, 2004. 
GOUREAU, O.; HICKS, D.; COURTOIS, Y.; DE KOZAK, Y. Induction and regulation of nitric oxide synthase in retinal Müller glial cells. J. Neurochem., v. 63, n. 1, p. 3107, 1994.

GROC, L.; HEINE, M.; COUSINS, S. L.; STEPHENSON, F. A.; LOUNIS, B.; COGNET, L.; CHOQUET, D. NMDA receptor surface mobility depends on NR2A-2B subunits. Proc. Natl. Acad. Sci. U.S.A., v. 103, n. 49, p. 18769-74, 2006.

GRÜNDER, T.; KOHLER, K.; KALETTA, A.; GUENTHER, E. The distribution and developmental regulation of NMDA receptor subunit proteins in the outer and inner retina of the rat. J. Neurobiol. v. 44, n. 3, p. 333-42, 2000.

GUENTHER, E.; SCHMID, S.; GRANTYN, R.; ZRENNER, E. In vitro identification of retinal ganglion cells in culture without the need of dye labeling. J. Neurosci. Methods., v. 51, n. 2, p. 177-81, 1994.

HABERECHT, M. F.; MITCHELL, C. K.; LO, G. J.; REDBURN, D. A. N-methylDaspartate-mediated glutamate toxicity in the developing rabbit retina. J. Neurosci. Res., v. 47, n. 4, p. 416-426, 1997.

HAHN, J. S.; AIZENMAN, E.; LIPTON, S. A. Central mammalian neurons normally resistant to glutamate toxicity are made sensitive by elevated extracellular $\mathrm{Ca}+$ : toxicity is blocked by the N-methyl-D-aspartate antagonist MK-801. Proc. Natl. Acad. Sci. U.S.A., v. 85, n. 17, p. 6556-6560, 1988.

HAKOSHIMA, T.; SHIMIZU, T.; MAESAKI, R. Structural basis of the Rho GTPase signaling. J. Biochem., v. 134, n. 3, p. 327-31, 2003.

HALL A. Rho GTPases and the actin cytoskeleton. Science, v. 279, n. 5350, p. 509514, 1998.

HALL, A. Rho GTPases and the control of cell behaviour. Biochem. Soc. Trans., v. 33, n. 5, p. 891-895, 2005.

HAMA, Y.; KATSUKI, H.; SUMINAKA, C.; KUME, T.; AKAIKE, A. Chloride-dependent acute excitotoxicity in adult rat retinal ganglion cells. Neuropharmacology, v. 55, n. 5, p. 677-686, 2008.

HAMASSAKI-BRITTO, D. E.; HERMANS-BORGMEYER, I.; HEINEMANN, S.; HUGHES, T. E. Expression of glutamate receptor genes in the mammalian retina: the localization of GluR1 through GluR7 mRNAs. J. Neurosci., v. 13, n. 5, p. 1888-1898, 1993.

HANKINS, M. W.; PEIRSON, S. N.; FOSTER, R. G. Melanopsin: an exciting photopigment. Trends. Neurosci. v. 31, n. 1, p. 27-36, 2008.

HARADA, C.; GUO, X.; NAMEKATA, K.; KIMURA, A.; NAKAMURA, K.; TANAKA, K.; PARADA, L. F.; HARADA, T. Glia- and neuron-specific functions of TrkB signalling during retinal degeneration and regeneration. Nat. Commun., n. 2, p. 189, 2011. 
HARADA, T.; HARADA, C.; KOHSAKA, S.; WADA, E.; YOSHIDA, K.; OHNO, S.; MAMADA, H.; TANAKA, K.; PARADA, L. F.; WADA, K. Microglia-Müller glia cell interactions control neurotrophic factor production during light-induced retinal degeneration. J. Neurosci., v. 22, n. 21, p. 9228-36, 2002.

HARDINGHAM, G. E. Pro-survival signalling from the NMDA receptor. Biochem. Soc. Trans., v. 34, n. 5, p. 936-8, 2006.

HARDINGHAM, G. E.; BADING, H. Synaptic versus extrasynaptic NMDA receptor signalling: implications for neurodegenerative disorders. Nat. Rev. Neurosci., v. 11, n. 10, p. 682-696, 2010.

HARUTA, M.; BUSH, R. A.; KJELLSTROM, S.; VIJAYASARATHY, C.; ZENG, Y.; LE, Y. Z.; SIEVING, P. A. Depleting Rac1 in mouse rod photoreceptors protects them from photo-oxidative stress without affecting their structure or function. Proc. Natl. Acad. Sci. U.S.A., v. 106, n. 23, p. 9397-402, 2009.

HATORI, M.; PANDA, S. The emerging roles of melanopsin in behavioral adaptation to light. Trends. Mol. Med., v. 16, n. 10, p. 435-446, 2010.

HATTON, C. J.; PAOLETTI, P. Modulation of triheteromeric NMDA receptors by Nterminal domain ligands. Neuron, v. 46, n. 2, p. 261-274, 2005.

HEHLGANS, T.; PFEFFER, K. The intriguing biology of the tumour necrosis factor/tumour necrosis factor receptor superfamily: players, rules and the games. Immunology, v. 115, n. 1, p. 1-20, 2005.

HENLE, F.; FISCHER, C.; MEYER, D.K.; LEEMHUIS, J. Vasoactive intestinal peptide and PACAP38 control N-methyl-D-aspartic acid-induced dendrite motility by modifying the activities of Rho GTPases and phosphatidylinositol 3-kinases. J. Biol. Chem., v. 281, n. 34, p. 24955-69, 2006.

HERNÁNDEZ, M.; GUERRIKAGOITIA, I.; MARTÍNEZ-MILLAN, L.; VECINO, E. NMDA-receptor blockade enhances cell apoptosis in the developing retina of the postnatal rat. Int. J. Dev. Biol., v. 51, n. 2, p. 117-22, 2007.

HICKS, D.; COURTOIS Y. The growth and behaviour of rat retinal Müller cells in vitro 1: an improved method for isolation and culture. Exp. Eye Res., v. 51, n. 2, p. 119129, 1990.

HIRAI, H.; KIRSCH, J.; LAUBE, B.; BETZ, H.; KUHSE, J. The glycine binding site of the N-methyl-D-aspartate receptor subunit NR1: identification of novel determinants of co-agonist potentiation in the extracellular M3-M4 loop region. Proc. Natl. Acad. Sci. U.S.A., v. 93, n. 12, p. 6031-6, 1996.

HOFMANN, H. D.; SCHULZ-KEY, S.; HERTLE, D.; KIRSCHNEW, M. Organotypic Cultures of the Rat Retina. New Methods for Culturing Cells from Nervous Tissues. BioValley Monogr. Basel Karger. p. 58-73, 2005. 
HOLLMANN, M.; HEINEMANN, S. Cloned glutamate receptors. Annu. Rev. Neurosci., n. 17, p. 31-108, 1994.

HOUAMED, K. M.; KUIJPER, J. L.; GILBERT, T. L.; HALDEMAN, B. A.; O'HARA, P. J.; MULVIHILL, E. R.; ALMERS, W.; HAGEN, F. S. Cloning, expression, and gene structure of a $G$ protein-coupled glutamate receptor from rat brain. Science, v. 252, n. 5010, p. 1318-21, 1991.

HUANG. W.; FILETA, J.; GUO, Y.; GROSSKREUTZ, C. L. Downregulation of Thy1 in retinal ganglion cells in experimental glaucoma. Curr. Eye Res., v. 31, n. 3, p. 26571, 2006.

HUETTNER, J. E.; BEAN, B. P. Block of N-methyl-D-aspartate-activated current by the anticonvulsant MK-801: selective binding to open channels. Proc. Natl. Acad. Sci. U.S.A., v. 85, n. 4, p. 1307-11, 1988.

HUME, R.I.; DINGLEDINE, R.; HEINEMANN, S. F. Identification of a site in glutamate receptor subunits that controls calcium permeability. Science, v. 253, n. 5023, p. 1028-31, 1991.

IHARA, K.; MURAGUCHI, S.; KATO, M.; SHIMIZU, T.; SHIRAKAWA, M.; KURODA, S.; KAIBUCHI, K.; HAKOSHIMA, T. Crystal structure of human RhoA in a dominantly active form complexed with a GTP analogue. J. Biol. Chem., v. 273, n. 16, p. 965666, 1998.

IKEDA, K.; NAGASAWA, M.; MORI, H.; ARAKI, K.; SAKIMURA, K.; WATANABE, M.; INOUE, Y.; MISHINA, M. Cloning and expression of the epsilon 4 subunit of the NMDA receptor channel. FEBS Lett., v. 313, n. 1, p. 34-8, 1992.

IKEDA, K.; TANIHARA, H.; HONDA, H; TATSUNO, T.; NOGUCHI, H.; NAKAYAMA, C. BDNF attenuates retinal cell death caused by chemically induced hypoxia in rats. Invest. Ophthalmol. Vis. Sci., v. 40, n. 9, p. 2130-40, 1999.

IKONOMIDOU, C.; BOSCH, F.; MIKSA, M.; BITTIGAU, P.; VOCKLER, J.; DIKRANIAN, K.; TENKOVA, T. I.; STEFOVSKA, V.; TURSKI, L.; OLNEY, J. W. Blockade of NMDA receptors and apoptotic neurodegeneration in the developing brain. Science, v. 83, n. 5398, p. 70-4, 1999.

IKONOMIDOU, C.; STEFOVSKA, V.; TURSKI, L. Neuronal death enhanced by Nmethyl-D-aspartate antagonists. Proc. Natl. Acad. Sci. U.S.A., v. 97, n. 23, p. 12885-90, 2000.

IKONOMIDOU, C.; TURSKI, L. Why did NMDA receptor antagonists fail clinical trials for stroke and traumatic brain injury? Lancet. Neurol. v. 1, n. 6, p. 383-6, 2002.

JAFFER, Z.M.; CHERNOFF, J. p21-activated kinases: three more join the Pak. Int. J. Biochem. Cell Biol. v. 34, n. 7, p. 713-7, 2002. 
JIANG, K.; ZHONG, B.; RITCHEY, C.; GILVARY, D.L.; HONG-GELLER, E.; WEI, S.; DJEU, J.Y. Regulation of Akt-dependent cell survival by Syk and Rac. Blood, v. 101, n. 1, p. 236-44, 2003.

JIN, S.; RAY, R. M.; JOHNSON, L. R. TNF-alpha/cycloheximide-induced apoptosis in intestinal epithelial cells requires Rac1-regulated reactive oxygen species. Am. J. Physiol. Gastrointest. Liver. Physiol., v. 294, n. 4, p. 928-937, 2008.

JINGAMI, H.; NAKANISHI, S.; MORIKAWA, K. Structure of the metabotropic glutamate receptor. Curr. Opin. Neurobiol., v. 13, n. 3, p. 271-8, 2003.

KALLONIATIS, M.; TOMISICH, G. Amino acid neurochemistry of the vertebrate retina. Prog. Retina Eye Res., v. 18, n. 6, p. 811-66, 1999.

KANEKURA, K.; HASHIMOTO, Y.; KITA, Y.; SASABE, J.; AISO, S.; NISHIMOTO, I.; MATSUOKA, M. A Rac1/phosphatidylinositol 3-kinase/Akt3 anti-apoptotic pathway, triggered by AlsinLF, the product of the ALS2 gene, antagonizes Cu/Zn-superoxide dismutase (SOD1) mutant-induced motoneuronal cell death. J. Biol. Chem., v. 280, n. 6, p. $4532-43,2005$.

KAPIN, M. A.; DOSHI, R.; SCATTON, B.; DESANTIS, L. M.; CHANDLER, M. L. Neuroprotective effects of eliprodil in retinal excitotoxicity and ischemia. Invest. Ophthalmol. Vis. Sci., v. 40, n. 6, p. 1177-82, 1999.

KATO, H.; NARITA, M.; MIYATAKE, M.; YAJIMA, Y.; SUZUKI, T. Role of neuronal NR2B subunit-containing NMDA receptor-mediated $\mathrm{Ca} 2+$ influx and astrocytic activation in cultured mouse cortical neurons and astrocytes. Synapse, v. 59, n. 1, p. 10-7, 2006.

KEMP, J. A.; MCKERNAN, R. M. NMDA receptor pathways as drug targets. Nat. Neurosci., v. 5, p. 1039-42, 2002.

KERN, T. S.; BARBER, A. J. Retinal ganglion cells in diabetes. J. Physiol., v. 586, n. 18, p. 4401-8, 2008.

KEW, J. N.; KEMP, J. A. An allosteric interaction between the NMDA receptor polyamine and ifenprodil sites in rat cultured cortical neurones. J. Physiol., v. 512, n. 1, p. 17-28, 1998.

KINNEY, W. A.; ABOU-GHARBIA, M.; GARRISON, D. T.; SCHMID, J.; KOWAL, D. M.; BRAMLETT, D. R.; MILLER, T. L.; TASSE, R. P.; ZALESKA, M. M.; MOYER, J. A. Design and synthesis of [2-(8,9-dioxo-2,6-diazabicyclo[5.2.0]non-1(7)-en-2-yl)ethyl]phosphonic acid (EAA-090), a potent $\mathrm{N}$-methyl-D-aspartate antagonist, via the use of 3-cyclobutene-1,2-dione as an achiral alpha-amino acid bioisostere. J. Med. Chem., n. 41, p. 236-246, 1998.

KITAOKA, Y.; KITAOKA, Y.; KUMAI, T.; LAM. T. T.; KURIBAYASHI, K.; ISENOUMI, K.; MUNEMASA, Y.; MOTOKI, M.; KOBAYASHI, S.; UENO, S. Involvement of RhoA and possible neuroprotective effect of fasudil, a Rho kinase inhibitor, in NMDAinduced neurotoxicity in the rat retina. Brain Res., v. 1018, n. 1, p. 111-118, 2004. 
KÖHR, G.; JENSEN, V.; KOESTER, H.J.; MIHALJEVIC, A.L.; UTVIK, J.K.; KVELLO, A.; OTTERSEN, O.P.; SEEBURG, P.H.; SPRENGEL, R.; HVALBY, O. Intracellular domains of NMDA receptor subtypes are determinants for long-term potentiation induction. J. Neurosci., v. 23, n. 34, p. 10791-9, 2003.

KOLB, $\mathrm{H}$. The architecture of functional neural circuits in the vertebrate retina. Invest. Ophthalmol. Vis. Sci. 35:2385-404 p. 1994.

KOLB, H. 2011. (http://webvision.med.utah.edu/).

KOWLURU, R. A.; KOPPOLU, P. Diabetes-induced activation of caspase-3 in retina: effect of antioxidant therapy. Free Radic. Res., v. 36, n. 9, p. 993-9, 2002

KRAPIVINSKY, G.; KRAPIVINSKY, L.; MANASIAN, Y.; IVANOV, A.; TYZIO, R.; PELLEGRINO, C.; BEN-ARI, Y.; CLAPHAM, D. E.; MEDINA, I. The NMDA receptor is coupled to the ERK pathway by a direct interaction between NR2B and RasGRF1. Neuron, v. 40, n. 4, p. 775-84, 2003.

KREIS, P.; BARNIER, J. V. PAK signalling in neuronal physiology. Cell Signal., v. 21, n. 3, p. 384-93, 2009.

KRISHNAMOORTHY, R. R.; AGARWAL, P.; PRASANNA, G.; VOPAT, K.; LAMBERT, W.; SHEEDLO, H. J.; PANG, I. H.; SHADE, D.; WORDINGER, R. J.; YORIO, T.; CLARK, A. F.; AGARWAL, N. Characterization of a transformed rat retinal ganglion cell line. Brain Res. Mol. Brain Res., v. 86, n. 1-2, p.1-12, 2001.

KUBO, M.; ITO, E. Structural dynamics of an ionotropic glutamate receptor. Proteins, v. 56, n. 3, p. 411-9, 2004.

KURYATOV, A.; LAUBE, B.; BETZ, H.; KUHSE, J. Mutational analysis of the glycinebinding site of the NMDA receptor: structural similarity with bacterial amino acidbinding proteins. Neuron, v. 12, n. 6, p. 1291-300, 1994.

KUTSUWADA, T.; KASHIWABUCHI, N.; MORI, H.; SAKIMURA, K.; KUSHIYA, E.; ARAKI, K.; LAUBE, B.; KUHSE, J.; BETZ, H. Evidence for a tetrameric structure of recombinant NMDA receptors. J Neurosci., v. 18, n. 8, p. 2954-61, 1998.

KWONG, J. M.; LAM, T. T. N -methyl- D -aspartate (NMDA) induced apoptosis in adult rabbit retinas. Exp. Eye Res., v. 71, n. 4, p. 437-44, 2000.

LAABICH, A.; LI, G.; COOPER, N. G. Enhanced expression of TNF-R1 protein in NMDA-mediated cell death in the retina. Brain Res. Mol. Brain Res., v. 109, n. 1-2, p. 239-46, 2002.

LAGRĖZE, W. A.; DARSTEIN, M.; FEUERSTEIN, T. J.; OTTO, T.; LANDWEHRMEYER, G. B. N-methyl-D-aspartate receptor subunit mRNA expression in human retinal ganglion cells. Graefes Arch. Clin. Exp. Ophthalmol., v. 238, n. 6, p. 486-90, 2000. 
LAMAS, M.; LEE-RIVERA, I.; LÓPEZ-COLOMÉ, A. M. Cell-specific expression of Nmethyl-D-aspartate receptor subunits in Müller glia and neurons from the chick retina. Invest. Ophthalmol. Vis. Sci., v. 46, n. 10, p. 3570-7, 2005.

LAUBE, B.; KUHSE, J.; BETZ H. Evidence for a tretameric structure of recombinant NMDA receptors. J. Neurosci., v. 18, n. 8, p. 2954-61, 1998.

LAURIE, D. J.; SEEBURG, P. H. Ligand affinities at recombinant N-methyl-Daspartate receptors depend on subunit composition. Eur. J. Pharmacol., v. 268, n. 3, p. 335-45, 1994.

LE, S. S.; LOUCKS, F. A.; UDO, H.; RICHARDSON-BURNS, S.; PHELPS, R. A.; BOUCHARD, R. J.; BARTH, H.; AKTORIES, K.; TYLER, K. L.; KANDEL, E. R.; HEIDENREICH, K. A.; LINSEMAN, D. A. Inhibition of Rac GTPase triggers a c-Junand Bim-dependent mitochondrial apoptotic cascade in cerebellar granule neurons. J. Neurochem., v. 94, n. 4, p. 1025-39, 2005.

LEBRUN-JULIEN, F.; DUPLAN, L.; PERNET, V.; OSSWALD, I.; SAPIEHA, P.; BOURGEOIS, P.; DICKSON, K.; BOWIE, D; BARKER, P. A.; DI POLO, A. Excitotoxic death of retinal neurons in vivo occurs via a non-cell-autonomous mechanism. J. Neurosci., v. 29, n. 17, p. 5536-45, 2009.

LEE, N. K.; CHOI, Y. G.; BAIK, J. Y.; HAN, S. Y.; JEONG, D. W.; BAE, Y. S.; KIM, N.; LEE, S. Y. A crucial role for reactive oxygen species in RANKL-induced osteoclast differentiation. Blood, v. 106, n. 3, p. 852-9, 2005.

LEHMANN, M.; FOURNIER, A.; SELLES-NAVARRO, I.; DERGHAM, P.; SEBOK, A.; LECLERC, N.; TIGYI, G.; MCKERRACHER, L. Inactivation of Rho signaling pathway promotes CNS axon regeneration. J. Neurosci., v. 19, n. 17, p. 7537-47, 1999.

LEVY, D. I.; LIPTON, S. A. Comparison of delayed administration of competitive and uncompetitive antagonists in preventing NMDA receptor-mediated neuronal death. Neurology, n. 40, p. 852-855, 1990.

LINDEN, R.; MARTINS, R. A.; SILVEIRA, M. S. Control of programmed cell death by neurotransmitters and neuropeptides in the developing mammalian retina. Prog. Retin. Eye Res., n. 24, p. 457-9, 2005.

LINSEMAN, D. A.; LAESSIG, T.; MEINTZER, M. K.; MCCLURE, M.; BARTH, H.; AKTORIES, K.; HEIDENREICH, K. A. An essential role for Rac/Cdc42 GTPases in cerebellar granule neuron survival. J. Biol. Chem., v. 276, n. 42, p. 39123-31, 2001.

LIPTON, S. A. Freshly dissociated and cultured rodent retinal ganglion cells. In: Kettenman, H.; Grantyn, R. Practical electrophysiological methods. Wiley Press. P. 7-83, 1993.

LIPTON, S. A. NMDA receptors, glial cells, and clinical medicine. Neuron, v. 50, n. 1, p. 9-11, 2006. 
LIPTON, S. A.; NICOTERA, P. Calcium, free radicals and excitotoxins in neuronal apoptosis. Cell Calcium, v. 23, n. 2-3, p. 165-71, 1998.

LIPTON, S. A.; NICOTERA. P. Calcium, free radicals and excitotoxins in neuronal apoptosis. Cell Calcium, v. 23, n. 2-3, p. 165-71, 1998.

LIU, Y.; WONG, T. P.; AARTS, M.; ROOYAKKERS, A.; LIU, L.; LAI, T. W.; WU, D. C.; LU, J.; TYMIANSKI, M; CRAIG, A. M.; WANG, Y. T. NMDA receptor subunits have differential roles in mediating excitotoxic neuronal death both in vitro and in vivo. J. Neurosci., v. 27, n. 11, p. 2846-57, 2007.

LUCAS, D. R.; NEWHOUSE, J. P. The toxic effect of sodium L-glutamate on the inner layers of the retina. Am. Med. Assoc. Arch. Ophthalmol., n. 58, p. 193-201, 1957.

LUO, H. R.; HATTORI, H.; HOSSAIN, M. A.; HESTER, L.; HUANG, Y.; LEE-KWON, W.; DONOWITZ, M.; NAGATA, E.; SNYDER, S. H. Akt as a mediator of cell death. Proc. Natl. Acad. Sci. U.S.A., v. 100, n. 20, p. 11712-7, 2003.

LYNCH, D. R.; GUTTMANN, R. P. Excitotoxicity: perspectives based on N-methyl-Daspartate receptor subtypes. J. Pharmacol. Exp Ther., v. 300, n. 3, p. 717-23, 2002.

LYNCH, D. R.; GUTTMANN, R. P. NMDA receptor pharmacology: perspectives from molecular biology. Curr. Drug Targets., v. 2, n. 3, p. 215-31, 2001.

LYNCH, D. R.; SHIM, S. S.; SEIFERT, K. M.; KURAPATHI, S.; MUTEL, V.; GALLAGHER, M. J.; GUTTMANN, R. P. Pharmacological characterization of interactions of RO 25-6981 with the NR2B (epsilon2) subunit. Eur. J. Pharmacol., v. 416, n. 3, p. 185-95, 2001.

MADDEN, K. NMDA receptor antagonists and glycine site NMDA antagonists. Curr. Med. Res. Opin., n. 2, p. 27-31, 2002.

MAHER, P.; HANNEKEN, A. The molecular basis of oxidative stress-induced cell death in an immortalized retinal ganglion cell line. Invest. Ophthalmol. Vis. Sci., v. 46 , n. 2, p. 749-57, 2005.

MALHERBE, P.; MUTEL, V.; BROGER, C.; PERIN-DUREAU, F.; KEMP, J. A.; NEYTON, J.; PAOLETTI, P.; KEW, J. N. Identification of critical residues in the amino terminal domain of the human NR2B subunit involved in the RO 25-6981 binding pocket. J. Pharmacol. Exp. Ther., v. 307, n. 3, p. 897-905, 2003.

MALINOW, R.; MALENKA, R. C. AMPA receptor trafficking and synaptic plasticity. Annu. Rev. Neurosci., n. 25, p. 103-26, 2002.

MANABE, S.; LIPTON, S. A. Divergent NMDA signals leading to proapoptotic and antiapoptotic pathways in the rat retina. Invest. Ophthalmol. Vis. Sci., v. 44, n. 1, p. 385-92, 2003. 
MARTEL, M. A.; WYLLIE, D. J.; HARDINGHAM, G. E. In developing hippocampal neurons, NR2B-containing N-methyl-D-aspartate receptors (NMDARs) can mediate signaling to neuronal survival and synaptic potentiation, as well as neuronal death. Neuroscience, n. 158, p. 334-343, 2009.

MARTINS, R. A.; SILVEIRA, M. S.; CURADO, M. R.; POLICE, A. I.; LINDEN, R. NMDA receptor activation modulates progammed cell death during early post-natal retinal development: a BDNF-dependent mechanism. J. Neurochem., n. 95, p. 24453, 2005.

MASLAND, R. H. Neuronal diversity in the retina. Curr. Opin. Neurobiol., v. 11, n. 4, p. 431-6, 2001.

MASU, M.; TANABE, Y.; TSUCHIDA, K.; SHIGEMOTO, R.; NAKANISHI, S. Sequence and expression of a metabotropic glutamate receptor. Nature, v. 349, n. 6312, p. 760-5, 1991.

MATHEW, S. J.; HAUBERT, D.; KRÖNKE, M.; LEPTIN, M. Looking beyond death: a morphogenetic role for the TNF signalling pathway. J. Cell Sci., v. 122, n. 12, p. 1939-46, 2009.

MATUTE, C.; ALBERDI, E.; IBARRETXE, G.; SÁNCHEZ-GÓMEZ, M. V. Excitotoxicity in glial cells. Eur. J. Pharmacol., v. 447, n. 2-3, p. 239-46, 2002.

MAYER, M.L. Glutamate receptor ion channels. Curr. Opin. Neurobiol., n. 15, p. 282-8, 2005.

MAYER, M. L.; ARMSTRONG, N. Structure and function of glutamate receptor ion channels. Annu. Rev. Physiol., n. 66, p. 161-81, 2004.

MEGURO, H.; MASAKI, H.; KUMANISHI, T.; ARAKAWA, M.; MISHINA, M. Molecular diversity of the NMDA receptor channel. Nature, v. 358, n. 6381, p. 36-41, 1992.

MENNITI, F.; CHENARD, B.; COLLINS, M.; DUCAT, M.; SHALABY, I.; WHITE, F. CP-101,606, a potent neuroprotectant selective for forebrain neurons. Eur. J. Pharmacol., v. 331, n. 2-3, p. 117-26, 1997.

MICHEAU, O.; TSCHOPP, J. Induction of TNF receptor I-mediated apoptosis via two sequential signaling complexes. Cell, v. 114, n. 2, p. 181-90, 2003.

MOLNÁR, A.; THEODORAS, A.M.; ZON, L.I.; KYRIAKIS, J.M. Cdc42Hs, but not Rac1, inhibits serum-stimulated cell cycle progression at G1/S through a mechanism requiring p38/RK. J. Biol.Chem., v. 272, n. 20, p. 13229-35, 1997.

MONYER, H.; BURNASHEV, N.; LAURIE, D.J.; SAKMANN, B.; SEEBURG, P.H. Developmental and regional expression in the rat brain and functional properties of four NMDA receptors. Neuron, v. 12, n. 3, p. 529-40, 1994.

MONYER, H.; SPRENGEL, R.; SCHOEPFER, R.; HERB, A.; HIGUCHI, M.; LOMELI, H.; BURNASHEV, N.; SAKMANN, B.; SEEBURG, P.H. Heteromeric NMDA 
receptors: molecular and functional distinction of subtypes. Science, v. 256, n. 5060, p. 1217-21, 1992.

MORREALE, A.; VENKATESAN, M.; MOTT, H. R.; OWEN, D.; NIETLISPACH, D.; LOWE, P. N.; LAUE, E. D. Structure of Cdc42 bound to the GTPase binding domain of PAK. Nat. Struct. Biol., v. 7, n. 5, p. 384-8, 2000.

MOTT, D. D.; DOHERTY, J. J.; ZHANG, S.; WASHBURN, M. S.; FENDLEY, M. J.; LYUBOSLAVSKY, P.; TRAYNELIS, S. F.; DINGLEDINE, R. Phenylethanolamines inhibit NMDA receptors by enhancing protein inhibition. Nat. Neurosci., n. 8, p. 659667, 1998.

MUNEMASA, Y.; OHTANI-KANEKO, R.; KITAOKA, Y.; KUMAI, T.; KITAOKA, Y.; HAYASHI, Y.; WATANABE, M.; TAKEDA, H.; HIRATA, K.; UENO, S. Pro-apoptotic role of c-Jun in NMDA-induced neurotoxicity in the rat retina. J. Neurosci. Res., v. 83 , n. 5, p. 907-18, 2006.

MUNEMASA, Y.; OHTANI-KANEKO, R.; KITAOKA, Y.; KURIBAYASHI, K.; ISENOUMI, K.; KOGO, J; YAMASHITA, K.; KUMAI, T.; KOBAYASHI, S.; HIRATA, K.; UENO, S. Contribution of mitogen-activated protein kinases to NMDA-induced neurotoxicity in the rat retina. Brain Res., v. 1044, n. 2, p. 227-240, 2005.

MUTEL, V.; BUCHY, D.; KLINGELSCHMIDT, A.; MESSER, J.; BLEUEL, Z.; KEMP, J. A.; RICHARDS, J. G. In vitro binding properties in rat brain of [3H]Ro 25-6981, a potent and selective antagonist of NMDA receptors containing NR2B subunits. J. Neurochem., v. 70, n. 5, p. 2147-55, 1998.

NAKANISHI, N.; TU, S.; SHIN, Y.; CUI, J.; KUROKAWA, T.; ZHANG, D.; CHEN, H. S.; TONG, G.; LIPTON, S. A. Neuroprotection by the NR3A subunit of the NMDA receptor. J. Neurosci., v. 29, n. 16, p. 5260-5, 2009.

NAKANISHI, S.; MASU, M. Molecular diversity and functions of glutamate receptors. Annu. Rev. Biophys. Biomol. Struct., n. 23, p. 319-48, 1994.

NAKAZAWA, T.; MATSUBARA, A.; NODA, K.; HISATOMI, T.; SHE, H.; SKONDRA, D.; MIYAHARA, S.; SOBRIN, L.; THOMAS, K. L.; CHEN, D. F.; GROSSKREUTZ, C. L.; HAFEZI-MOGHADAM, A.; MILLER, J. W. Characterization of cytokine responses to retinal detachment in rats. Mol. Vis., n. 12, p. 867-78, 2006.

NAKAZAWA, T.; SHIMURA, M.; RYU, M.; NISHIDA, K.; PAGĖS, G.; POUYSSÉGUR, J.; ENDO, S. ERK1 plays a critical protective role against N-methylD-aspartate-induced retinal injury. J. Neurosci. Res., v. 86, n. 1, p. 136-44, 2008.

NEUFELD, A. H.; LIU, B. Glaucomatous optic neuropathy: when glia misbehave. Neuroscientist., n. 9, n. 6, p. 485-95, 2003.

NEWMAN, E. A. A dialogue between glia and neurons in the retina: modulation of neuronal excitability. Neuron. Glia Biol., v. 1, n. 3, p. 245-252, 2004. 
NEWMAN, E. A. Glial modulation of synaptic transmission in the retina. Glia. v. 47, n. 3, p. 268-74, 2004.

NICHOLLS, D. G.; BUDD, S. L.; CASTILHO, R. F.; WARD, M. W. Glutamate excitotoxicity and neuronal energy metabolism. Ann. N. Y. Acad. Sci., n. 893, p. 112, 1999.

NICKELLS, R. W. Retinal ganglion cell death in glaucoma: the how, the why, and the maybe. J. Glaucoma, v. 5, n. 5, p. 345-56, 1996.

NING, K.; PEI, L.; LIAO, M.; LIU, B.; ZHANG, Y.; JIANG, W.; MIELKE, J. G.; LI, L.; CHEN, Y.; EL-HAYEK, Y. H.; FEHLINGS, M. G.; ZHANG, X.; LIU, F.; EUBANKS, J.; WAN, Q. Dual neuroprotective signaling mediated by downregulating two distinct phosphatase activities of PTEN. J. Neurosci., v. 24, n. 16, p. 4052-60, 2004.

NONG, Y.; HUANG, Y. Q.; SALTER, M.W. NMDA receptors are movin' in. Curr. Opin. Neurobiol., v. 14, n. 3, p. 353-61, 2004.

OLOFSSON, B. Rho guanine dissociation inhibitors: pivotal molecules in cellular signalling. Cell Signal, v. 11, n. 8, p. 545-54, 1999.

OLNEY, J.; PRICE, M.; SALLES, K. S.; LABRUYERE, J.; FRIERDICH, G. MK-801 powerfully protects against N-methyl aspartate neurotoxicity. Eur. J. Pharmacol., v. 141, n. 3, p. 357-61, 1987.

OLNEY, J. W. Glutamate-induced retinal degeneration in neonatal mice: electron microscopy of the acutely evolving lesion. J. Neuropathol. Exp. Neurol., n. 28, p. 455-474, 1969.

OLNEY, J. W.; ADAMO, N. J.; RATNER, A. Monosodium glutamate effects. Science, v. 172 , n. 980 , p. $294,1971$.

OLNEY, J. W.; HO, O. L. Brain damage in infant mice following oral intake of glutamate, aspartate or cysteine. Nature, n. 227, p. 609-611, 1970.

OLNEY, J. W.; IKONOMIDOU, C.; MOSINGER, J. L.; FRIERDICH, G. MK-801 prevents hypobaric-ischemic neuronal degeneration in infant rat brain. J. Neurosci., n. 9, p. 1701-4, 1989.

OOTO, S.; AKAGI, T.; KAGEYAMA, R.; AKITA, J.; MANDAI, M.; HONDA, Y.; TAKAHASHI, M. Potential for neural regeneration after neurotoxic injury in the adult mammalian retina. Proc. Natl. Acad. Sci. U.S.A., v. 101, n. 37, p. 13654-9, 2004.

OSBORNE, N. N.; DESANTIS, L.; BAE, J. H.; UGARTE, M.; WOOD, J. P.; NASH, M. S.; CHIDLOW, G. Topically applied betaxolol attenuates NMDA-induced toxicity to ganglion cells and the effects of ischaemia to the retina. Exp. Eye Res., v. 69, n. 3, p. 331-42, 1999.

OZAKI, M.; HAGA, S.; ZHANG, H. Q.; IRANI, K.; SUZUKI, S. Inhibition of hypoxia/reoxygenation-induced oxidative stress in HGF-stimulated antiapoptotic 
signaling: role of PI3-K and Akt kinase upon Rac1. Cell Death Differ., v. 10, n. 5, p. 508-15 p. 2003.

PAASCHE, G.; HUSTER, D.; REICHENBACH, A. The glutathione content of retinal Müller (glial) cells: the effects of aging and of application of free-radical scavengers. Ophthalmic. Res., n. 30, p. 351-360, 1998.

PAOLETTI, P.; NEYTON, J. NMDA receptor subunits: function and pharmacology. Curr. Opin. Pharmacol., v. 7, n. 1, p. 39-47, 2007.

PAPADIA, S.; HARDINGHAM, G. E. The dichotomy of NMDA receptor signaling. Neuroscientist., v. 13, n. 6, p. 572-9, 2007.

PAPADIA, S.; SORIANO, F.X.; LÉVEILLÉ, F.; MARTEL, M. A.; DAKIN, K. A.; HANSEN, H. H.; KAINDL, A.; SIFRINGER, M.; FOWLER, J.; STEFOVSKA, V.; MCKENZIE, G.; CRAIGON, M.; CORRIVEAU, R.; GHAZAL, P.; HORSBURGH, K.; YANKNER, B. A.; WYLLIE, D. J.; IKONOMIDOU, C.; HARDINGHAM, G. E. Synaptic NMDA receptor activity boosts intrinsic antioxidant defenses. Nat. Neurosci., v. 11, n. 4, p. 476-87, 2008.

PAPAKONSTANTI, E. A.; STOURNARAS, C. Tumor necrosis factor-alpha promotes survival of opossum kidney cells via Cdc42-induced phospholipase C-gamma1 activation and actin filament redistribution. Mol. Biol. Cell, v. 15, n. 3, p. 1273-86, 2004.

PENNICA, D.; NEDWIN, G. E.; HAYFLICK, J. S.; SEEBURG, P. H.; DERYNCK, R; PALLADINO, M. A.; KOHR, W. J.; AGGARWAL, B. B.; GOEDDEL, D. V. Human tumour necrosis factor: Precursor structure, expression and homology to lymphocytotoxin. Nature, v. 312, n. 5996, p. 724-9, 1984.

PERRY, V. H.; HENDERSON, Z.; LINDEN, R. Postnatal changes in retinal ganglion cell and optic axon populations in the pigmented rat. J. Comp. Neurol., v. 219, n. 3, p. 356-68, 1983.

PETRUKHIN, K. New therapeutic targets in atrophic age-related macular degeneration. Expert. Opin. Ther. Targets, v. 11, n. 5, p. 625-39, 2007.

PODDAR, R.; DEB, I.; MUKHERJEE, S.; PAUL, S. NR2B-NMDA receptor mediated modulation of the tyrosine phosphatase STEP regulates glutamate induced neuronal cell death. J. Neurochem., v. 115, n. 6, p. 1350-62, 2010.

POURCHO, R.G.; QIN, P.; GOEBEL, D.J. Cellular and subcellular distribution of NMDA receptor subunit NR2B in the retina. J. Comp. Neurol., v. 433, n. 1, p. 75-85, 2001.

POW, D. V.; ROBINSON, S. R. Glutamate in some retinal neurons is derived solely from glia. Neuroscience, v. 60, n. 2, p. 355-66, 1994.

PRYBYLOWSKI, K.; WENTHOLD, R. J. N-Methyl-D-aspartate receptors: subunit assembly and trafficking to the synapse. J. Biol. Chem., n. 279, p. 9673-6, 2004. 
PROVENCIO, I.; JIANG, G.; DE GRIP, W. J.; HAYES, W. P.; ROLLAG, M. D. Melanopsin: An opsin in melanophores, brain, and eye. Proc. Natl. Acad. Sci. U.S.A., v. 95, n. 1, p. 340-5, 1998.

PROVENCIO, I.; RODRIGUEZ, I. R.; JIANG, G.; HAYES, W. P.; MOREIRA, E. F.; ROLLAG, M. D. A novel human opsin in the inner retina. J. Neurosci., v. 20, n. 2, p. $600-5,2000$.

QUIGLEY, H. A.; NICKELLS, R. W.; KERRIGAN, L. A.; PEASE, M. E.; THIBAULT, D. J.; ZACK, D. J. Retinal ganglion cell death in experimental glaucoma and after axotomy occurs by apoptosis. Invest. Ophthalmol. Vis. Sci., n. 36, p. 774-86, 1995.

RANDLETT, O.; NORDEN, C.; HARRIS, W. A. The vertebrate retina: A model for neuronal polarization in vivo. Dev. Neurobiol., v. 71, n. 6, p. 567-83, 2011.

REN, X. D., AND M. A. SCHWARTZ. Determination of GTP loading on Rho. Methods Enzymol., n. 325, p. 264-272, 2000.

RIDLEY, A. J. Rho GTPases and cell migration. J. Cell Sci., v. 114, n. 15, p. 271322, 2001.

RIEPE, R. E.; NORENBURG, M. D. Müller cell localisation of glutamine synthetase in rat retina. Nature, v. 268, n. 5621, p. 654-5, 1977.

ROCHA, M.; MARTINS, R. A.; LINDEN, R. Activation of NMDA receptors protects against glutamate neurotoxicity in the retina: evidence for the involvement of neurotrophins. Brain Res., v. 827, n. 1-2, p. 79-92, 1999.

ROSENMUND, C.; STERN-BACH, Y.; STEVENS, C.F. The tetrameric structure of a glutamate receptor channel. Science, v. 280, n. 5369, p. 1596-9, 1998.

RUSCHER, K.; RZECZINSKI, S.; THEIN, E.; FREYER, D.; VICTOROV, I. V.; LAM, T. T.; DIRNAGL, U. Neuroprotective effects of the beta-carboline abecarnil studied in cultured cortical neurons and organotypic retinal cultures. Neuropharmacology, v. 52, n. 7, p. 1488-95, 2007.

RZECZINSKI, S.; VICTOROV, I. V.; LYJIN, A. A.; ALEKSANDROVA, O. P.; HARMS, C.; KRONENBERG, G.; FREYER, D.; SCHEIBE, F.; PRILLER, J.; ENDRES, M.; DIRNAGL, U. Roller culture of free-floating retinal slices: a new system of organotypic cultures of adult rat retina. Ophthalmic. Res., v. 38, n. 5, p. 263-9, 2006.

SABEL, B. A.; SAUTTER, J.; STOEHR, T.; SILIPRANDI, R. A behavioral model of excitotoxicity: retinal degeneration, loss of vision, and subsequent recovery after intraocular NMDA administration in adult rats. Exp. Brain Res., v. 106, n. 1, p. 93105, 1995.

SATTLER, R.; TYMIANSKI, M. Molecular mechanisms of calcium-dependent excitotoxicity. J. Mol. Med., n, 78, p. 3-13, 2000. 
SATTLER, R.; TYMIANSKI, M. Molecular mechanisms of glutamate receptormediated excitotoxic neuronal cell death. Mol. Neurobiol., n. 24, p. 107-29, 2001.

SCHMIDT, A.; HALL, A. Guanine nucleotide exchange factors for Rho GTPases: turning on the switch. Genes Dev., v. 16, n. 13, p. 1587-609, 2002.

SEMENOVA, M. M.; MAKI-HOKKONEN, A. M.; CAO, J.; KOMAROVSKI, V.; FORSBERG, K. M.; KOISTINAHO, M.; COFFEY, E. T.; COURTNEY, M. J. Rho mediates calcium-dependent activation of p38alpha and subsequent excitotoxic cell death. Nat. Neurosci., v. 10, n. 4, p. 436-43, 2007.

SHI, Y.; ZHOU, L.; TIAN, J.; WANG, Y. Transplantation of neural stem cells overexpressing glia-derived neurotrophic factor promotes facial nerve regeneration. Acta. Otolaryngol., v. 129, n. 8, p. 906-14, 2009.

SILIPRANDI, R.; CANELLA, R.; CARMIGNOTO, G.; SCHIAVO, N.; ZANELLATO, A.; ZANONI, R.; VANTINI, G. N-methyl-D-aspartate-induced neurotoxicity in the adult rat retina. Vis. Neurosci., v. 8, n. 6, p. 567-73, 1992.

SILVEIRA DOS SANTOS-BREDARIOL, A; HAMASSAKI-BRITTO, D .E. Ionotropic glutamate receptors during the development of the chick retina. J. Comp. Neurol., n. 441 , p. 58-70, 2001;

SORIANO, F. X.; MARTEL, M. A.; PAPADIA, S.; VASLIN, A.; BAXTER, P.; RICKMAN, C.; FORDER, J.; TYMIANSKI, M.; DUNCAN, R.; AARTS, M.; CLARKE, P.; WYLLIE, D. J.; HARDINGHAM, G. E. Specific targeting of pro-death NMDA receptor signals with differing reliance on the NR2B PDZ ligand. J. Neurosci., v. 28, n. 42, p. 10696-710, 2008.

ST JOHN, P. A.; KELL, W. M.; MAZZETTA, J. S.; LANGE, G. D.; BARKER, J .L. Analysis and isolation of embryonic mammalian neurons by fluorescence-activated cell sorting. J. Neurosci., v. 6, n. 5, p. 1492-512, 1986.

STAWSKI, P.; JANOVJAK, H.; TRAUNER, D. Pharmacology of ionotropic glutamate receptors: A structural perspective. Bioorg. Med. Chem., v. 18, n. 22, p. 7759-72, 2010.

STONE, T. W.; ADDAE, J. I. The pharmacological manipulation of glutamate receptors and neuroprotection. Eur. J. Pharmacol., v. 447, n. 2-3, p. 285-96, 2002.

SUGIHARA, H.; MORIYOSHI, K.; ISHII, T.; MASU, M.; NAKANISHI, S. Structures and properties of seven isoforms of the NMDA receptor generated by alternative splicing. Biochem. Biophys. Res. Commun., v. 185, n. 3, p. 826-32, 1992.

SWANSON, G. T.; FELDMEYER, D.; KANEDA, M.; CULL-CANDY, S. G. Effect of RNA editing and subunit co-assembly single-channel properties of recombinant kainate receptors. J. Physiol., n. 492, p. 129-42, 1996 
SWANSON, G. T.; KAMBOJ, S. K.; CULL-CANDY, S. G. Single-channel properties of recombinant AMPA receptors depend on RNA editing, splice variation, and subunit composition. J. Neurosci., v. 17, n. 1, p. 58-69, 1997.

TAKADERA, T.; MATSUDA, I.; OHYASHIKI, T. Apoptotic cell death and caspase-3 activation induced by $\mathrm{N}$-methyl-D-aspartate receptor antagonists and their prevention by insulin-like growth factor I. J. Neurochem., v. 73, n. 2, p. 548-56, 1999.

TAKAHASHI, T.; FELDMEYER, D.; SUZUKI, N.; ONODERA, K.; CULL-CANDY, S.G.; SAKIMURA, K.; MISHINA, M. Functional correlation of NMDA receptor epsilon subunits expression with the properties of single-channel and synaptic currents in the developing cerebellum. J. Neurosci., v. 16, n. 14, p. 4376-82, 1996.

TANAKA, H.; GROOMS, S.Y.; BENNETTI, M. V.; ZUKIN, R. S. The AMPAR subunit GluR2: still front and center-stage. Brain Res., n. 886, p. 190-207, 2000.

TAYLOR, S.; SRINIVASAN, B.; WORDINGER, R. J.; ROQUE, R. S. Glutamate stimulates neurotrophin expression in cultured Müller cells. Mol. Brain Res., n. 111, p. 189-197, 2003.

TEZEL, G.; YANG, X.; YANG, J.; WAX, M. B. Role of tumor necrosis factor receptor1 in the death of retinal ganglion cells following optic nerve crush injury in mice. Brain Res., v. 996, n. 2, p. 202-12, 2004.

TEZEL, G.; LI, L. Y.; PATIL, R. V.; WAX, M. B. TNF-alpha and TNF-alpha receptor-1 in the retina of normal and glaucomatous eyes. Invest. Ophthalmol. Vis. Sci., v. 42, n. 8, p. 1787-94, 2001.

TEZEL, G.; WAX, M. B. Increased production of tumor necrosis factor-alpha by glial cells exposed to simulated ischemia or elevated hydrostatic pressure induces apoptosis in cocultured retinal ganglion cells. J. Neurosci. v. 20, n. 23, p. 8693-700, 2000.

THORESON, W. B.; WITKOVSKY, P. Glutamate receptors and circuits in the vertebrate retina. Prog. Retina Eye Res., v. 18, n. 6, p. 765-810, 1999.

TOLIAS, K. F.; BIKOFF, J. B.; BURETTE, A.; PARADIS, S.; HARRAR, D.; TAVAZOIE, S.; WEINBERG, R. J.; GREENBERG, M. E. The Rac1-GEF Tiam1 couples the NMDA receptor to the activity-dependent development of dendritic arbors and spines. Neuron., v. 45, n. 4, p. 525-38, 2005.

TOVAR, K. R.; WESTBROOK, G. L. The incorporation of NMDA receptors with a distinct subunit composition at nascent hippocampal synapses in vitro. J. Neurosci., v. 19 , n. 10 , p. $4180-8,1999$.

TRAYNELIS, S. F.; WOLLMUTH, L. P.; MCBAIN, C. J.; MENNITI, F. S.; VANCE, K. M.; OGDEN, K. K.; HANSEN, K. B.; YUAN, H.; MYERS, S. J.; DINGLEDINE, R. Glutamate receptor ion channels: structure, regulation, and function. Pharmacol. Rev., v. 62, n. 3, p. 405-96, 2010. 
TSUKAMOTO, Y.; MORIGIWA, K.; UEDA, M.; STERLING, P. Microcircuits for night vision in mouse retina. J. Neurosci., v. 21, n. 21, p. 8616-23, 2001.

TU, H.; WIGLER, M. Genetic evidence for Pak1 autoinhibition and its release by Cdc42. Mol. Cell Biol., v. 19, n. 1, p. 602-11, 1999.

TU, W.; XU, X.; PENG, L.; ZHONG, X.; ZHANG, W.; SOUNDARAPANDIAN, M. M.; BALEL, C.; WANG, M.; JIA, N.; ZHANG, W.; LEW, F.; CHAN, S. L.; CHEN, Y.; LU, Y. DAPK1 interaction with NMDA receptor NR2B subunits mediates brain damage in stroke. Cell, v. 140, n. 2, p. 222-234, 2010.

TURA, A.; SCHUETTAUF, F.; MONNIER, P. P.; BARTZ-SCHMIDT, K. U.; HENKEFAHLE, S. Efficacy of Rho-kinase inhibition in promoting cell survival and reducing reactive gliosis in the rodent retina. Invest. Ophthalmol. Vis. Sci., v. 50, n. 1, p. 452$61,2009$.

UEDA, T.; KIKUCHI, A.; OHGA, N.; YAMAMOTO, J.; TAKAI, Y. Purification and characterization from bovine brain cytosol of a novel regulatory protein inhibiting the dissociation of GDP from and the subsequent binding of GTP to rhoB p20, a ras p21like GTP-binding protein. J. Biol. Chem., v. 265, n. 16, p. 9373-80, 1990.

ULLIAN, E. M.; BARKIS, W. B.; CHEN, S.; DIAMOND, J.S.; BARRES, B.A. Invulnerability of retinal ganglion cells to NMDA excitotoxicity. Mol. Cell Neurosci., v. 26 , n. 4, p. 544-57, 2004.

VAN BERGEN, N. J.; WOOD, J. P.; CHIDLOW, G.; TROUNCE, I. A.; CASSON, R. J.; JU, W. K.; WEINREB, R. N.; CROWSTON, J. G. Recharacterization of the RGC-5 retinal ganglion cell line. Invest. Ophthalmol. Vis. Sci., v. 50, n. 9, p. 4267-72, 2009.

VANDENBERGHE, W.; BREDT, D. S. Early events in glutamate receptor trafficking. Curr. Opin. Cell Biol., v. 16, n. 2, p. 134-9, 2004.

VERARDO, M. R.; LEWIS, G. P.; TAKEDA, M.; LINBERG, K. A.; BYUN, J.; LUNA, G.; WILHELMSSON, U.; PEKNY, M.; CHEN, D. F.; FISHER, S. K. Abnormal reactivity of muller cells after retinal detachment in mice deficient in GFAP and vimentin. Invest. Ophthalmol. Vis. Sci., v. 49, n. 8, p. 3659-65, 2008.

VERMA, A.; MOHINDRU, M.; DEB, D. K.; SASSANO, A.; KAMBHAMPATI, S.; RAVANDI, F.; MINUCCI, S.; KALVAKOLANU, D. V.; PLATANIAS, L.C. Activation of Rac1 and the p38 mitogen-activated protein kinase pathway in response to arsenic trioxide. J. Biol. Chem., v. 277, n. 47, p. 44988-95, 2002.

VON ENGELHARDT, J.; COSEREA, I.; PAWLAK, V.; FUCHS, E. C.; KÖHR, G.; SEEBURG, P. H.; MONYER, H. Excitotoxicity in vitro by NR2A- and NR2Bcontaining NMDA receptors. Neuropharmacology, v. 53, n. 1, p. 10-7, 2007.

WANG, Y. H.; WANG, Y.; WANG, D. W.; WU, N.; LIU, D. N.; YIN, Z. Q. Distribution and expression of RhoA in rat retina after optic nerve injury. Ophthalmic. Res., v. 39, n. 3, p. 174-8, 2007. 
WAXMAN, E. A.; LYNCH, D. R. N-methyl-D-aspartate receptor subtype mediated bidirectional control of p38 mitogen-activated protein kinase. J. Biol. Chem., v. 280, n. 32, p. 29322-33, 2005.

WEBER, A. J.; HARMAN, C. D.; VISWANATHAN, S. Effects of optic nerve injury, glaucoma, and neuroprotection on the survival, structure, and function of ganglion cells in the mammalian retina. J. Physiol., v. 586, n. 18, p. 4393-400, 2008.

WELLS, C .M.; JONES, G. E. The emerging importance of group II PAKs. Biochem. J., v. 425, n. 3, p. 465-73, 2010.

WENTHOLD, R. J.; SANS, N.; STANDLEY, S.; PRYBYLOWSKI, K.; PETRALIA, R. $\mathrm{S}$. Early events in the trafficking of $\mathrm{N}$-methyl-D-aspartate (NMDA) receptors. Biochem. Soc. Trans., v. 31, n. 4, p. 885-8, 2003.

WENZEL, A.; FRITSCHY, J. M.; MOHLER, H.; BENKE, D. NMDA receptor heterogeneity during postnatal development of the rat brain: differential expression of the NR2A, NR2B, and NR2C subunit proteins. J. Neurochem., v. 68, n. 2, p. 469-78, 1997.

WENZEL, A.; VILLA, M.; MOHLER, H.; BENKE, D. Developmental and regional expression of NMDA receptor subtypes containing the NR2D subunit in rat brain. $\mathbf{J}$. Neurochem., v. 66, n. 3, p. 1240-8, 1996.

WILLIAMS, A. J.; DAVE, J. R.; LU, X. M.; LING, G.; TORTELLA, F. C. Selective NR2B NMDA receptor antagonists are protective against staurosporine-induced apoptosis. Eur. J. Pharmacol., v. 452, n. 1, p. 135-6, 2002.

WISDEN, W.; SEEBURG, P. H. Mammalian ionotropic glutamate receptors. Curr. Opin. Neurobiol., n. 3, p. 291-8, 1993.

WONG, E. H.; KEMP, J. A.; PRIESTLEY, T.; KNIGHT, A. R.; WOODRUFF, G. N.; IVERSEN, L. L. The anticonvulsant MK-801 is a potent N-methyl-D-aspartate antagonist. Proc. Natl. Acad. Sci. U.S.A., v. 83, n. 18, p. 7104-8, 1986.

WONG, W. T.; FAULKNER-JONES, B. E.; SANES, J. R.; WONG, R. O. Rapid dendritic remodeling in the developing retina: dependence on neurotransmission and reciprocal regulation by Rac and Rho. J. Neurosci., v. 20, n. 13, p. 5024-36, 2000.

WONG, W. T.; SANES, J. R.; WONG, R. O. L. Developmentally regulated spontaneous activity in the embryo chick retina. J. Neurosci., n. 18, p. 8839-8852, 1998.

YING, S. W.; FUTTER, M.; ROSENBLUM, K.; WEBBER, M. J.; HUNT, S. P.; BLISS, T. V.; BRAMHAM, C. R. Brain-derived neurotrophic factor induces long-term potentiation in intact adult hippocampus: requirement for ERK activation coupled to CREB and upregulation of Arc synthesis. J. Neurosci., v. 22, n. 5, p. 1532-40, 2002. 
YOSHIDA, K.; WATANABE, D.; ISHIKANE, H.; TACHIBANA, M.; PASTAN, I.; NAKANISHI, S. A key role of starburst amacrine cells in originating retinal directional selectivity and optokinetic eye movement. Neuron. 30(3):771-80 p. 2001.

ZHANG, C.; HAMASSAKI-BRITTO, D. E.; BRITTO, L. R.; DUVOISIN, R. M. Expression of glutamate receptor subunit genes during development of the mouse retina. Neuroreport., v. 8, n. 1, p. 335-40, 1996.

ZHANG, T.; LU, X.; BEIER, F.; FENG, Q. Rac1 activation induces tumour necrosis factor- $\alpha$ expression and cardiac dysfunction in endotoxemia. J. Cell Mol. Med., v. 15, n. 5, p. 1109-21, 2011.

ZHOU, M.; BAUDRY, M. Developmental changes in NMDA neurotoxicity reflect developmental changes in subunit composition of NMDA receptors. J. Neurosci., v. 26, n. 11, p. 2956-63, 2006. 